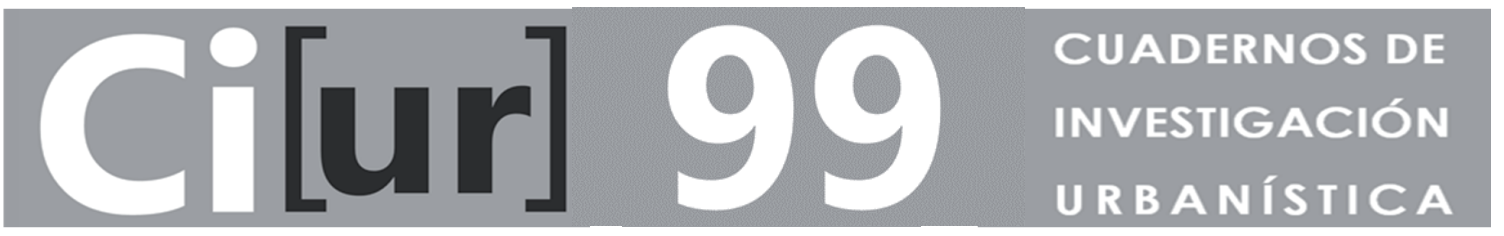

\title{
LA CATALOGACIÓN DEL PATRIMONIO ARQUITECTÓNICO DE LA CIUDAD DE VALENCIA
}

\section{MARÍA TERESA BROSETA PALANCA}

Doctora Arquitecta

\begin{abstract}
Este documento es un resumen del Capítulo IV de la tesis doctoral "Registro, catalogación y planificación del patrimonio urbano arquitectónico: una aproximación al caso valenciano", dirigida por el profesor Francisco Taberner Pastor y leída por su autora el día 12 de junio de 2014, en la Escuela Técnica Superior de Arquitectura de Valencia.
\end{abstract}

Marzo / Abril 2015 


\begin{tabular}{|c|c|}
\hline Director: & José Fariña Tojo \\
\hline \multicolumn{2}{|c|}{ Consejo de Redacción: } \\
\hline Director & Ester Higueras García \\
\hline Jefe de redacción & María Emilia Román López \\
\hline Vocales & $\begin{array}{l}\text { Julio Alguacil Gómez (Univ. Carlos III de Madrid), Pilar Chías Navarro (Univ. } \\
\text { Alcalá de Henares, Madrid), José Antonio Corraliza Rodríguez (Univ. Autónoma } \\
\text { de Madrid), Alberto Cuchí Burgos (Univ. Politécnica de Cataluña), José Fariña } \\
\text { Tojo (Univ. Politécnica de Madrid), Agustín Hernández Aja (Univ. Politécnica de } \\
\text { Madrid), Mariam Leboreiro Amaro (Univ. Politécnica de Madrid), Rafael Mata } \\
\text { Olmo (Univ. Autónoma de Madrid), Fernando Roch Peña (Univ. Politécnica de } \\
\text { Madrid), Carlos Manuel Valdés (Univ. Carlos III de Madrid) }\end{array}$ \\
\hline Consejo Asesor: & $\begin{array}{l}\text { Ma Teresa Arredondo (Directora de Relaciones con Latinoamérica, Univ. } \\
\text { Politécnica de Madrid), Luis Maldonado (Director de la Escuela Superior de } \\
\text { Arquitectura, Univ. Politécnica de Madrid), Antonio Elizalde, Julio García Lanza, } \\
\text { Josefina Gómez de Mendoza, José Manuel Naredo, Julián Salas, Fernando de } \\
\text { Terán }\end{array}$ \\
\hline Comité Científico: & $\begin{array}{l}\text { Antonio Acierno (Univ. Federico II di Napoli, Nápoles, ITALIA), Miguel Ángel } \\
\text { Barreto (Univ. Nal. del Nordeste, Resistencia, ARGENTINA), Luz Alicia Cárdenas } \\
\text { Jirón (Univ. de Chile, Santiago de Chile, CHILE), José Luis Carrillo (Univ. } \\
\text { Veracruzana, Xalapa, MÉXICO), Marta Casares (Univ. Nal. de Tucumán, } \\
\text { ARGENTINA), María Castrillo (Univ. de Valladolid, ESPAÑA), Mercedes Ferrer } \\
\text { (Univ. del Zulia, Maracaibo, VENEZUELA), Fernando Gaja (Univ. Politécnica de } \\
\text { Valencia, ESPAÑA), Alberto Gurovich (Univ. de Chile, Santiago de Chile, CHILE), } \\
\text { Josué Llanque (Univ. Nal. S. Agustín Arequipa, PERÚ), Angelo Mazza (Univ. } \\
\text { Federico II di Napoli, Nápoles, ITALIA), Luis Moya (Univ. Politécnica de Madrid, } \\
\text { ESPAÑA), Joan Olmos (U. Politécnica de Valencia, ESPAÑA), Ignazia Pinzello } \\
\text { (Univ. degli Studi di Palermo, Palermo, ITALIA), Julio Pozueta (Univ. Politécnica } \\
\text { de Madrid, ESPAÑA), Alfonso Rivas (UAM Azcapotzalco, Ciudad de México, } \\
\text { MÉXICO), Silvia Rossi (Univ. Nal. de Tucumán, ARGENTINA), Adalberto da Silva } \\
\text { (Univ. Estadual Paulista, Sao Paulo, BRASIL), Carlos Soberanis (Univ. Francisco } \\
\text { Marroquín, Guatemala, GUATEMALA), Carlos A. Torres (Univ. Nal. de Colombia, } \\
\text { Bogotá, COLOMBIA), Graziella Trovato (Univ. Politécnica de Madrid, ESPAÑA) } \\
\text { Carlos F. Valverde (Univ. Iberoamericana de Puebla, MÉXICO), Paz Walker (Univ. } \\
\text { de la Serena, Santiago de Chile, CHILE), Fernando N. Winfield (Univ. } \\
\text { Veracruzana, Xalapa, MÉXICO) }\end{array}$ \\
\hline
\end{tabular}

Maquetación: Antonio Jesús Antequera Delgado: ciur.urbanismo.arquitectura@upm.es

Distribución: Mairea Libros: distribucion@mairea-libros.com

(C) COPYRIGHT 2015

MARÍA TERESA BROSETA PALANCA

I.S.S.N. (edición impresa): 1886-6654

I.S.S.N. (edición digital): 2174-5099

Año VIII, Núm. 99, marzo-abril 2015, 94 págs.

Edita: Instituto Juan de Herrera

Imprime: FASTER, San Francisco de Sales 1, Madrid 


\title{
DESCRIPTORES:
}

Catálogo urbano / Patrimonio arquitectónico / Planeamiento / Gestión urbanística / Valencia

\section{KEY WORDS:}

\author{
Urban catalogue / Built heritage / Town planning / Urban Development / Valencia
}

\section{RESUMEN:}

El presente trabajo es una adaptación del capítulo cuarto de la tesis doctoral realizada por la autora donde se analiza el tratamiento del patrimonio urbano arquitectónico en el ámbito del urbanismo y se aportan propuestas para la mejora de la conservación y difusión de los valores patrimoniales, a través de la optimización de los medios de catalogación. Para ello se comprueba la vigencia de los instrumentos de protección del patrimonio arquitectónico y su aplicación en la planificación urbanística de la Comunidad Valenciana, tanto a escala territorial como en los ámbitos urbanos de la ciudad de Valencia y núcleos de menor población. Asimismo, se analizan las técnicas de registro y catalogación de inmuebles y la adaptación de las TICS a estas prácticas tradicionales, mediante un sistema "eheritage" como plataforma digital de datos, que garantice la operatividad de la gestión, y la comunicación y difusión del patrimonio por las administraciones. Como contribución, se propone la actualización y digitalización del catálogo de la ciudad Valencia, exportable al resto de catálogos municipales, como herramienta básica en la gestión del patrimonio, en consecución de la primera fase hacia su conservación, el conocimiento de los valores que llevaron a su catalogación.

\section{ABSTRACT:}

This work is the fourth chapter adaptation of author's doctoral thesis, whose main purpose is the knowledge of the validity of heritage preservation tools in town planning and land development management, with the aim to get useful proposals to improve the preservation and dissemination of the heritage values. The document explains the traditional methods of registration and cataloguing and their adaptation to ICT by an e-heritage digital data system, as guarantee of effective heritage policy of preservation, communication and diffusion by public administration. In the same way, the study provides the relation between built heritage management and land use and development regulation of Comunidad Valenciana, either on large territory scale or on urban area of Valencia and underpopulated towns. Given the right study, it provides improvements in the method of heritage identification and designation, as well as progress in built heritage protection rules for Valencian historic towns; furthermore, it contributes to update and digitize the heritage city catalogue of Valencia, with a system exportable to other cities, as a basic tool in cultural heritage management, towards the better identification of the values which cause designation and preservation. 


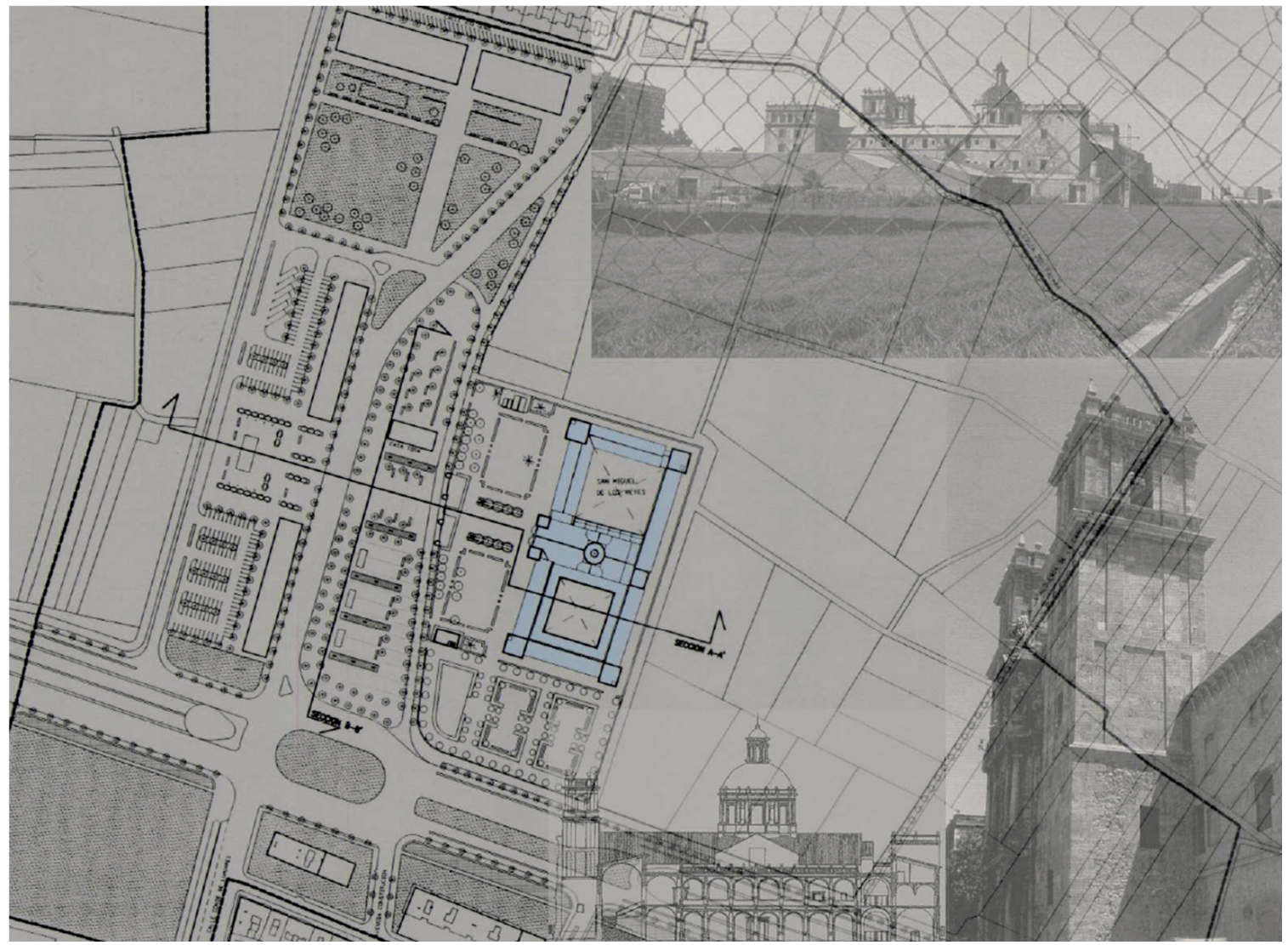

Figura 0. Antiguo Monasterio de San Miguel de los Reyes sede de la Biblioteca Valenciana, declarado BIC en 2008 (Barrio Els Orriols, Valencia).

Fuente: Archivo de la autora

CONSULTA DE NÚMEROS ANTERIORES/ACCESS TO PREVIOUS WORKS:

La presente publicación se puede consultar en color en formato pdf en la dirección:

This document is available in pdf format and full colour in the following web page:

http://www2.aq.upm.es/Departamentos/Urbanismo/institucional/publicaciones/ciur/ 


\section{ÍNDICE}

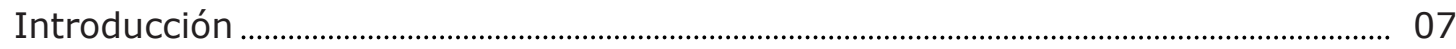

1 El catálogo urbanístico en Valencia ................................................................................... 08

1.1 Catálogo de Bienes y Espacios Protegidos del PGOU de Valencia................. 09

1.2 Normas urbanísticas sobre protección de inmuebles catalogados ............... 12

1.3 Contenido normativo del catálogo .................................................................................. 14

1.4 Los niveles de protección frente a convenciones de intervención en patrimonio arquitectónico............................................................................................ 16

1.5 Modificaciones del catálogo: la Cárcel Modelo y la Tabacalera ..................... 23

2 La ampliación y revisión del catálogo.................................................................................... 29

2.1 La ampliación del Catálogo con los Planes Parciales........................................... 29

2.2 El Catálogo BYEP de Planes Especiales y Planes Especiales de Reforma Interior .................................................................................................................. 30

2.3 Catálogo BYEP de Palnes Especiales de Protección............................................ 31

2.4 La Revisión Simplificada del Plan General de Valencia. Catálogo Estructural de Bienes y Espacios Protegidos............................................................ 31

2.5 La multiplicidad de catálogos en el Término Municipal de Valencia............ 33

3 La Catalogación de los Planes Especiales de Protección........................................... 34

3.1 Planes de Acción Territorial y Catálogos de Paisaje .............................................. 34

3.2 Catálogo de Bienes y Espacios Rurales Protegidos del Plan de Acción Territorial de Protección de laHuerta (PATH) ........................................................... 35

3.3 Intervenciones en la Huerta Protegida de Valencia: La Punta y La Torre 39

4 La catalogación de los Planes Especiales de Protección............................................. 43

4.1 Planes Especiales de Protección de la ciudad de Valencia................................ 43

4.2 Normativa Urbanística del PGOU de Valencia sobre Palnes Especiales de Protección .......................................................................................................................... 45

4.3 Propuesta de ordenación de los PEPRI del Conjunto Histórico de la ciudad de Valencia.............................................................................................................. 46

4.4 La catalogación. Niveles de protección propuestos en los Planes ............... 48

4.5 Conclusión: cuadro comparativo de los diferentes criterios de intervención sobre inmuebles catalogados en los PEPRIS valencianos..... 63

5 Catalogación de entornos BIC. La duplicidad de catálogos........................................ 66

5.1 PE de Protección del entorno BIC de la Iglesia de Nuestra Señora de la Misericordia de Campanar. 
5.2 PE de Protección del entorno de los BIC: Puerta de los Serranos, Iglesia y Convento de Santo Domingo, Museo de Bellas Artes, Monasterio del Temple, Palacio de Justicia, Exconvento del Carmen e Iglesia de Santa Cruz y Palacio de los Condes de Cervellón..

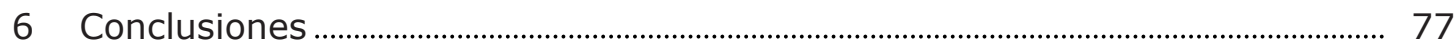

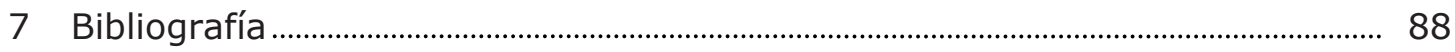




\section{INTRODUCCIÓN}

El trabajo que se presenta a continuación es una adaptación del capítulo cuarto de la tesis doctoral titulada: Registro, catalogación y planificación de patrimonio urbano arquitectónico, una aproximación al caso valenciano. La tesis repasa a través de cinco bloques temáticos el tratamiento de protección y recuperación que se le da al patrimonio arquitectónico desde la ordenación urbanística. El trabajo analiza las técnicas de registro e inventario, la relación compleja entre la legilación urbanística y de patrimonio y las técnicas de planificación urbanística a través de la catalogación, centradas en el ámbito de la Comunidad Valenciana.

El catálogo municipal de bienes protegidos, más allá de los registro de bienes con expresa declaración de interés cultural, constituyen el documento que recoge la mayor parte de nuestro patrimonio inmueble y regula su conservación y su futuro aprovechamiento, a través de la gestión de la administración local.

La tesis desarrolla un trabajo de revisión de catálogos del ámbito valenciano, con el fin de arrojar datos útiles sobre la situación concreta de catalogación de inmuebles y lo adecuado de su técnica, a fin de unificar, homologar y estandarizar los conceptos que vienen recogidos en las diferentes normas, y proponer su mejora y su digitalización.

En el medio rural el setenta por ciento de los municipios con población inferior a los 5000 habitantes, disponen de un planeamiento general anterior a 1998, cuyo régimen de protección se basa en políticas desarrollistas muy alejadas de las actuales teorías de conservación del patrimonio. En los municipios mayores se propicia la multiplicidad de catálogos que se incorporan a cada nuevo plan de desarrollo, en sustitución de la revisión y/o modificación del catálogo del Plan General. Esta superposición de contenidos no homogéneos, acaba en un galimatías de datos y regímenes de protección complejos de descifrar para la administración, los propietarios y los profesionales.

La adopción de las nuevas tecnologías no ha alcanzado el campo de la catalogación de inmuebles: faltan herramientas adecuadas para el tratamiento de documentos cada vez con mayor profusión informativa y normativa, imposible de abarcar por los usuarios, con medios tradicionales de adquisición de conocimiento.

Los trabajos de revisión de los catálogos municipales son fundamentales para la conservación del patrimonio urbano, el Ayuntamiento de Valencia presenta recientemente la revisión estructural de su catálogo y contrata un ambicioso proyecto de redacción de planes especiales de los entornos de los monumentos BIC en Ciutat Vella. El esfuerzo de revisión del catálogo es notable, aunque sólo abarca una pequeña proporción respecto de los más de 3.800 inmuebles del catálogo municipal.

Este último caso se ilustra a través del capítulo seleccionado: el análisis del patrimonio catalogado de la ciudad de Valencia a través de los diferentes documentos normativos vigentes, las conclusiones obtenidas y su propuesta de gestión. 


\section{METOdOLOGÍA}

En el momento actual, a la vista de la normativa vigente, los Catálogos deben abarcar de manera sucinta, el estudio y evaluación de todos los campos de interés patrimonial de naturaleza inmueble presentes en el municipio, destancando los valores concretos, los diversos grados de protección y tipos de intervención posibles según los criterios de artículo 39.2, epígrafe $\mathrm{g}^{1}$, de la Ley de Patrimonio Cultural Valenciano.

Los Catálogos dejarán constancia de todos aquellos inmuebles que formen parte del Inventario General del Patrimonio Cultural Valenciano, con indicación, en su caso, de los respectivos entornos de protección. (Art. 39.2 LPCV)

El Catálogo será redactado por equipos pluridisciplinares en cuya composición participarán necesariamente titulados superiores en las disciplinas de arquitectura, arqueología, historia del arte, y etnología o antropología que garanticen la solvencia técnica de los trabajos. (Art. 47.2 LPCV)

El catálogo debe incluir los Bienes de Interés Cultural presentes en el municipio, así como los inmuebles previstos en la Disposición Adicional Primera de la LPCV, con consideración genérica BIC y la delimitación de sus entornos de protección, que presentan la condición urbanística de ordenación estructural.

Corresponde a los Ayuntamientos proponer, justificadamente, a través del Catálogo de Bienes y Espacios, la selección de los inmuebles de su término municipal que aspiren al reconocimiento de Bien de Relevancia Local (art. 47.1 LPCV). Por ello, se indicará qué elementos incluidos en el Catálogo se consideran Bienes de Relevancia Local y, en caso de inexistencia, el Catálogo incluirá una justificación motivada, según establece el art.46.3 LPCV.

Tras la modificación introducida por la Ley 10/2012, de 21 de diciembre, que modifica la Disposición Adicional Quinta de la LPCV, tienen la consideración genérica de Bienes Inmuebles de Relevancia Local, y con esta denominación deberán ser incluidos en los respectivos Catálogos de Bienes y Espacios Protegidos, las siguientes categorías de elementos arquitectónicos: los "pous o caves de neu" o neveras, las chimeneas de tipo industrial construidas de ladrillo anteriores a 1940, los antiguos molinos de viento, las barracas tradicionales de la comarca de l'Horta de Valencia, las lonjas y salas comunales anteriores al siglo XIX, la arquitectura religiosa anterior al año 1940 incluyendo los Calvarios Tradicionales que estén concebidos autónomamente como tales, y los paneles cerámicos exteriores anteriores al año 1940. No obstante, mediante resolución singular de la Conselleria competente en materia de cultura, se podrá exceptuar este reconocimiento para elementos que, analizados singularmente, no acrediten reunir valores culturales suficientes para su inscripción en el Inventario General del Patrimonio Cultural Valenciano (art. 15, del Decreto 62/2011 del Consell).

\footnotetext{
1 [...] Catálogo de Bienes y Espacios Protegidos que defina los grados de protección y tipos de intervención posibles. Incluirá inmuebles cultural o arquitectónicamente destacados y abarcará todos aquellos con patrones caracterizadores del conjunto que puedan ser objeto de conservación o rehabilitación. Cuando resulte destruido un bien catalogado el terreno subyacente pemanecerá sujeto al régimen propio de la edificación precedente.
} 
El Catálogo establecerá las medidas de protección que, en función de los valores reconocidos, aseguren la adecuada conservación y apreciación de dichos bienes. El contenido mínimo de la ficha del Catálogo en lo que respecta a los Bienes de Relevancia Local será el siguiente:

a) Situación y descripción detallada del bien y de los elementos protegidos

b) Determinación de los valores patrimoniales que justifican la calificación de relevancia local

c) Entorno de afección, salvo justificación de innecesidad.

d) Definición del grado de protección y del régimen de intervención autorizado

La ficha del inmueble dejará constancia de la categoría que le corresponda al BRL. De todos los entornos de protección que se delimiten, se redactará una ordenanza de edificación específica que dé adecuada respuesta al inmueble patrimonial. El Catálogo dejará constancia de la exigencia de comunicar a la Conselleria competente en materia de Cultura de las actuaciones que vayan a realizarse en estos inmuebles, las licencias de intervención concedidas y las órdenes de ejecución que se dicten sobre los mismos, que regula el procedimiento de declaración y el régimen de protección de los bienes de relevancia local. ${ }^{2}$

\subsection{Catálogo de Bienes y Espacios Protegidos del Plan General de Valencia}

Vistos los requerimientos para el catálogo urbanístico valenciano, profundizamos en la realidad del catálogo de la ciudad de Valencia comenzando por los documentos que sirvieron de referencia para su redacción.

En primer lugar la resolución de incoación del expediente de declaración de la Dirección General de Patrimonio Artístico, Archivos y Museos, de 22 de febrero de 1978, que incluía seis zonas de la ciudad, un listado con tres categorías de protección: edificios de Interés Particularizado, Conjuntos y Elementos Singulares (no edificios). Se califican de interés casi exclusivamente los monumentos, con la inclusión de conjuntos de vivienda obrera-seriada y de casas palaciegas, como excepción.

El Plano Guía de Arquitectura de la Ciudad de Valencia de 1978, realizado por el Centro de Servicios e Informes del Colegio de Arquitectos de Valencia y Murcia, cuyo objetivo y criterio era: "llenar el hueco existente hasta el momento en el tema [...] de la arquitectura de la ciudad. Otras guías han sido realizadas anteriormente (Cruilles, Tormo, Galiana,...); no obstante éstas abordando el tema de la arquitectura, rara vez han pasdo de las citas monumentales, y por otra parte en todas ellas, el repertorio arquitectónico a finales del siglo XIX y posterior a penas se encuentra aludido [...] La necesidad de catalogación, para conocimiento y defensa de la arquitectura rural y urbana de nuestro país, ha sido siempre el motor de las tareas desarrolladas por el archivo histórico del COAVM."

2 Artículo 50.4 de la Ley 4/1998, de 11 de junio, del Patrimonio Cultural Valenciano y artículo 14 del Decreto 62/2011 del Consell 
El plano guía contiene el listado de elementos sin establecer niveles de protección. La incorporación de ejemplares de la arquitectura de los siglos XIX y XX, supone un avance importante, sin embargo predomina la concepción del edificio singular frente al valor tipológico de los ejemplares repetidos.

El Inventario del Patrimonio Arquitectónico de la Provincia de 1979, promovido por el Ministerio de Cultura, más exhaustivo que los anteriores, distinguía entre Conjuntos, Edificios Aislados y Elementos Singulares, con variedad de tipologías y épocas, más allá de la consideración monumental.

El Avance de Catálogo que el Ayuntamiento encargó al Colegio de Arquitectos, redactado por el Centro de Servicios e Informes del Colegio, en una primera fase dedicado a Ciutat Vella, fue entendido como actuación de urgencia para frenar la oleada de derribos que tenían lugar, con un número de edificios protegidos muy alto. Consideraban las siguientes variables en la identificación y valoración de los elementos:

a. Cualidades ambientales, de paisaje urbano y de trazado histórico

b. Cualidades arquitectónicas

c. Valores testimoniales de diversas formas de vida, de producción y de organización social.

d. Cualidades tipológicas

e. Posibilidades reales de rehabilitación

Se establecían los siguientes niveles de protección:

- Protección Individual (P.I.)

- Protección Individual Total en Monumentos Histórico-Artísticos, declarados o incoados, y a los elementos de alto valor singular en todas sus partes, merecedores de restauración integral.

- Protección Individual con Reconstrucción y Saneamiento, en elementos cuyo alto interés arquitectónico aconseja el mantenimiento de la organización funcional y espacial, pudiéndose realizar obras tendentes a conseguir niveles de habitabilidad mejorados.

- Protección Individual Parcial, en edificios de valor parcial, permitiéndose la reestructuración de la organización funcional con mantenimiento de los elementos valorados.

- Protección Ambiental (P.A.)

En edificios que sin ser singulares dentro de sus tipologías, forman parte de un conjunto de interés ambiental o histórico. Pueden ser objeto, en determinados casos, de sustituciones controladas, estableciéndose las restricciones adecuadas desde los Planes Especiales.

El presente catálogo urbanístico como documento complementario del Plan General contiene la enumeración ordenada de aquellos bienes que por sus especiales características son objeto de específica protección a fin de garantizar su defensa y preservación física. 
El catálogo valenciano aprobado definitivamente por resolución del Conseller de Obras Públicas, Urbanismo y Territorio el 22 de diciembre de 1992 (DOGV 3/5/93), se estructura en cuatro partes: Conjuntos y edificios protegidos, especies arbóreas y jardines protegidos, áreas de protección arqueológica y delimitación de Entornos de Bienes de Interés Cultural y relación de Monumentos.

Cada parte se constituye de un listado de bienes, con una exposición previa de los contenidos y conceptos que en ellos se incluyen. Como documentos complementarios se acompaña de tres planos:

- Hoja N01: División del municipio en distritos con señalización de las cuadrículas de la base cartográfica a escala 1:2.000 y escala 1:5.000

- Hoja N02: Elementos protegidos en el viejo Cauce del río Turia.

- Hoja N03: Delimitación de los Entornos de los Bienes de Interés Cultural y localización de Monumentos.

El listado de conjuntos y edificios protegidos, con 3.866 elementos incluidos, queda ordenado alfabéticamente en función del nombre de la vía pública a la que los inmuebles recaen. Con el código correspondiente al distrito, y al barrio en aquellos distritos donde la repetición de claves de identificación pudiera originar errores en su reconocimiento.

La clave es el código que identifica de forma precisa e inequívoca un elemento catalogado dentro de un barrio y un distrito dado. Esta clave hace referencia a los números de identificación de los elementos incluidos en el Preinventario e Inventario de edificios, conjuntos y elementos de interés arquitectónico del municipio, a excepción del área comprendida entre las Grandes Vías y la Primera Ronda, en los que se ha utilizado los códigos de identificación empleados por el Archivo Histórico del Colegio de Arquitectos de Valencia en la elaboración del Avance del Catálogo del Primer Ensanche de la Ciudad.

Para cada elemento se señala la identificación del Plano Parcelario realizado por el Servicio de Valoración Urbana del Ministerio de Hacienda, en el que se encuentra. A excepción del ámbito del primer ensanche, entre Colón y las Grandes Vías de Marqués del Turia y de Germanías, donde los Planos Parcelarios son los realizados por el Consorcio para la Gestión e Inspección de las Contribuciones Territoriales de Valencia Capital (1985). Asimismo, se referencia a la hoja de la Cartografía Básica Municipal, en la que se emplaza el elemento catalogado.

Se indica el nivel de protección conforme a los establecidos en las Normas Urbanísticas del Plan General, y si el elemento está localizado en un ámbito de planeamiento de desarrollo, por lo que se le asigna protección transitoria $(T)$ hasta la redacción de dicho plan.

El Catálogo no desarrolla los catálogos del Plan Especial de Reforma Interior de Carpesa, ni los correspondientes a los Planes Especiales de Protección de Ciutat Vella, sino que asume sus contenidos con las condiciones que señalan las Disposiciones Transitorias de las Normas Urbanísticas ${ }^{3 .}$

3 Disposición Transitoria Quinta de las Normas Urbanísticas del Plan General de Ordenación Urbana de Valencia: 
Los "Planes Especiales de protección incorporarán su propio catálogo de protección, cuyas determinaciones podrán ser coincidentes o no con las correlativas del Catálogo contenido en éste Plan; en caso de que no lo sean vendrán a sustituirlas en el ámbito respectivo sin necesidad de Modificación del Plan General, dado el carácter transitorio del Catálogo para estas zonas." (Art.2.7.4 PGOU Valencia).

"[...] En los ámbitos recogidos como anexo al Catálogo de Protección del presente Plan, las determinaciones resultantes del Plano $C$ se entenderán transitorias hasta que se apruebe el Plan Especial correspondiente." (Art.2.7.6 PGOU Valencia).

"El Catálogo del presente Plan General será susceptible de ser desarrollado mediante un Plan Especial de Protección en el que se aborden los siguientes aspectos relativos a los elementos protegidos: (Art.3.61.3 PGOU Valencia).

a) Redefinición de los grados de protección y de los elementos protegidos.

b) Concreción pormenorizada de los elementos de interés constitutivos de los conjuntos, edificios, y jardines objeto de protección.

c) Definición del régimen de usos, atendiendo a su compatibilidad con las tipologías y con los elementos protegidos".

\subsection{Normas urbanísticas sobre protección de inmuebles catalogados en el Plan General de Valencia}

Sobre la licencia de intervención sobre edificio protegido (Art.1.18):

No se podrán conceder licencias de demolición con relación a inmuebles catalogados sino, en todo caso, licencia de intervención que contemple tanto las operaciones de demolición como las de otra naturaleza y el resultado final de la actuación sobre el inmueble.

Sobre consultas en materia de intervención sobre elementos protegidos (Art.1.28): Los interesados podrán recabar dictamen previo de la Comisión Municipal de Patrimonio, u Órgano técnico consultivo equivalente, para que precise las concretas exigencias que se deriven del Régimen y Nivel de Protección a que se encuentre sujeto un edificio o elemento catalogado.

Sobre la conservación de parámetros de la edificación. (Art. 3.69)

- Hasta tanto se aprueben los Planes Especiales de Protección previstos en el artículo 6.7 de estas Normas y conforme al artículo 19 del vigente Reglamento de Planeamiento, se establece el siguiente régimen transitorio para la subzona $\mathrm{CHP}-1$ :

a) Serán de aplicación las determinaciones contenidas en los siguientes documentos de los Planes Especiales de Protección aprobados por el Ayuntamiento para los cinco barrios de Ciutat Vella:

- Planos de Ordenación, Protección y Régimen del Suelo.

- Ordenanzas.

- Catálogos.

b) En todo lo no previsto en dichos documentos se aplicarán las determinaciones generales del presente Plan, debiéndose seguir, en cualquier caso, las previsiones del Programa de Actuación del mismo.

c) La vigencia de dichas determinaciones se entenderá sin perjuicio de las facultades fiscalizadoras qué, conforme a la Ley de Patrimonio Histórico, correspondan a las autoridades competentes por razón de la materia. 
1. Sin perjuicio de lo que establezcan las ordenanzas particulares de zona no se podrá incrementar el volumen ni alterar los parámetros esenciales de los elementos propios de la edificación existente como consecuencia de las obras de intervención que se realicen sobre edificios sujetos a protección, aunque podrá aceptarse un incremento de la superficie construida sobre rasante siempre que se cumplan las Ordenanzas Generales de la Edificación y no se altere el volumen geométrico preexistente.

2. Sólo por circunstancias justificadas de interés general podrá permitirse, en los casos de protección ambiental, la alteración de la distribución del volumen dentro de la parcela, sin que ello pueda suponer incremento absoluto del volumen global originario con incumplimiento de las ordenanzas de edificación de la zona, aunque sí variación de los parámetros esenciales de la edificación preexistente en aras de una mejor integración del edificio en el entorno protegido.

3. No serán de aplicación aquellas condiciones generales de la edificación reguladas en el Título Quinto ${ }^{4}$ que impidan o dificulten el correcto tratamiento de los edificios protegidos, salvo en los casos de sustitución previstos dentro del régimen de protección ambiental.

4. Las profundidades edificables grafiadas en los planos C sólo serán de aplicación a edificios protegidos que las superen y en los que se autorice la demolición total o parcial con conservación de fachada

Sobre la protección de plantas bajas, parcelación y superficies anexas. (Art.3.70)

1. Para todas las categorías de protección queda prohibida la instalación de rótulos de carácter comercial o similar, insertos en la fachada del inmueble, debiendo eliminarse los existentes en el plazo de dos años desde la aprobación definitiva de este Plan. Se exceptúan los que se adosen a los huecos de la planta baja cuando su superficie no exceda de un metro cuadrado y los que se integren formalmente en el cerramiento o acristalamiento de dichos huecos.

2. Los proyectos de renovación de plantas bajas para ubicación de locales comerciales u otros usos permitidos, deberán situar los huecos de fachada en los ejes de simetría correspondientes a las plantas altas, quedando prohibidas todo tipo de marquesinas y salientes no originales. En todo caso deberá respetarse la continuidad y homogeneidad del tratamiento respecto a las plantas superiores.

3. La protección se extiende a la totalidad de la parcela en que se encuentra situado el edificio, afectando su régimen a la totalidad del arbolado y jardinería existente en ella. Solo se admitirá la segregación parcelaria, cuando las obras de intervención se acometieran sobre varios inmuebles radicados en diversas parcelas y la segregación pretendida permitiese conservar, con mayor eficacia, los valores arquitectónicos que se traten de proteger en el conjunto de ellos.

\footnotetext{
4 Título Quinto: Ordenanzas Generales de la Edificación. PGOU Valencia.
} 
Sobre la adecuación de los materiales.(Art.3.71):

En las obras de intervención sobre edificios protegidos los materiales empleados habrán de adecuarse a los que presentaba el edificio en su forma originaria o de mayor interés. En las obras reguladas en el artículo $3.59^{5}$ y concordantes, habrán de adecuarse a las exigencias ambientales del entorno como las concrete la autorización correspondiente aunque los materiales utilizados difieran de los originarios.

Sobre el tratamiento del entorno. Conjuntos Arquitectónicos (PAR). (Art.3.73):

1. Las construcciones e instalaciones próximas a conjuntos, edificios o jardines objeto de protección, deberán adecuarse en su diseño y composición a los elementos protegidos armonizando con ellos y sin crear barreras visuales.

2. El Plan, de conformidad con las previsiones específicas de su Catálogo, sujeta con Nivel de Protección número 3, todos los conjuntos arquitectónicos (PAR) de la ciudad. El objetivo primario perseguido es la preservación de la unidad del proyecto originario que dio lugar a la edificación conjunta. Para el tipo básico de protección arquitectónica se autorizarán las obras de conservación, reforma y modernización precisas para el buen uso de los edificios, sin modificación de los elementos compositivos de la fachada y cubierta.

La protección subsidiaria ambiental comportará la sustitución total o parcial de los edificios que se encuentren en ruina; la nueva edificación deberá mantener estrictamente las condiciones del resto de los edificios del conjunto, en particular, la parcela mínima presente en éste, alineaciones, edificabilidad, alturas y condiciones estéticas de la edificación, debiéndose reproducir las características compositivas externas propias del conjunto protegido.

3. [...], se entiende por conjunto arquitectónico el grupo de edificios ordenados y edificados simultáneamente, según proyecto unitario, determinando una parcelación regular, la repetición de tipología arquitectónica y una secuencia de espacios intermedios con orden preciso.

\subsection{Contenido normativo del catálogo ${ }^{6}$}

Cada nivel de protección relacionado con un tipo básico de protección cuenta con un tipo subsidiario de protección que supone la realización de otras obras distintas a las contempladas en el tipo básico, siempre que se pruebe ante la autoridad y así se declare por ésta, que dichas obras permiten lograr, con mayores garantías de eficacia, la protección de los valores arquitectónicos o urbanísticos que persigue la catalogación.

- Nivel N01: Protección Monumental (básica) e Integral (subsidiaria)

- Nivel N02: Protección Estructural (básica) y Parcial (subsidiaria)

- Nivel N03: Protección Arquitectónica (básica) y Ambiental (subsidiaria)

\footnotetext{
5 Artículo 3.59.- Adecuación al ambiente de las obras sobre edificaciones. PGOU Valencia.

${ }^{6}$ Artículo 3.62. - Normas Urbanísticas del Plan General de de Ordenación urbana de Valencia
} 
El Régimen Jurídico de los niveles de protección se resume en la siguientes tablas, donde se compara los criterios de intervención de los niveles del Reglamento de Planemiento y en el catálogo de Valencia (Figura 1), así como en el ROGTU (Figura 2), de mayor adaptación a las cartas internacionales de patrimonio:

\begin{tabular}{|c|c|c|}
\hline \multicolumn{2}{|c|}{ NIVELES REGLAMENTO PLANEAMIENTO (1998) } & $\begin{array}{l}\text { CATÁLOGODE } \\
\text { VALENCIA }\end{array}$ \\
\hline \multirow{4}{*}{ INTEGRAL } & Obras de restauración y conservación para mantenimiento estructural y mejora instalaciones & \multirow{3}{*}{ MONUMENTAL } \\
\hline & Demolición cuerpos de obra añadidos que desvirtúen unidad arquitectónica original & \\
\hline & $\begin{array}{l}\text { Reconstrucción o reposición cuerpos y huecos primitivos en beneficio del valor cultural del } \\
\text { conjunto }\end{array}$ & \\
\hline & $\begin{array}{l}\text { Obras excepcionales de redistribución interior, sin alterar caracteristicas estructurales y } \\
\text { exteriores del edificio. }\end{array}$ & $\begin{array}{l}\text { PROTECCIÓN } \\
\text { SUBSIDIARIA } \\
\text { INTEGRAL } \\
\end{array}$ \\
\hline \multirow{2}{*}{ PARCIAL } & $\begin{array}{l}\text { Obras congruentes con los valores catalogados con respeto de los elementos definitorios de } \\
\text { la estructura arquitectónica o espacial: espacios libres, alturas y forjados, jerarquización } \\
\text { volúmenes interiores, escaleras principales, zaguán, fachada y demás elementos propios. }\end{array}$ & ESTRUCTURAL \\
\hline & $\begin{array}{l}\text { Demolición de los elementos anteriores cuando no gocen de protección específica desde el } \\
\text { catálogo, sean de escaso valor definitorio para el conjunto y su preservación comporte } \\
\text { graves problemas para la conservación del inmueble. }\end{array}$ & $\begin{array}{l}\text { PROTECCIÓN } \\
\text { SUBSIDIARIA } \\
\text { PARCIAL }\end{array}$ \\
\hline \multirow{2}{*}{ AMBIENTAL } & $\begin{array}{l}\text { Demolición de sus partes no visibles desde la vía pública, preservando y restaurando sus } \\
\text { elementos propios y acometiendo la reposición del volumen preexistente respetando el } \\
\text { entorno y los caracteres originarios de la edificación }\end{array}$ & ARQUITECTÓNICA \\
\hline & $\begin{array}{l}\text { La demolición o reforma de la fachada y elementos visibles desde la vía pública con licencia } \\
\text { de intervención para proyecto de fiel reconstrucción, remodelación o construcción alternativa } \\
\text { de superior interés arquitectónico que contribuya a preservar los rasgos definitorios del } \\
\text { ambiente protegido. }\end{array}$ & $\begin{array}{l}\text { PROTECCIÓN } \\
\text { SUBSIDIARIA } \\
\text { AMBIENTAL }\end{array}$ \\
\hline
\end{tabular}

Figura 1. Comparativa entre los niveles de protección aprobados en el catálogo de Valencia (1993) y los aprobados en el Reglamento de Planeamiento de la Comunidad Valenciana (1998)

Fuente: Elaboración propia

\begin{tabular}{|c|c|c|}
\hline NIVELES & REGLAMENTO PLANEAMIENTO, 1998 & $\begin{array}{l}\text { ROGTU, } 2006 \text { (novedades introducidas en } \\
\text { azul) }\end{array}$ \\
\hline \multirow{4}{*}{ INTEGRAL } & \multicolumn{2}{|c|}{ Obras de restauración y conservación para mantenimiento estructural y mejora instalaciones } \\
\hline & $\begin{array}{l}\text { Demolición cuerpos de obra añadidos que desvirtúen unidad } \\
\text { arquitectónica original }\end{array}$ & DEROGADO \\
\hline & \multicolumn{2}{|c|}{$\begin{array}{l}\text { Reconstrucción o reposición de cuerpos y huecos primitivos en beneficio del valor cultural del conjunto utilizando } \\
\text { siempre técnicas y soluciones constructivas propias de la época de su construcción y recuperando el diseño original, } \\
\text { ulilizando soluciones de acabados que permilan distinguir las partes reconstruidas de las originales }\end{array}$} \\
\hline & \multicolumn{2}{|c|}{ Obras excepcionales de redistribución interior, sin alterar características estructurales y exteriores del edificio. } \\
\hline \multirow{2}{*}{ PARCIAL } & \multicolumn{2}{|c|}{$\begin{array}{l}\text { Obras congruentes con los valores catalogados con respeto de los elementos definitorios de la estructura arquitectónica } \\
\text { o espacial: espacios libres, alturas y forjados, jerarquización volúmenes interiores, escaleras principales, zaguán, } \\
\text { fachada y demás elementos propios. }\end{array}$} \\
\hline & \multicolumn{2}{|c|}{$\begin{array}{l}\text { Demolición de los elementos anteriores cuando no gocen de protección específica desde el catálogo, en bienes no } \\
\text { inscritos en el llnventario General del Paltrimonio Cullural Valenciano, sean de escaso valor definitorio para el conjunto y } \\
\text { su preservación comporte graves problemas para la conservación del inmueble. }\end{array}$} \\
\hline
\end{tabular}




\begin{tabular}{|c|c|c|}
\hline NIVELES & REGLAMENTO PLANEAMIENTO, 1998 & $\begin{array}{l}\text { ROGTU, } 2006 \text { (novedades inlroducidas en } \\
\text { azull) }\end{array}$ \\
\hline \multirow{4}{*}{ AMBIENTAL } & \multicolumn{2}{|c|}{$\begin{array}{l}\text { Demolición de sus partes no visibles desde la vía pública, preservando y restaurando sus elementos propios y } \\
\text { acometiendo la reposición del volumen preexistente respetando el entorno y los caracteres originarios de la edificación }\end{array}$} \\
\hline & $\begin{array}{l}\text { La demolición o reforma de la fachada y elementos visibles desde la vía } \\
\text { pública con licencia de intervención para proyecto de fiel reconstrucción, } \\
\text { remodelación o construcción alternativa de superior interés } \\
\text { arquitectónico que contribuya a preservar los rasgos definitorios del } \\
\text { ambiente protegido. }\end{array}$ & DEROGADO \\
\hline & & 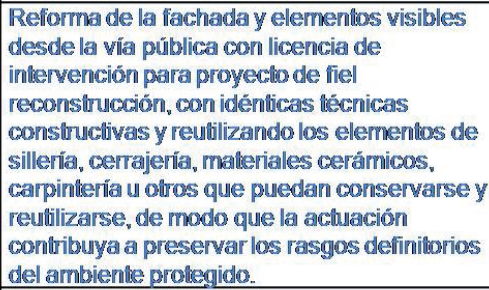 \\
\hline & $\begin{array}{l}\text { En áreas de renovación tipológica, la demolición total, selectiva, a } \\
\text { medida que se asegure la renovación conjunta de entornos visuales } \\
\text { completos. }\end{array}$ & DEROGADO \\
\hline
\end{tabular}

Figura 2. Comparativa entre los niveles de protección aprobados en Reglamento de Planeamiento (1993) y los aprobados en el Reglamento de Ordenación y Gestión Territorial y Urbanística, ROGTU (2006). Se incluyen en azul las modificaciones introducidas por el ROGTU.

Fuente: Elaboración propia

\subsection{Contenido normativo del catálogo}

Las Cartas de Restauro italianas como referente en este ámbito y las convenciones internacionales sobre criterios de intervención en el patrimonio histórico arquitectónico se resumen en las siguientes:

- Criterios de intervención de la Carta de Restauro de 1932

- Máxima importancia a los cuidados continuos de mantenimiento en la obra de consolidación, encaminada a la resistencia y duración del monumento.

- Operaciones de "repristino"7 sólo cuando se base en datos absolutamente ciertos proporcionados por el monumento y no en hipótesis.

- En monumentos antiguos debe excluirse todo completamiento, sólo recomposición de partes desmembradas existentes, con la adición eventual de aquellos elementos neutros que representen el mínimo necesario para integrar la línea y asegurar las condiciones de conservación.

- En monumentos "vivos" sólo deben admitirse usos no muy diferentes de los destinos primitivos, de forma que no se afectúen alteraciones esenciales en el edificio.

- Deben conservarse los elementos con carácter artístico o de recuerdo histórico, independientemente de la época a la que pertenezcan y sólo podrán eliminarse aquéllos privados de importancia y significado que representen afeamientos

7 Restauración de repristino o estilística, es la que intenta eliminar el lapso de tiempo entre la conclusión de la obra y el presente, al pretender recuperar la obra en su estado original. SÁNCHEZ FERNÁNDEZ, 2012. 
inútiles, el juicio sobre tales valores debe ser discutido y no remitido al juicio personal del autor del proyecto.

- Junto al respecto por el monumento debe seguir el de sus condiciones ambientales, no alteradas por aislamientos inoportunos, por construcciones de nuevas fábricas invasoras por su masa, color o estilo.

- En los añadidos necesarios para la consolidación, reintegración o para la reutilización del monumento se limitarán al mínimo posible y se les dará un carácter de desnuda simplicidad y de correspondencia con el esquema constructivo. Tales añadidos serán señalados con materiales diferentes al primitivo o con adopción de marcas de contorno, siglas o epígrafes, de modo que ninguna restauración pueda producir engaño a los estudiosos y representar una falsificación de un documento histórico.

- Con el fin de reforzar la estática del monumento, se utilizará medios constructivos modernos cuando la adopción de medios constructivos análogos a los antiguos no logre su fin.

- En la restauración de monumentos debe ser condición esencial y taxativa que se acompañe a los trabajos de la documentación compuesta por informes analíticos recogidos en un diario de restauración e ilustrados con dibujos y fotografías.

- Criterios de intervención de la Carta de Venecia de 1964

- El monumento histórico comprende tanto la creación arquitectónica aislada como el ambiente urbano o paisajístico que constituya el testimonio de una civilización particular, de una evolución significativa o paisajística.

- La conservación de los monumentos impone su mantenimiento sistemático. La conservación favorecida por su utilización no debe alterar la distribución y el aspecto del edificio.

- La conservación de las condiciones ambientales debe rechazar cualquier nueva construcción, destrucción y utilización que pueda alterar las relaciones de los volúmenes y colores.

- Los elementos de escultura, pintura o decoración integrantes del monumento no pueden ser separados de él.

- La restauración debe tener carácter excepcional, estará precedida siempre por estudio arqueológico e histórico del monumento y debe detenerse allí donde empiezan las hipótesis. El trabajo encaminado a completar, indispensable por razones estéticas y teóricas, debe distinguirse del conjunto arquitectónico y deberá llevar el sello de nuestra época.

- En la restauración deben respetarse todas las aportaciones, no importa la época, la unidad de estilo no es el fin de la restauración. El juicio sobre el valor de los elementos y la decisión sobre las eliminaciones no pueden depender tan sólo del autor del proyecto.

- Los elementos destinados a reemplazar las partes que falten deben integrarse armoniosamente en el conjunto, pero distinguiéndose de las partes originales. 
- Criterios de intervención de la Carta del Restauro de 1972. Se entiende una concepción más amplia de las obras de arte: desde el ambiente urbano a los monumentos arquitectónicos. Se incluye en el documento los conjuntos de edificios de interés monumental, histórico o ambiental, especialmente los centros históricos y jardines y parques de especial importancia, para su salvaguardia ${ }^{8}$ y restauración ${ }^{9}$.

- En las operaciones de restauración se prohíbe:

1) Complementos estilísticos o analógicos, incluso en formas simplificadas y aunque existan documentos gráficos o plásticos que indiquen cuál era el estado o aspecto de la obra completa.

2) Remociones o demoliciones, a menos que se limiten a alteraciones deformadoras o incongruentes respecto a valores históricos de la obra o de complementos en estilo que la falsifiquen.

3) Remociones, reconstrucciones o traslados a emplazamientos distintos de los originales.

4) Alteraciones de las condiciones accesorias o ambientales, del conjunto monumental o ambiental, el conjunto de decoración interior, el jardín, el parque, etc.

5) Alteración o remoción de las pátinas.

- En las operaciones de restauración se admite:

1) Añadidos de partes de función estática o reintegraciones de pequeñas partes históricamente verificadas, determinando de forma clara la periferia de las integraciones 0 adoptando otro material diferenciado pero acorde distinguible a simple vista, en particular en los puntos de encuentro con las partes antiguas, que además deben ser marcadas y fechadas donde sea posible.

2) Modificaciones y nuevas inserciones con fines estáticos y de conservación de la estructura interna, que no altere su aspecto exterior.

3) Nueva ambientación o colocación de la obra, cuando no exista ya o se hayan destruido el ambiente o la sistematización tradicional, o cuando las condiciones de conservación exijan el traslado.

- Como instrucciones para la ejecución de restauraciones arquitectónicas:

Se recomienda la vigilancia continua y las medidas de carácter preventivo a fin de evitar intervenciones de mayor amplitud. Las operaciones de restauración deben tener un carácter eminentemente conservador, respetando todos los elementos añadidos y evitando en todo caso intervenciones innovadoras y de repristino. Es exigencia fundamental respetar la autenticidad de los elementos constructivos. Se pueden considerar nuevos usos, cuando éstos no resulten

\footnotetext{
${ }^{8}$ Se entiende por salvaguardia cualquier medida conservadora que no implique la intervención directa sobre la obra.

9 Se entiende por restauración cualquier intervención encaminada a mantener vigente, a facilitar la lectura y trasmitir íntegramente al futuro las obras de arte, monumentos, conjuntos históricos y jardienes y parques de especial interés.
} 
incompatibles con los intereses histórico-artísticos. Las obras de adaptación deberán limitarse al mínimo, conservando escrupulosamente las formas externas, evitando las alteraciones de la tipología y la secuencia de los recorridos internos.

- Principios para la conservación y restauración del patrimonio construido de la Carta de Cracovia de 2000.

- La conservación puede realizarse mediante diferentes tipos de intervención como el control medio ambiental, mantenimiento, reparación, restauración, renovación y rehabilitación.

- Debe evitarse la reconstrucción en "el estilo del edificio" de partes enteras del mismo.

- Se admite excepcionalemente la reconstrucción de partes muy limitadas, con significado arquitectónico, basada en una documentación precisa e indiscutible.

- Se permite la incorporación de partes espaciales y funcionales más extensas con un lenguaje arquitectónico actual, para un uso adecuado del edificio.

- El proyecto de restauración debe definir los métodos y objetivos de la intervención, y el edificio debe albergar un uso apropiado y compatible con el espacio y significado existente.

- La intervención elegida debe respetar la función original y asegurar la compatibilidad con los materiales y las estructuras existentes, así como con los valores arquitectónicos.

Como síntesis de criterios vigentes hasta Cracovia, se podría considerar los siguientes tipos de intervención con sus criterios de actuación:

- Mantenimiento de carácter preventivo para evitar la restauración. EXIGIDO.

- "Repristino", intervención de recuperación de un estilo. PROHIBIDO.

- Restauración, de carácter excepcional que puede conllevar (PERMITIDO):

- Modificaciones o añadidos estructurales que no alteren su aspecto exterior.

- Reconstrucción de partes muy limitadas, con significado arquitectónico, basada en una documentación precisa e indiscutible

- Demolición de alteraciones deformadoras o incongruentes respecto a los valores históricos de la obra o de complementos en estilo que la falsifiquen.

- Adaptación de un uso adecuado al edificio, (sin alteración del aspecto exterior, la tipología constructiva y la secuencia de recorridos interiores), con posibilidad de incorporación de partes espaciales y funcionales más extensas con un lenguaje arquitectónico actual. PERMITIDO

Los criterios de intervención en actuaciones de restauración contemplados en la Ley de Patrimonio Histórico Español, se recogen en su artículo 39:

- Prohibido el "repristino" 
- Los añadidos para su estabilidad estructural deberán ser reconocibles y evitar las confusiones miméticas.

- Prohibida la reconstrucción, salvo cuando se utilicen partes originales y pueda probarse su autenticidad.

- Demolición de partes con carácter excepcional y siempre que dichos elementos supongan una evidente degradación del bien y su eliminación fuere necesaria para permitir una mejor interpretación histórica del mismo.

Los criterios de intervención en Monumentos, Jardines Históricos y Espacios Etnológicos en la Comunidad Valenciana se recogen en el artículo 38 LPCV:

- Prohibido el "repristino"

- En caso de que se autorice la demolición de alguna parte deberá quedar debidamente documentada ${ }^{10}$.

- Se permiten reconstrucciones totales o parciales del bien siempre que exista alguna pervivencia de elementos originales o conocimiento documental suficiente de lo perdido, se procurará la utilización de procedimientos y materiales originarios.

- Los bienes muebles vinculados como pertenencias o accesorios a un inmueble declarado de interés cultural sólo podrán ser separados del mismo en beneficio de su propia protección y de su difusión pública o cuando medie un cambio de uso y siempre con autorización de la conselleria competente en materia de cultura.

Los criterios de intervención en edificios catalogados en la Comunidad Valenciana, en función de su grado de protección se recogen en el ROGTU, desarrollo reglamentario de la Ley Urbanística Valenciana:

1) Protección integral (Edificios de carácter singular o monumental):

- Obras de restauración y conservación que persigan el mantenimiento o refuerzo de los elementos estructurales así como la mejora del estado general o instalaciones. No obstante, puede autorizarse:

- Reposición o reconstrucción de aquellos cuerpos y huecos primitivos cuando redunden en beneficio del valor cultural del conjunto, utilizando siempre técnicas y soluciones constructivas propias de la época de su construcción y recuperando el diseño original, utilizando soluciones de acabados que permitan distinguir las partes reconstruidas de las originales.

- Las obras excepcionales de redistribución del espacio interior sin alterar las características estructurales o exteriores del edificio, siempre que ello no desmerezca los valores protegidos ni afecte a elementos constructivos a conservar.

\footnotetext{
${ }^{10}$ Queda sin definir en qué condiciones puede autorizarse la demolición.
} 
- Si el Catálogo prohibiera la demolición de elementos concretos su enumeración se entenderá vinculante aunque no exhaustiva.

2) Protección parcial: en caso de protección parcial pueden autorizarse:

- Obras que mantengan los elementos definitorios de la estructura arquitectónica o espacial tales como los espacios libres, alturas y forjados, jerarquización de volúmenes interiores, escaleras principales, el zaguán si lo hubiera, la fachada y demás elementos propios. No obstante, podrá autorizarse:

- La demolición de algunos de los elementos señalados en el apartado anterior cuando no gocen de protección específica por el catálogo, en bienes no inscritos en el Inventario General del Patrimonio Cultural Valenciano, y, además, sean de escaso valor definitorio del conjunto o cuando su preservación comporte graves problemas de cualquier índole para la mejor conservación del inmueble.

- En ningún caso podrán ser objeto de demolición la fachada o fachadas principales o características ni los espacios principales de acceso o distribución interior.

- Cuando su estado de conservación exija intervenciones de demolición parcial, siempre se reconstruirá el elemento demolido con idénticas técnicas constructivas y reutilizando los elementos de sillería, cerrajería, materiales cerámicos, carpintería u otros que puedan conservarse y reutilizarse.

3) Protección ambiental (inmuebles sin un especial valor individual contribuyen a definir un entorno valioso para el paisaje urbano o están integrados en unidades urbanas que configuren espacios urbanos como calles, plazas o bordes, que deben ser preservados por el valor histórico o ambiental de su imagen o ambiente urbano). Se puede autorizar:

- La demolición de sus partes no visibles desde la vía pública, preservando y restaurando sus elementos propios y acometiendo la reposición del volumen preexistente respetando el entorno y los caracteres originarios de la edificación.

- La reforma de la fachada y elementos visibles desde la vía pública con licencia de intervención para proyecto de fiel reconstrucción, con idénticas técnicas constructivas y reutilizando los elementos de sillería, cerrajería, materiales cerámicos, carpintería u otros que puedan conservarse y reutilizarse, de modo que la actuación contribuya a preservar los rasgos definitorios del ambiente protegido.

A través de un cuadro sinóptico establecemos la comparación entre los criterios establecidos en cada norma (Tabla 3), que permite demostrar, entre otras disparidades, la dualidad de exigencias en la intervención de monumentos con declaración expresa BIC, entre la legislación del estado y la valenciana; y entre inmuebles BIC y aquéllos catalogados con protección integral en los catálogos urbanísticos. 


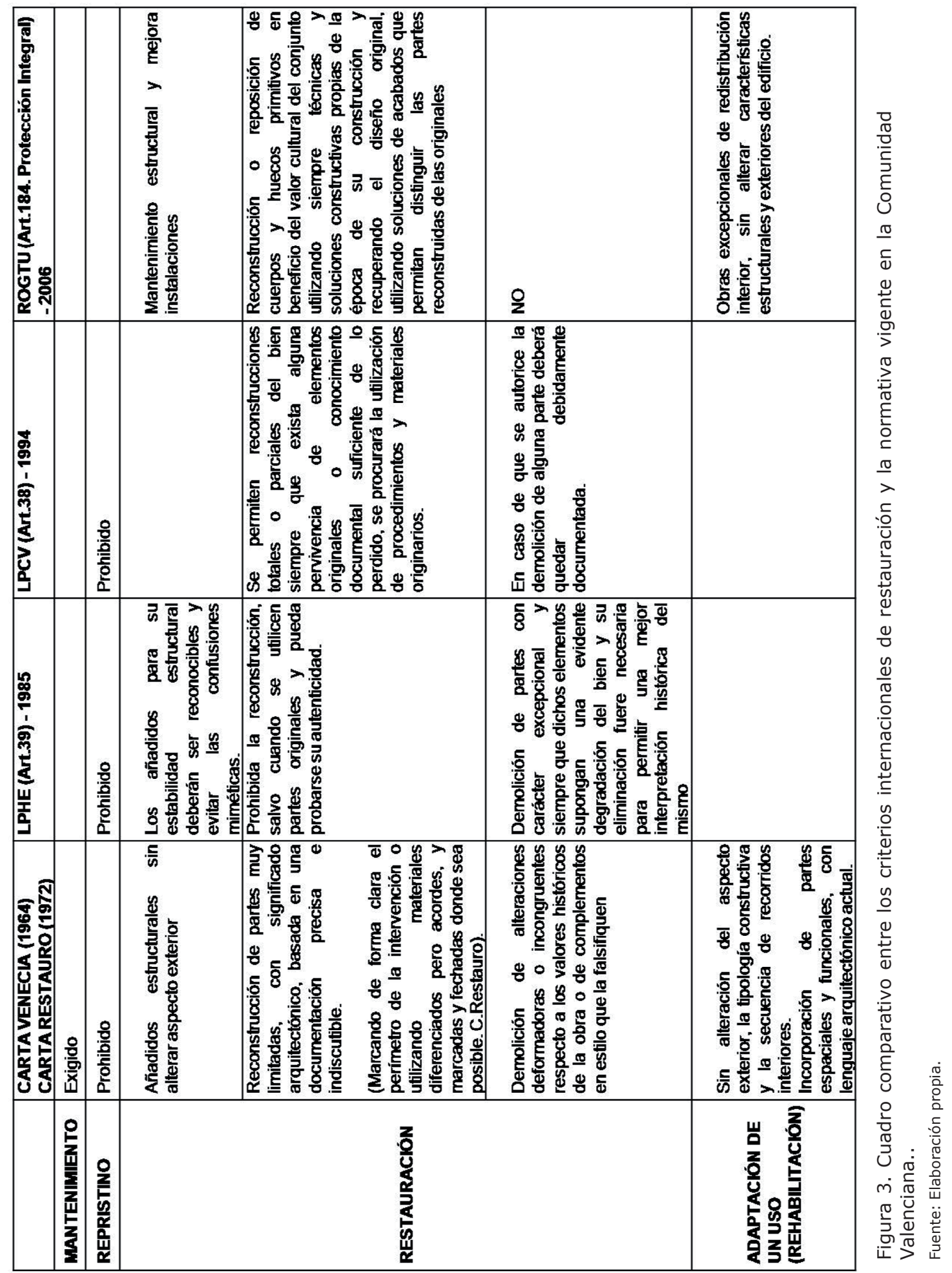


En principio la Ley estatal prohíbe la reconstrucción, salvo con partes originales con probada autenticidad, mientras que en la Comunidad Valenciana, las reconstrucciones serán totales o parciales mientras exista alguna pervivencia de elemento original o documentación suficiente de lo perdido. La protección integral asignada por un catálogo urbanístico permite sobre el inmueble la reconstrucción o reposición de cuerpos o huecos originales en el diseño propio del edificio, con técnicas o soluciones constructivas de la época, pero con acabados que permita diferenciarlos del cuerpo preexistente; lo que en el ámbito valenciano, contrasta con la posibilidad de reconstrucción total y la utilización de materiales originarios sin aportar acabados que permitan la distinción de las partes reconstruidas en monumentos BIC.

\subsection{Contenido normativo del catálogo}

Antes de continuar con el estudio de la catalogación en la ciudad de Valencia, analizaremos dos propuestas de intervención en patrimonio de la Generalitat Valenciana y el Ayuntamiento de Valencia, respectivamente, de las que se deduce que la propia administración es proclive a orillar su propia regulación.

La modificación del Plan General de Valencia en el ámbito de la Cárcel Modelo se aprueba definitivamente el 17 de septiembre de 2001. La iniciativa la promueve la Consellería de Economía, Hacienda y Empleo, con el fin de establecer un complejo administrativo en la parcela donde se ubica la antigua cárcel modelo de Valencia en la manzana delimitada por las calles Castañ Tobeñas, Nueve de Octubre, Luis Lamarca y Rincón de Ademuz.

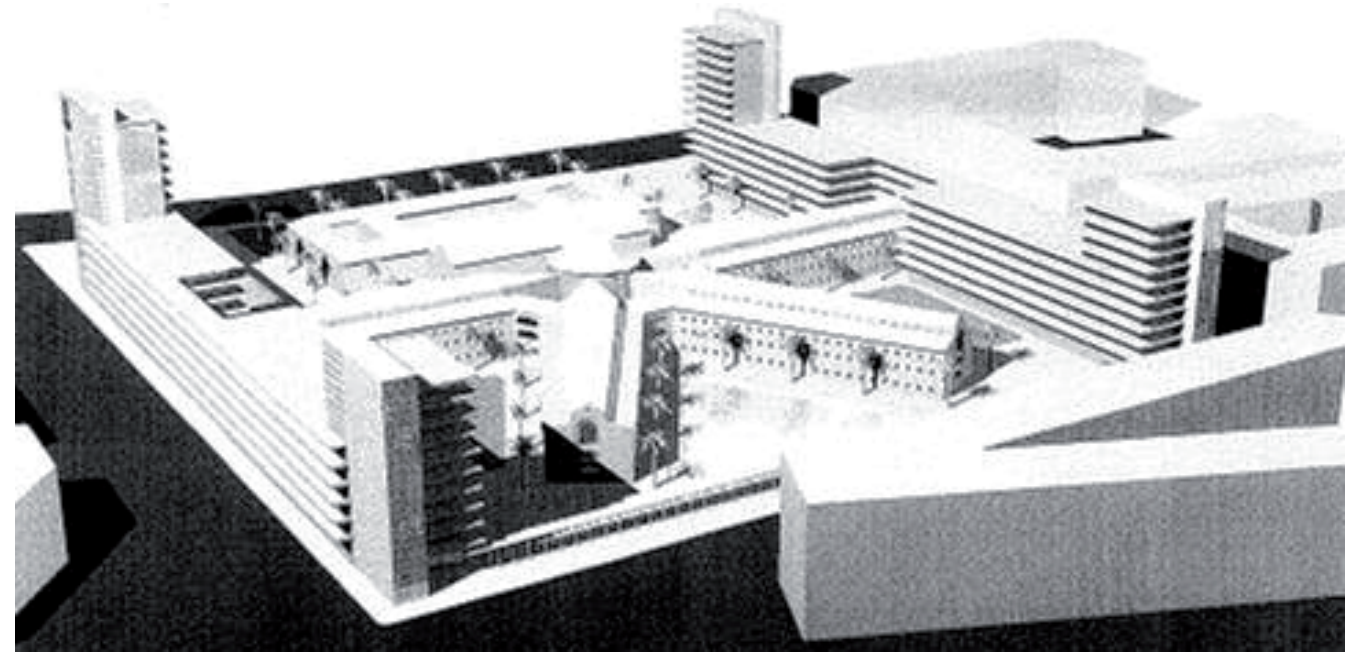

Figura 4. Propuesta de Rehabilitación y ampliación del complejo administrativo Nueve de Octubre en el solar de la antigua cárcel modelo de Valencia. Esta propuesta no es la que acaba implantándose, por maclarse el nuevo edificio al antiguo y no mantener exento el inmueble protegido.

Fuente: Anexo 6 de infografías de la Memoria de la Modificación Puntual del Plan General en la Manzana GSP-2 delimitada por las calles Castan Tobeñas, Nueve de Octubre, Luis Lamarca y Rincón de Ademuz, Consellería d'Economía, Hisenda i Administració Pública, Generalitat Valenciana, febrero 2001. 
La modificación consiste en la ampliación de usos de la parcela, en origen sociocultural (GSP-2), al que se suma el uso dotacional administrativo (GSP-4) y la modificación del nivel de protección asignado al edificio por el catálogo, de protección monumental (Nivel 1-PGOU) a protección estructural (nivel 2-PGOU).

De acuerdo con el autor de la actuación, la implantación del nuevo uso, justifica la modificación del nivel de protección del inmueble, para poder llevar a cabo la rehabilitación del edificio, adaptando las condiciones del inmueble a los nuevos usos propuestos: con la eliminación de todos aquellos elementos constructivos y edificaciones, que careciendo de interés arquitectónico, sean añadidos a la obra original del arquitecto Joaquín María Belda. De manera, que se propone el derribo del módulo de mujeres de reciente construcción, de las crujías laterales a base de pórticos de hormigón adosados al cuerpo de guardia que da acceso a la rótula de distribución de las alas, así como talleres, cobertizos, garitas, y demás elementos sin interés arquitectónico, punto que pone en cuestión los criterios de rehabilitación para el uso de edificios monumentales, debiendo ser éstos compatibles con la configuración del edificio.

Por otro lado se propone colmatar la edificabilidad de la parcela hasta $47.297 \mathrm{~m}^{2}$ de techo del total del excedente de aprovechamiento de $50.144 \mathrm{~m}^{2}$ de techo que alberga la parcela, lo que permite la construcción de nuevos edificios para servicios administrativos, guardería, comedor, gimnasio y otros usos complementarios.

En el momento en que se presenta la propuesta, el edificio de la carcel estaba incluido en el catálogo urbanístico del Plan General de Valencia, con nivel de protección 1, no sujeto a planeamiento de desarrollo, con un ámbito de protección que alcanzaba la totalidad de la parcela conforme al plano de ordenación del Plan General de Valencia y el artículo 3.70.3 de las Normas Urbanísticas del mismo.

Aprobada la modificación de planeamiento, se presenta un Estudio de Detalle $(1 / 2 / 2007)$ sobre la manzana, con el fin de ordenar los nuevos volúmenes de edificación en la parcela.

El Colegio de Arquitectos de Valencia, mediante informe de fecha 12/1/2007, cuestiona la procedencia y legalidad de la modificación del Plan General y su Catálogo, en la propuesta de referencia, no por la minoración del nivel de protección, que justifica una intervención de rehabilitación más flexible, sino por la asignación al solar una volumetría que no le era propia, ya que al tratarse de un edificio protegido la única volumetría permitida es la que el propio edificio tiene y que el plan protege. Circunstancia que se evidencia por lo expuesto en el artículo 3.69 de las Normas Urbanísticas del PGOU:

"Sin perjuicio de los que establezcan las ordenanzas particulares de zona no se podrá incrementar el volumen ni alterar los parámetros esenciales de los elementos propios de la edificación existente como consecuencia de las obras de intervención que se realicen sobre edificios sujetos a protección, aunque podrá aceptarse un incremento de la superficie construida sobre rasante siempre que se cumplan las Ordenanzas Generales de la Edificación y no se altere el volumen geométrico preexistente" 
Con la aprobación de la duplicación de volumetría sobre la parcela, "cualquier propuesta que se plantee es evidente que vulnera los valores patrimoniales que se pretendía preservar por el propio Plan General." ${ }^{11}$

En lo que se refiere al valor arquitectónico del conjunto, el informe apunta su indiscutible valor como materialización formal de una voluntad regeneradora, por medio del aislamiento de presos, siendo pocos los ejemplos de cárceles de esta concepción que quedan en España actualmente, lo que la erige en un ejemplar valioso, que hace incomprensible su degradación en el nivel de protección, sin justificación que lo avale.

"Dicho nivel, aun en su actual propuesta de "parcial" debería extenderse en todo caso a la totalidad de la manzana sin permitir en ningún caso la invasión del terreno limitado por el muro de cerramiento y la fachada principal por nuevas edificaciones que en cualquier caso perturbarían la adecuada visión del edificio contraviniendo las directrices de la Ley 4/2004, de 30 de junio, de la Generalitat, de Ordenación del Territorio y Protección del Paisaje: Las construcciones emplazadas en las inmediaciones de bienes inmuebles de bienes de carácter artístico, histórico, arqueológico, típico o tradicional han de armonizar con ellos, aun cuando en su entorno sólo haya uno con esas características. Los estudios de paisaje identificarán tales inmuebles en el inventario de recursos paisajísticos y delimitarán los entornos afectados. "12
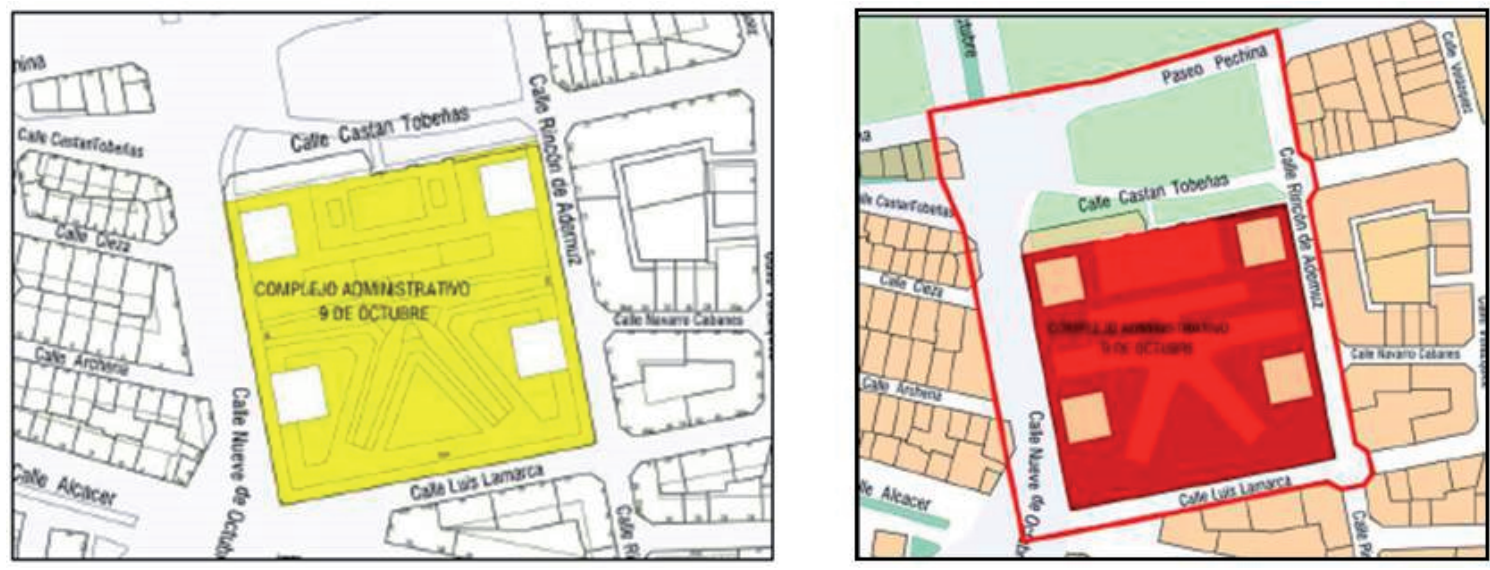

Figura 5. Detalle del plano parcelario municipal 2009 SIGESPA con el ámbito BRL propuesto (izquierda) y plano de delimitación del entorno de protección del BRL (derecha)

Fuente: ficha del catálogo estructural de Valencia de la Revisión simplificada del Plan General, mayo 2013.

Pocos años después de la aprobación municipal que posibilitó la intervención, el Ayuntamiento de Valencia expone al público la parte estructural del Catálogo integrante de la revisión simplificada del Plan General. En él se cataloga la Antigua

\footnotetext{
11 Taberner Pastor, F.: Informe de fecha 12 de enero de 2007, del Colegio Territorial de Arquitectos en contestación a la solicitud presentada por D. Salvador Blanco, representante de la plataforma Recuperem la Model.

12 Taberner Pastor, F.: Informe de fecha 12 de enero de 2007, del Colegio Territorial de Arquitectos en contestación a la solicitud presentada por D. Salvador Blanco, representante de la plataforma Recuperem la Model.
} 
Carcel Modelo, tras la intervención de rehabilitación y de colmatació de edificabilidad, asumiendo todo lo que el informe aportó en su día: el relevante valor del edificio por su singularidad, la asignación de su protección a toda la parcela que circundaba el muro de la cárcel y la delimitación de un entorno de protección. Se propone la declaración de BRL, no sólo del edificio, sino de su espacio libre circundante, sobre el que también se ha intervenido, eso sí, excluyendo de la protección las torres edificadas en los cuatro flancos del edificio, como si éstas nunca hubieran existido y no crearan un enorme impacto visual sobre la parcela que ahora proponen como BRL.
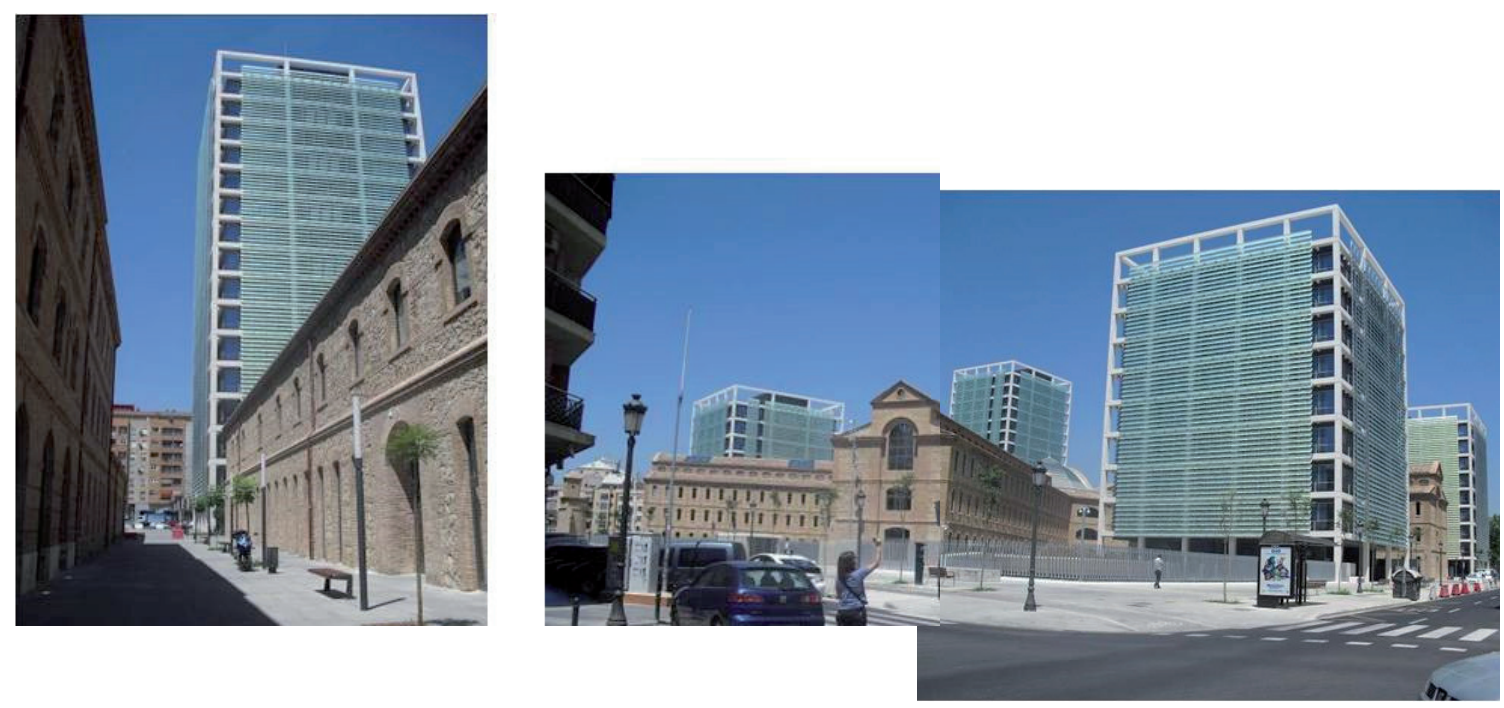

Figura 6. Imagen del complejo administrativo Nou d'Octubre ya finalizado, que difiere de la primera propuesta de intervención: se mantiene exento el edificio original de la cárcel, y se erige toda la edificabilidad permitida en las cuatro esquinas de la parcela, en forma de una torre de 16 plantas y tres torres de 9 plantas.

Fuente: Autora $(1 / 7 / 2013)$

Se hace patente cómo este tipo de intervenciones se desvían de los criterios internacionales de conservación del patrimonio que no alcanzaron las normas regionales y locales, de forma que no se llegan a adaptar a los catálogos municipales, o bien, las que existen no se interpretan a favor de la conservación, para evitar estas actuaciones.

"El paisaje constituye un patrimonio común de todos los ciudadanos y elemento fundamental de su calidad de vida, que la ley aborda desde la más actual concepción del mismo emanada del Convenio Europeo del Paisaje"13. "Son fines de toda actuación pública de regulación del uso y aprovechamiento del suelo, o de utilización de éste: Conservar y, en su caso, preservar los espacios, recursos y elementos naturales y culturales, para impedir la alteración o degradación de sus valores paisajísticos"14

\footnotetext{
13 Preámbulo de la Ley 4/2004, de 30 de junio, de Ordenación del territorio y Protección del Paisaje (LOTPP).

${ }^{14}$ Artículo 28 LOTPP.
} 
Caso similar se repite con la modificación de planeamiento en el ámbito de la Fábrica de Tabacos, que se tramita conjuntamente con la modificación del edificio destinado a Centro Municipal en la Calle Navarro Reverter.

Mediante convenio firmado entre el Ayuntamiento de Valencia, ALTADIS, S.A. e Inmobiliaria Guadalmedina, S.A. (IGSA), se obtiene el edificio destinado para Fábrica de Tabacos para el patrimonio público con destino a dependencias municipales. El mismo estaba destinado al uso industrial en el Plan General y catalogado, tal como se aprecia en el Plano de Estructura Urbana del Plan General de valencia

El conjunto protegido viene recogido en el Catálogo como "Edificio Tabacalera" con nivel de protección 2, del que puede consultarse el inventario previo y la correspondiente ficha, con identificación fotográfica y descripción: "edificio aislado, solar regular rectangular, cuatro plantas, fachada simétrica, estructura de muro de carga, cubierta a varias vertientes de teja árabe".

Del análisis del valor cultural del edificio, que se realiza para la redacción y firma del convenio urbanístico con la promotora inmobiliaria y el actual dueño del edificio, deriva el mantenimiento, como edificación protegida en el Catálogo del Plan General, de las tres piezas originales que persisten de los dos certámenes celebrados, en 1909 la Exposición Regional Valenciana y en 1910 la Exposición nacional; como son el Palacio de Industrias, la Nave-Sala de Maquinaria y la NaveSale de Motores, otorgándoles el nivel de protección integral, por sus características singulares y por razones históricas o artísticas, con la categoría de Bien de Relevancia Local.

Incluyendo esta iniciativa y la ampliación de usos en el recinto, se redacta la modificación del Plan General y el Catálogo Urbanístico de Valencia, extrayendo del mismo las dos naves laterales construidas posteriormente, cuando el conjunto se convirtió en Fábrica de Tabacos, en las calles Naturalista Arévalo Baca y Naturalista Rafael Cisternes, y promiviendo su derribo, conjuntamente con las naves adosadas a la Nave-Sala de Motores, recayente en la calle Micer Mascó.

De acuerdo al criterio del informe de la Dirección General de Patrimonio Cultural Valenciano, de 8 de noviembre de 2004, la modificación preservará los dos primeros tramos modulares cabecera de las naves laterales más representativos y formalmente ricos, en aras al reconocimiento inicial de las tres piezas originales de los dos certámenes.

Simultáneamente a la modificación del catálogo, en la parte posterior de la parcela, y a ambos lados de la nave de la sala de motores, se delimitan dos parcelas edificables recayentes a la calle Micer Mascó, que se adaptan al régimen de usos y alturas características del entorno urbano próximo propio de la calificación urbanística Ensanche (ENS-1), de manera, que en la cláusula $2^{a}$ del Convenio se recoge como requisito un máximo de $25.776 \mathrm{~m} 2 \mathrm{t}$ de uso residencial y de $6.444 \mathrm{~m} 2 \mathrm{t}$ de uso terciario, sobre rasante, equivalentes al $20 \%$ del total de la edificabilidad objetiva autorizada.

La modificación del Plan General se aprueba definitivamente el 19 de septiembre de 2006, con incorporación de una nueva ficha en el catálogo que incorpora la propuesta de derribo, y la declaración de BRL de la parte del conjunto remanente. 
Curiosamente en la modificación del catálogo, redactada previa a la construcción de los nuevos edificios, se delimitaba el entorno de protección del inmueble con inclusión de ambos edificios en proyecto.
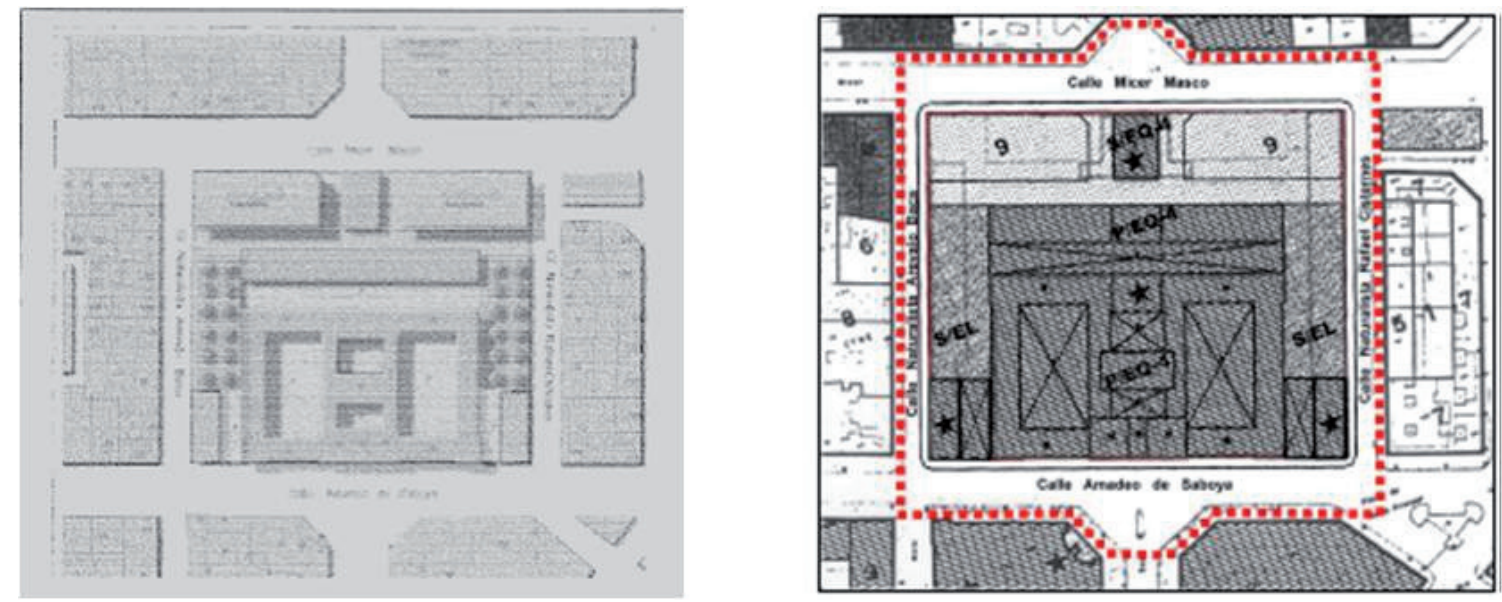

Figura 7. Plano de Estructura Urbana Propuesta en la ficha del catálogo de la Modificación del Plan General de las manzanas delimitadas por las calles Amadeo de Saboya, Naturalista Arévalo Baca, [...] (izquierda) y plano de delimitación del entorno de protección del BRL (derecha)

Fuente: Ficha del catálogo estructural de Valencia de la Revisión simplificada del Plan General, mayo 2013

En la Revisión del Plan General y de la parte estructural del catálogo municipal, la ficha del edificio incorpora similar propuesta, con inclusión de la delimitación del entorno del BRL a la totalidad de la parcela y calles circundantes, conforme a la LPCV, (que incluye a los nuevos edificios de nueve alturas construidos sobre la parcela).

Años después de finalizadas las obras de derribo, rehabilitación y construcción de uno de los edificios sobre la parcela, se reabre el proceso judicial que interpuso la plataforma Salven Tabacalera contra la actuación del Ayuntamiento. La Sección Quinta de la Sala de lo Contencioso Administrativo del Tribunal Supremo (TS) ha anulado la sentencia del Tribunal Superior de Justicia de la Comunidad Valenciana (TSJCV) que avaló en 2010 los derribos de las dos naves del edificio.

Según información obtenida del medio El País, el 29 de julio de 2013, en el procedimiento debieron analizarse pruebas documentales en contra de la actuación urbanística que los magistrados del TSJCV no admitieron y que ahora deberán estudiar para dictar una nueva sentencia sobre el caso.

"El Alto Tribunal ha estimado varios de los motivos del recurso presentado por Salvem Tabacalera contra la sentencia del TSJCV que bendijo la modificación del Plan General de Ordenación Urbana (PGOU), de 30 de junio de 2006, que permitió derribar parte del antiguo edificio Tabacalera. El Supremo anula la resolución valenciana y obliga a retrotraer las actuaciones al momento de la entrega de documentación en la fase de pruebas del contencioso. "15

\footnotetext{
15 Nota de Prensa: El País, Comunidad Valenciana, 29 de julio de 2013.
} 
No hace falta revisar los informes periciales en contra del derribo para saber que la base en que se sustentan no era sólida: empezando por las condiciones de protección de un catálogo obsoleto, que no contempla la figura de protección BRL y la delimitación de entornos, para edificios tan emblemáticos como la cárcel y la tabacalera, cuyos criterios de intervención se alejan de las convenciones europeas.
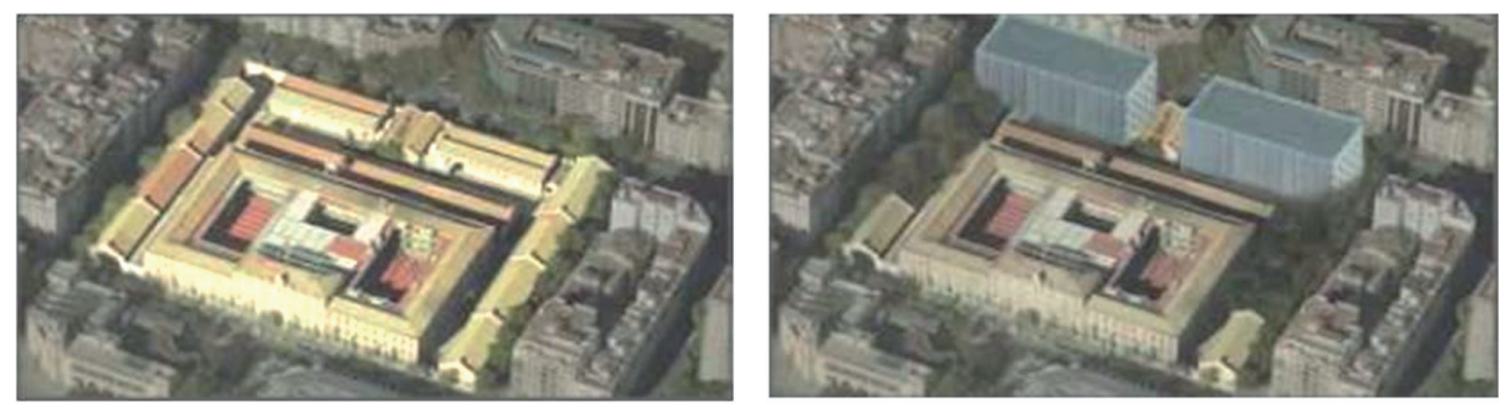

Figura 8. Imágenes virtuales de la Tabacalera antes y después de las demoliciones Fuente: "El Supremo obliga al TSJ a revisar la operación de tabacalera en Valencia", Velert, S., El País. 29 Julio 2013.

\section{LA AMPLIACIÓN Y REVISIÓN DEL CATÁLOGO DE LA CIUDAD DE VALENCIA}

Como ya se ha comentado el Catálogo de Bienes y Espacios Protegidos es un documento integrante del plan general (Art.64, Ley 16/2005, de 31 de diciembre) así como parte integrante de la documentación de los Planes Parciales (Art.68, Ley 16/2005, de 31 de diciembre).

El contenido de los Planes Especiales de Protección en la legislación valenciana (Art. 39, Ley 4/1998, de 11 de junio, de Patrimonio Cultural Valenciano) también consta de un Catálogo de Bienes y Espacios Protegidos que define los diversos grados de protección y tipos de intervención posibles; del mismo modo este precepto será de aplicación en los planes especiales de protección de los monumentos, jardines históricos y, en su caso espacios etnológicos y sus entornos. (Art.39.3.c LPCV)

\subsection{La ampliación del Catálogo con los Planes Parciales}

En cumplimiento de la normativa urbanística, los planes parciales que albergan sus propios catálogos por contener sus sectores inmuebles de interés patrimonial son los planes de Benicalap Norte y Campanar Norte, aprobados respectivamente el 7 de octubre de 2002 y el 25 de abril de 2000.

El Plan Parcial del Sector NPR1 "Benicalap Norte" del año 2002, cataloga los 8 inmuebles del Camino de Barracas de Lluna, que no se incluiyen en el catálogo municipal, al menos no se localizan en el distrito 16 de Benicalap. Sobre este punto cabe mencionar la inmensa dificultad que supone la localización y comparación entre los elementos catalogados en planes de desarrollo y planes complementarios y aquéllos que se incluyeron en el catálogo general de 1993, por no existir un sistema informatizado de identificación de inmuebles. 
El objetivo del Plan Parcial del Sector NPRR-13 de Campanar Norte fue conservar la trama urbana definida por el conjunto de edificios ordenados en torno a los caminos del Pouet y de Paterna a Campanar, haciéndola compatible con las demandas funcionales y formales de la ordenación del sector.

Los edificios del camino del Pouet, $\mathrm{n}^{0} 2$ y 4 , se encontraban altamente degradados y conforme expone el documento de planeamiento su rehabilitación supondría unas inversiones tan elevadas que no la justificarían. Sin embargo, las edificaciones que conforman el trazado del Camino del Paterna a Campanar o Camino del Cementerio en los números 4, 6, 8 y 10 definen un proyecto unitario de viviendas tipo "cases de poble", para las que el plan aconseja su protección con nivel de protección 3. De esta manera se extiende la protección transitoria del PGOU para los edificios en el número 8 y 10 del Camino del Pouet, a todo el conjunto, no $4,6,8$ y 10 .

\subsection{El catálogo BYEP de Planes Especiales y Planes Especiales de Reforma Interior}

La inclusión de un catálogo urbanístico en los Planes Especiales del municipio de Valencia es la interpretación que hace de la ordenanza de su Plan General, cuando habla de ampliar el catálogo municipal:

"Con motivo de la redacción de un Plan Especial de Reforma Interior podrán incluirse en el catálogo algunos de los elementos construidos o naturales que, singularmente, puedan existir en su ámbito o, incluso, establecer alguna ordenanza particular de protección para manzanas o calles concretas." (Art.2.8.5 PGOU Valencia).

Se aporta en la siguiente página el listado de planes especiales que incluyen un catálogo urbanístico, o cuyo contenido influye en la ordenación de un elemento catalogado:

En el Anexo 7 de la tesis se puede consultar el listado de bienes catalogados por los planes especiales enumerados, que ascienden a 740 inmuebles, de los cuales los hay sin ficha de catalogación, con fichas de diferente contenido y con niveles de protección de diferente cosecha: algunos adaptados a los niveles del Reglamento de Planeamiento, otros a la clasificación específica del PGOU de Valencia y otros incluyen niveles con criterios de propia creación. 


\begin{tabular}{|c|c|c|}
\hline & DENOMINACIÓN & $\begin{array}{l}\text { APROBACIÓ } \\
\text { N }\end{array}$ \\
\hline PERI & PE de Reforma Interior Carpesa & $07 / 03 / 1985$ \\
\hline PERI & PE de Reforma Interior M-3 Ordenación del Paseo Marítimo & $31 / 01 / 1991$ \\
\hline MPERI & $\begin{array}{l}\text { Modificación del PE de Reforma Interior M-3 UE N02 Balneario } \\
\text { de las Arenas M-10 }\end{array}$ & $29 / 06 / 2002$ \\
\hline PRI & Plan de Reforma Interior de Borbotó (PN-4) & $22 / 12 / 2005$ \\
\hline PRI & Plan de Reforma Interior C/Moncayoy Homologación & $24 / 02 / 2005$ \\
\hline PRI & Plan de Reforma Interior Atarazanas-Grao (M-5) & $23 / 08 / 2006$ \\
\hline PRI & $\begin{array}{l}\text { Plan de Reforma Interior "Camino Hondo del Grao" C/Juan } \\
\text { Verdequer, Bello, Avda de Francia e lbiza }\end{array}$ & $26 / 10 / 2005$ \\
\hline PRI & Plan de Reforma Interior Periodista Gil Sumbiela & $30 / 11 / 2007$ \\
\hline PRI & $\begin{array}{l}\text { Plan de Reforma Interior Castellar-Oliveral (PS-1)y } \\
\text { Homologación }\end{array}$ & 21/12/1999 \\
\hline PRI & Plan de Reforma Interior Benimaclet (T-3) & $18 / 06 / 1999$ \\
\hline PRI & Plan de Reforma Interior Benimamet (PO-1-3-4) & $19 / 06 / 1999$ \\
\hline PRI & Plan de Reforma Interior Benifaraig (PN-2) y Homologación & $21 / 03 / 2001$ \\
\hline PRI & Plan de Reforma Interior Beniferri (PO-2) & 21/06/1999 \\
\hline PRI & Plan de Reforma Interior Massarrojos (PN-1) & $23 / 10 / 2000$ \\
\hline PERI & PE de Reforma Interior del Palmar & $01 / 02 / 1993$ \\
\hline PERI & PE de Reforma Interior de San Miquel de los Reyes & $13 / 09 / 2001$ \\
\hline PE & Plan Especial Asentamiento rural de La Punta R-3 & $18 / 12 / 2002$ \\
\hline PE & Plan especial Infraestructuras Benimamet/Feria y Homologación & $13 / 01 / 2003$ \\
\hline $\mathrm{PE}$ & Pla Especial Seu-Xerea ampliación de les Corts Valencianes & $13 / 06 / 2008$ \\
\hline
\end{tabular}

Figura 9. Listado de planes especiales en el término municipal de valencia, que incluyen un catálogo urbanístico, o cuyo contenido influye en la ordenación de un elemento catalogado.

Fuente: Elaboración propia

\subsection{Catálogo BYEP de Planes Especiales de Protección}

El contenido que estos planes aportan al catálogo lo veremos con mayor desarrollado en el epígrafe 4 sobre La catalogación de los Planes Especiales de Protección en la Ciudad de Valencia.

\subsection{La Revisión Simlificada del Plan General de Valencia. Catálogo Estructural de Bienes y Espacios Protegidos}

El nuevo documento ${ }^{16}$ completa y revisa las determinaciones estructurales del catálogo aprobado en 1993 para adaptarlo a la LPCV y sus modificaciones. El contenido urbanístico y patrimonial del catálogo se limita a las determinaciones que la legislación vigente considera de carácter estructural:

- La catalogación de los bienes declarados de interés cultural (Sección primera del Inventario General del Patrimonio Cultural Valenciano, IGPCV, en adelante).

16 El Excmo. Ayuntamiento Pleno en sesión celebrada el 22 de febrero de 2013 adopta el acuerdo de someter a exposición pública el Catálogo Estructural de la Revisión Simplificada del Plan General de Ordenación Urbana de Valencia. La publicación del período de información pública se publica el 5 de marzo de 2013, DOCV N06.978. La aprobación provisional del Catálogo Estructural se decreta el 31 de mayo de 2013. 
- Los bienes que el plan considere Bienes de Relevancia Local:

- Bienes incluidos en la sección segunda del IGPCV.

- Los inmuebles que contaban con expediente de incoación BIC y no fueron objeto de declaración por Decreto 169/2007, de 28 de septiembre, por el que se culmina la primera fase de actualización de adaptación de la Sección primera del Inventario del Patrimonio Cultural Valenciano.

- Los bienes contenidos en la base de datos de la Dirección General de Patrimonio o puestos de manifiesto por esta dirección entre los campos: Refugios y defensas de la Guerra Civil, arquitectura e ingeniería civil o industrial, arquitectura e ingeniería rural e hidráulica, palacios o casa señoriales, arquitectura contemporánea (S.XX), jardines y espacios públicos, espacios de protección arqueológica.

- Los bienes incluidos en la Disposición Adicional Quinta de la LPCV: Núcleos históricos tradicionales y chimeneas de tipo industrial construidas de ladrillo, arquitectura religiosa y paneles cerámicos anteriores a 1940.

\section{Normas de Protección}

A título informativo se recoge el contenido normativo del documento de Normas urbanísticas de la revisión del catálogo estructural, en relación al patrimonio arquitectónico.

- Régimen general: deber de conservación, situación legal de ruina, amenaza de ruina inminente y pérdida de elementos catalogados, conservación de los parámetros de la edificación, adecuación de materiales y régimen de intervención en bienes y espacios catalogados.

- Régimen de los Bienes de Interés Cultural: régimen de intervención en monumentos, zonas arqueológicas, conjuntos históricos y jardines históricos.

- Régimen de los Bienes de Relevancia Local: normativa aplicable, régimen de intervención en inmuebles, rn espacios de protección arqueológica, en núcleos históricos tradicionales-BRL y asentamientos rurales históricos-BRL, en jardines históricos-BRL, en chimeneas, paneles históricos y sitios históricos declarados BRL con categoría sitio histórico de interés local.

- Régimen de protección de los inmuebles catalogados no inscritoe en el inventario del Patrimonio Cultural Valenciano.

- La delimitación de entornos de protección se realiza sobre base cartográfica; los entornos de los BIC (monumento, jardín histórico y zona arqueológica) se han delimitado atendiendo a su decreto de declaración; en cuanto a los BRL, sólo se ha delimitado entorno de protección en los monumentos de interés local (MIL), no delimitándose en caso de estar incluido en el Conjunto Histórico de Valencia, en un entorno de protección de un BIC o en ámbitos de periferia, cuando no conserva relación con su entorno próximo.

- El modelo predeterminado de ficha parte del contenido descrito en la LPCV para los Bienes de Relevancia Local. Modelo definido en el Decreto 62/2011, de 20 de 
mayo, del Consell, por el que se regula el procedimiento de declaración y el régimen de protección de los bienes de relevancia local.

A modo de cuadro sinóptico se resumen los tipos de intervención definidos en el catálogo estructural, según los niveles de protección y los límites que aporta a cada tipo de intervención la legislación urbanística a través del ROGTU. (Figura 10)

\begin{tabular}{|c|c|c|c|}
\hline NIVEL & \multicolumn{2}{|c|}{ TIPO DE INTERVENCIÓN CATÁLOGO ESTRUCTURAL } & LIMITES LEGISLACIÓN URBANISTICA (ROGTU) \\
\hline \multirow{6}{*}{ INTEGRAL } & CONSERVACIÓN & $\begin{array}{l}\text { Carácter precautorioy periódico: limpiezas, pinturas, } \\
\text { repaso de carpinterías o reposición de instalaciones } \\
\text { menores }\end{array}$ & \\
\hline & \multirow{3}{*}{ RESTAURACIÓN } & Recuperación de la imagen del edificio & Mantenimiento estructural y mejora de instalaciones \\
\hline & & Eliminación de elementos impropios & $\begin{array}{l}\text { NO PERMITIIDA la demolición cuerpos de obra } \\
\text { añadidos que desvirtúen unidad arquitectónica } \\
\text { original }\end{array}$ \\
\hline & & Reposición de elementos primitivos & $\begin{array}{l}\text { Con técnicas y soluciones constructivas propias de } \\
\text { la época de su construcción y acabados que } \\
\text { permitan distinguir las partes reconstruidas de las } \\
\text { originales }\end{array}$ \\
\hline & \multirow[b]{2}{*}{ REHABILITACIÓN } & REFORMA & \\
\hline & & REDISTRIBUCIÓN INTERIOR & $\begin{array}{l}\text { Obras excepcionales de redistribución interior, sin } \\
\text { alterar características estructurales y exteriores del } \\
\text { edificio. }\end{array}$ \\
\hline \multirow{7}{*}{ PARCIAL } & CONSERVACIÓN & IGUAL QUE P.INTEGRAL & \\
\hline & RESTAURACIÓN & IGUAL QUE P.INTEGRAL & \\
\hline & \multirow{4}{*}{ REHABILITACIÓN } & REFORMA & \\
\hline & & REDISTRIBUCIÓN INTERIOR & \\
\hline & & $\begin{array}{l}\text { Mantenimiento de elementos definitorios de su estructura } \\
\text { arquitectónica o espacial y de los que presenten valor } \\
\text { intrínseco o sean visibles desde espacios públicos }\end{array}$ & \\
\hline & & $\begin{array}{l}\text { Demolición de anteriores elementos de escaso valor } \\
\text { definitorio del conjunto, o cuya preservación comporte } \\
\text { graves problemas para la mejor conservación del } \\
\text { inmueble }\end{array}$ & $\begin{array}{l}\text { En bienes no inscritos en el Inventario General del } \\
\text { Patrimonio Cultural Valenciano. }\end{array}$ \\
\hline & RECONSTRUCCIÓN & $\begin{array}{l}\text { Construcción de nuevas edificaciones en sustitución de } \\
\text { las demolidas }\end{array}$ & \begin{tabular}{|l} 
NO PERMITIDO \\
\end{tabular} \\
\hline \multirow{3}{*}{ AMBIENTAL } & $\begin{array}{l}\text { CONSERVACIÓN } \\
\text { RESTAURACIÓN }\end{array}$ & \begin{tabular}{|l|} 
IGUALQUEP.INTEGRAL \\
IGUAL QUEP.NTTEGRAL \\
\end{tabular} & \\
\hline & REHABILITACIÓN & $\begin{array}{l}\text { Demolición de elementos definitorios de su estructura } \\
\text { arquitectónica de escaso valor definitorio del conjunto, o } \\
\text { cuya preservación comporte graves problemas para la } \\
\text { mejor conservación del inmueble }\end{array}$ & $\begin{array}{l}\text { Excepto la fachada y elementos visibles desde la } \\
\text { vía pública. }\end{array}$ \\
\hline & RECONSTRUCCIÓN & $\begin{array}{l}\text { Construcción de nuevas edificaciones en sustitución de } \\
\text { las demolidas }\end{array}$ & NO PERMITIDO \\
\hline
\end{tabular}

Figura 10. Cuadro resumen de los tipos de intervención permitidos por niveles en el catálogo estructural de la Revisión Simplificada del Plan General de Valencia y los límites que el ROGTU les aplica.

Fuente: Elaboración propia

\subsection{La multiplicidad de catálogos en el Término Municipal de Valencia}

Con lo que se ha expuesto, concluimos que en un mismo municipio, como el de Valencia, podemos encontrar un solo CATÁLOGO DE BIENES Y ESPACIOS PROTEGIDOS y una serie de "catálogos" contenedores de Bienes Culturales, ajustados o no a la legislación en lo que respecta a su contenido, con mayor o menor ámbito de alcance, que lo completan, lo modifican o lo condicionan; asimismo también encontramos documentos modificativos y homologaciones del 
Plan General y del Planeamiento de Desarrollo que pueden influir, introduciendo cambios en el catálogo urbanístico. Sobre algunos de ellos ya hemos hablado; sobre el resto desarrollaremos y expondremos información y ejemplos en los epígrafes siguientes:

a) Catálogo BYEP ${ }^{17}$ de Planes de Desarrollo o Planes Parciales. (Epígrafe 2.1)

b) Catálogo BYEP de Planes Especiales y Planes Especiales de Reforma Interior. (Epígrafe 2.2)

c) Catálogo Estructural de la Revisión Simplificada del Plan General de Valencia (Epígrafe 2.4)

d) Catálogo de Bienes y Espacios Rurales Protegidos del Plan de Acción Territorial de Protección de la Huerta (Epígrafe 3.2)

e) Catálogo de Paisaje, de ámbito local o regional. (Epígrafe 3.4)

f) Catálogo BYEP de Planes Especiales de Protección BIC y su entorno. (Epígrafe 4.1)

\section{LA CATALOGACIÓN EN LOS PLANES TERRITORIALES}

\subsection{Los Planes de Acción Territorial y los Catálogos de Paisaje}

Los Planes de Acción Territorial y, en su ausencia o complemento, los Planes Generales deben definir y orientar las políticas de paisaje en la Comunidad Valenciana. Con ese fin deben contener un estudio de paisaje que permita adoptar medidas específicas de catalogación, valoración y protección del paisaje en sus respectivos ámbitos de aplicación.

El Plan de Infrestructura Verde y Paisaje de la Comunidad Valenciana, actualmente en fase de propuesta del Gobierno Valenciano, tiene como objetivos poner en valor el paisaje de la comunidad, considerardo en los procesos de planificación territorial y coordinar las actuaciones de las distintas administraciones en materia de paisaje. Su función, entre otras, es establecer criterios y directrices para la elaboración de Estudios de Paisaje y de Integración Paisajística, para la mejora visual de los accesos a los núcleos urbanos y de las áreas de actividad económica y para la protección de las vistas más valiosas y desde los principales recorridos.

El citado plan inventariará y catalogará los recursos paisajísticos, tanto naturales como culturales, mediante catálogos paisajísticos de ámbito local o regional independientes de los citados instrumentos. Los primeros tendrán la tramitación de los planes generales y los segundos la correspondiente a planes especiales. (Art. 30 LOTPP). De acuerdo con el Capítulo V del Reglamento del Paisaje de la Comunidad Valenciana, los catálogos podrán tramitarse de forma independiente o como parte de los estudios de paisaje y constituirán documento de eficacia normativa cuyo contenido será ordenación estructural del municipio.

\footnotetext{
17 BYEP: Bienes y Espacios Protegidos
} 
El catálogo de Paisaje incluirá las unidades de paisaje de reconocido valor alto o muy alto, así como recursos paisajísticos, objeto de protección especial conforme a la legislación de Espacios Naturales, y los entornos de los bienes y conjuntos incluidos en el perímetro de su declaración como bien de interés cultural conforme a la legislación de patrimonio cultural.

El Reglamento, además, reitera que el PAT del Paisaje de la Comunitat Valenciana deberá identificar y proteger los paisajes de interés regional, añadiendo en su caso, los de relevancia local. Con los mismos criterios, el Plan de Acción Territorial de Protección de la Huerta Valenciana incluirá un Catálogo de Bienes y Espacios Rurales Protegidos, conforme al artículo 22.7, sobre revitalización del patrimonio rural, de la Ley 4/2004, de 30 de Junio de la Generalitat, de Ordenación de Territorio y Protección del Paisaje (LOTPP):

"6. La Huerta de la Comunidad Valenciana, como espacio de acreditados valores medioambientales, históricos y culturales, debe ser objeto de protección. Para ello, el Consell de la Generalitat aprobará un Plan de Acción Territorial de Protección de la Huerta Valenciana, en el que se definirán las zonas merecedoras de protección y las medidas urbanísticas correspondientes, así como los programas de actuación pública necesarios para favorecer el sostenimiento de las actividades propias de la huerta y la permanencia de la población con un nivel de vida adecuado.

7. El Plan de Acción Territorial de Protección de la Huerta Valenciana incluirá un Catálogo de Bienes y Espacios Rurales Protegidos en el que se comprendan las edificaciones, construcciones y cualquier otro elemento de interés cuya alteración deba someterse a condiciones o limitaciones restrictivas, de acuerdo con la especial valoración que merezcan dichos bienes y espacios protegidos, sin perjuicio de que por los municipios afectados se elabore un documento de protección más específico."

\subsection{Catálogo de Bienes y Espacios Rurales Protegidos del Plan de Acción Territorial de Protección de la Huerta (PATH)}

\section{La estructura del Catálogo}

El Catálogo de Bienes y Espacios Rurales Protegidos se estructura en 21 Unidades de Paisaje (UPP), que delimitan las siguientes áreas:

UP[01] Huerta de Moncada-Extremales

UP[02] Huerta de Moncada-zona final

UP[03] Huerta de Moncada-zona central

UP[04] Huerta de Moncada-acequia madre

UP[05] Huerta de I'Arc de Moncada

UP[06] Huerta de Alboraya-Almàssera

UP[07] Huerta de Sant Miquel dels Reis

UP[08] Huerta de Petra

UP[09] Huerta de Burjassot-Borbotó-Carpesa (Tormos)

UP[10] Huerta de Campanar-Riu vell

UP[11] Huerta de Manises-Paterna

UP[12] Huerta de Quart-Aldaia 
UP[13] Huerta de Xirivella

UP[14] Huerta de Benàger

UP[15] Huera de Rovella-Francs

UP[16] Huerta de Mislata-Andarella

UP[17] Huerta de Faitanar

UP[18] Huerta de Favara

UP[19] Huerta de Castellar-Oliverar

UP[20] Huerta de la Séquia de I'Or-arrossars de I'Albufera

UP[21] Huerta de Picanya i Paiporta

De las unidades de paisaje se seleccionan los bienes patrimoniales en zona agrícola, y aquellos bienes que por su naturaleza y localización, son importantes para comprender el conjunto de este patrimonio rural, aún estando en suelo urbano.

\section{La clasificación según la categoría de los Bienes}

1. Nivel estructurante o Primer grado:

"Bienes en los que radica el reconocimiento de identidad cultural de los habitantes y que son reconocidos social, intelectual e históricamente como piezas esenciales de nuestra cultura material inmueble o paisajística. "18

Pertenecen a este nivel los BIC y BRL, (incluidos los recogidos en la Disposición Adicional Quinta-LPCV) y los monumentos históricos ya declarados; así como los bienes generadores de la estructura del territorio: caminos y acequias históricas, y las muestras más destacadas de las tipologías de referencias, usadas en los distintos momentos de la historia en la arquitectura rural de la huerta, o los sistemas hidráulicos de valor particular a nivel paisajístico (propuestos BRL desde el catálogo). Este conjunto de inmuebles, combinan la protección integral de ciertos cuerpos con otros niveles en el conjunto de sus partes.

2. Nivel no estructurante o segundo grado:

"Bienes que sin incidir en la propia ordenación estructural del territorio, son valiosos en la definición y conservación del patrimonio cultural inmueble o paisajístico; bien por incluir elementos de valor singular en las series tipológicas que definen las construcciones de un lugar, o bien, por ser edificios que sin ese plus singular contribuyen a definir un ambiente valioso por su belleza, tipismo o carácter tradicional, y se dan además algunas de las siguientes condiciones:

- Es característico de un entorno rural determinado y se configura como parte del paisaje

- Es un edificio rural capaz de ser identificado dentro de una serie tipológica y forma parte del conjunto de morfologías de la misma

- Tiene unas determinadas condiciones formales, seccionales, constructivas o distributivas, capaces de aportar determinada condición al conjunto de casas rurales del ámbito.

18 Plan de Acción Territorial de Protección de la Huerta de Valencia. Propuesta de plan para la información pública (abril 2010). Documento VI: Catálogo de Bienes y Espacios Rurales Protegidos. Página 13. 


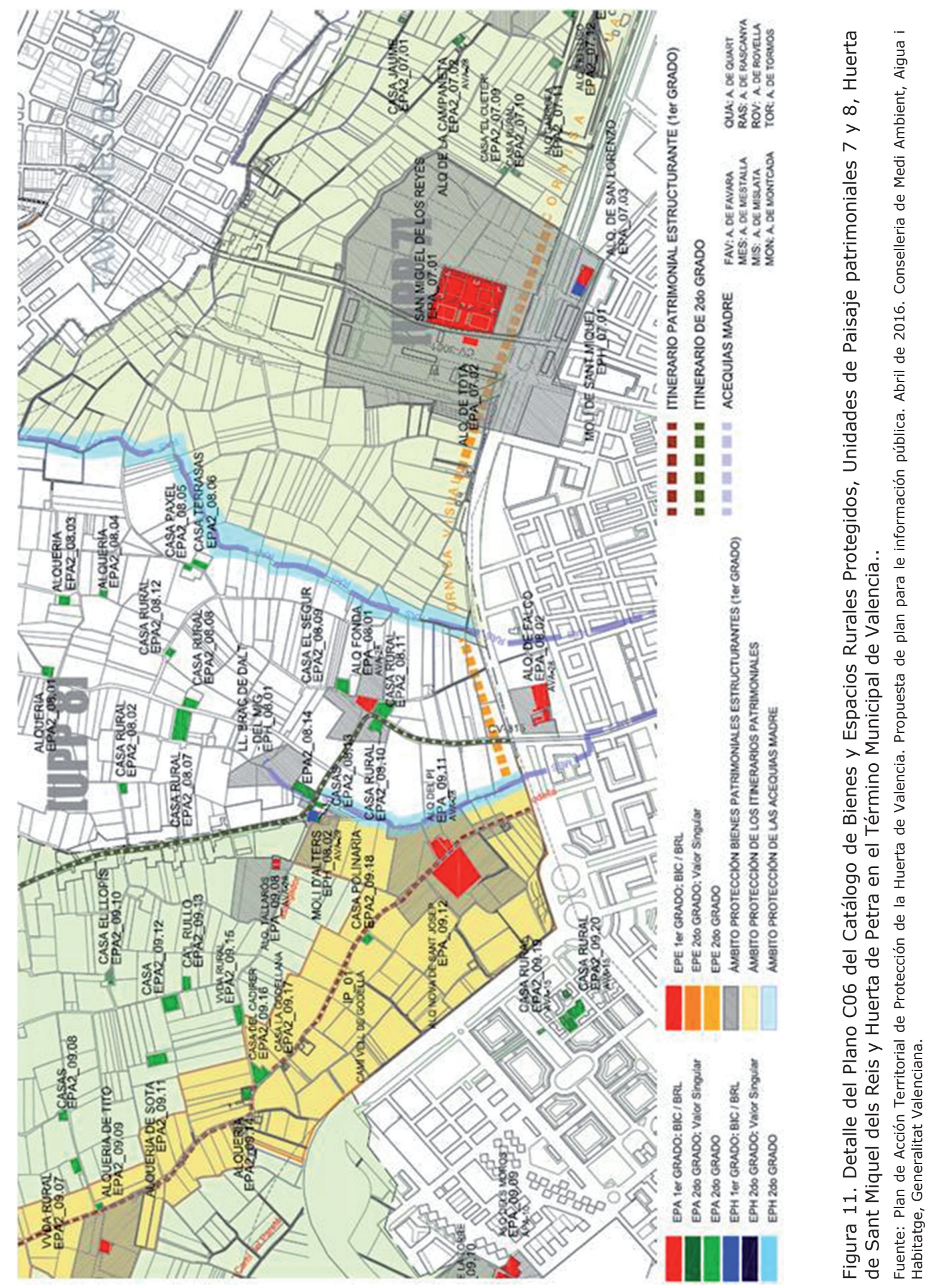


- En el caso de Bienes de Carácter Hidráulico o cualquier otro, forma parte del conjunto de elementos estructurantes del territorio, capaces de ser usados o hacer comprensible un paisaje. Ostentan, generalmente, la protección ambiental de sus cuerpos, pero pueden incorporar otro nivel de protección en sus partes. Son elementos de valor singular en las series tipológicas del lugar o edificios que contribuyen a crear un ambiente valioso. Los catálogos municipales les darán el grado de protección oportuno en función de las condiciones urbanísticas y paisajísticas propias del ámbito donde se ubiquen.

\section{La clasificación según la naturaleza de los Bienes}

En las Unidades de Paisaje (U.P.P.) se designan los elementos patrimoniales por un código relativo a su naturaleza, el número de unidad del paisaje, y el ordinal del elemento en esa unidad. Los códigos otorgados a la naturaleza del bien, en sus cinco alternativas son:

- Bienes de Naturaleza Hidráulica (EPH): acequias, azudes, lenguas y molinos.

- Bienes de Naturaleza Arquitectónica (EPA): casas, barracas y alquerías de huerta.

- Bienes de Naturaleza Etnológica (EPE): ermitas, calvarios, paneles cerámicos, chimeneas de ladrillo anteriores a 1940, lugares de especial interés, cruces de término, etc.

- Bienes de Naturaleza Arqueológica (*)

- Itinerarios Patrimoniales (IP): Itinerarios históricos, caminos o acequias.

Los Itinerarios Patrimoniales son caminos históricos que permiten crear vías verdes de interés social y paisajístico, donde coincide el interés patrimonial.

Los Niveles de protección del Plan son de nueva creación e incompatibles con la norma en vigor.

Las normas de intervención en los inmuebles dependerán de la categoría del bien, los ya declarados BIC ó BRL se regirán por lo establecido en las fichas de los Catálogos de Bienes y Espacios Protegidos municipales o por las fichas del catálogo del PAT de la Huerta. Lo que es de una gran indefinición si el contenido de las fichas se contrapone, lo que sería posible al no coincidir los criterios del catálogo de la huerta con los del ROGTU. Los bienes BRL propuestos, y otros bienes de $1^{0}$ grado no declarados BIC o BRL con anterioridad, se regirán por las normas establecidas en las fichas del PATH. Los bienes de 20 grado deben ser incorporados y establecido su régimen jurídico en Catálogos de Bienes y Espacios Protegidos municipales. De ya existir su régimen debería ser corregido al nivel establecido por el PATH, que no está ajustado al ROGTU, lo que provocará futuros problemas de interpretación en la adaptación de los catálogos municipales.

El Catálogo cuenta con 205 inmuebles de 10 grado, 5 Itinerarios Patrimoniales, 8 acequias y 2 barrancos, de los cuales:

-18 ostentan declaración previa de BIC y de Monumentos Histórico: 10 EPH-EPA +8 azudes 
-187 son declaraciones BRL: 156 Elementos Patrimoniales, 30 Barracas y 5 Itinerarios Patrimoniales

El listado de bienes de $2^{\circ}$ grado cuenta con 350 inmuebles y 3 Itinerarios Patrimoniales.

Sólo en el término municipal de Valencia se han catalogado 343 elementos de distinta naturaleza en diferentes categorías.

De naturaleza hidrológica (EPH), se catalogan 18 elementos con categoría de primer grado, con establecimiento de las normas propias para su protección y 6 elementos patrimoniales de segundo grado, pendientes de incorporar en el catálogo municipal; a ellos se suma el trazado de 8 acequias históricas a su paso por el término de Valencia: Montcada, Quart-Benàger-Faitanar, Tormos, Mislata, Mestalla, Favara, Rascanya y Rovella.

De carácter etnológico (EPE) se catalogan 18 bienes de primer grado y uno de segundo grado, así como el trazado de 8 itinerarios patrimoniales (IP) a su paso por el término de Valencia: Camí Vell de Godella, de Borbotó a Massarrojos, de Alfara a Carpesa, de Picassent y de Torrent; El Camino de Montcada, el Camino del entorno del Pou d'Aparisi y del Fiscal y el Camino del Molí de Campaneta, estos tres últimos de segundo grado.

El catálogo alberga 64 viviendas tradicionales, entre alquerías, barracas y casas de huerta, catalogadas en la categoría de primer grado; también en este ámbito, el monumento histórico de San Miguel dels Reis. Mayor es el número de las mismas tipologías catalogadas en un segundo nivel, 228 casas tradicionales de segundo grado, entre alquerías, casas y barracas, entre las que hay una porxada y un silo.

\subsection{Intervenciones en la Huerta Protegida de Valencia: los casos de La Punta y La Torre}

El Plan General de Valencia reserva para el cultivo parte del suelo de huerta en su área metropolitana, clasificándolo protegido agrícola (PA-1), donde se prohíben las actuaciones de urbanización y edificación, que se circunscriben al suelo urbanizable, con el fin de preservar el uso agrícola; este es el caso del suelo circundante de las pedanías de La Torre y la Punta de Valencia

El Ayuntamiento de Valencia tramitó la Homologación Modificativa y Plan Especial del Sector de Suelo No Urbanizable de protección agrícola La TorreSociópolis para el desarrollo de vivienda pública (VPP), planes que fueron aprobados definitivamente el 25 de Noviembre de 2005.

La intervención propone la urbanización de unos terrenos calificados como no urbanizables, que estima idóneos para absorber la demanda de vivienda de protección y equipamientos, en la época de mayor incremento de precio del suelo previo a la congelación del mercado. La intervención define la huerta de la Torre como un paisaje agrícola insostenible, que ha sufrido un gran declive por diversas causas: el envejecimiento de la población dedicada a la agricultura y su desprestigio social, la estructura minifundista del suelo incompatible con la realidad productiva y la presión urbanística por las altas expectativas en el valor del suelo. 
El IVVSA en el diseño urbano proyectado, propone una actuación de "valor ejemplar" para las actuaciones que pudieran producirse en la huerta valenciana. Aborda un proyecto donde, según ellos, la conservación de la huerta es uno de sus principales objetivos, recuperación y regeneración de una zona de huerta físicamente degradada, como reza la memoria informativa del documento de homologación modificativa.
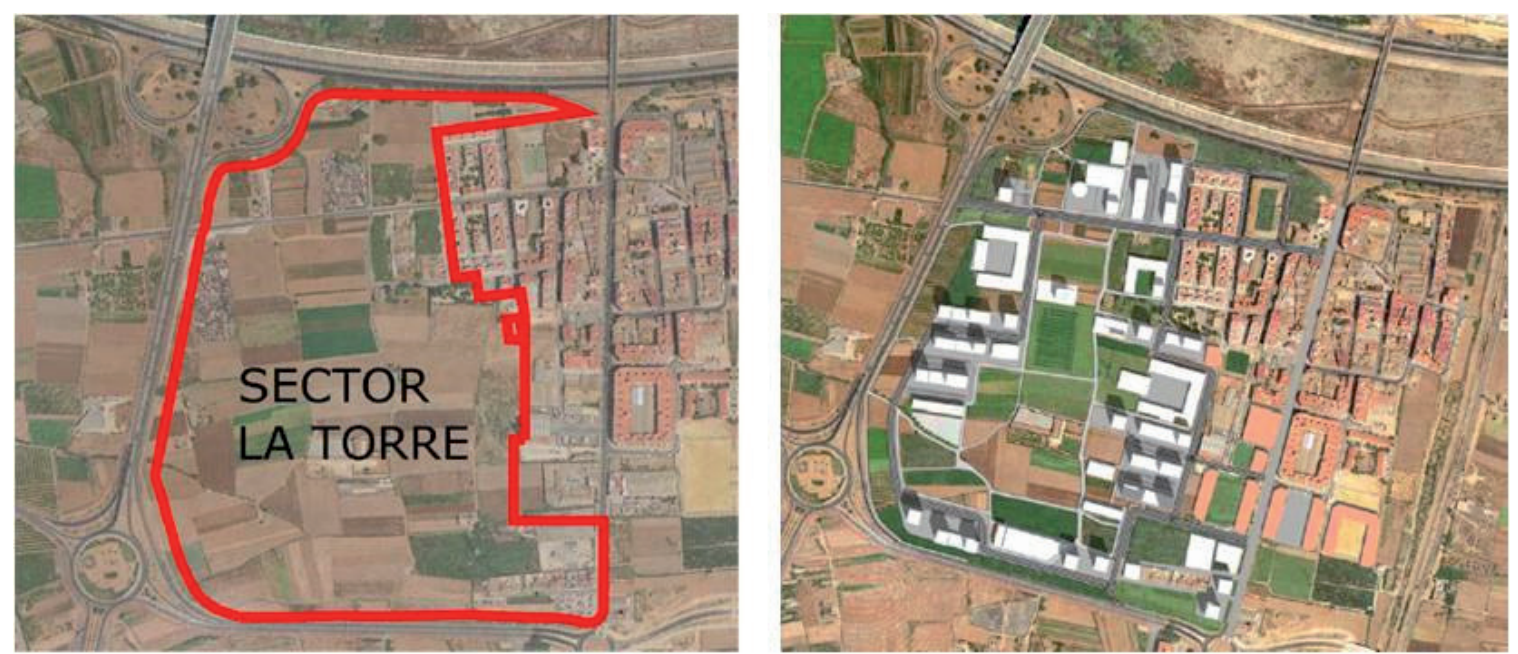

Figura 12. Delimitación del ámbito de reclasificación de suelo protegido agrícola (PA-1) a urbanizable en la pedanía de La Torre (Valencia)

Fuente: Plan Especial de Reserva y Ordenación de Usos para Dotacional Público y Vinculación a Vivienda Protegida, en el ámbito del sector La Torre (Valencia). Enero, 2005. Ayuntamiento de Valencia.

La justificación de la desprotección del ámbito, considera que la conservación de la huerta no implica necesariamente que dicha protección se haya de realizar en toda su superficie, cumpliendo tres premisas fundamentales: garantizar la conservación de porciones significativas de suelo actualmente en cultivo en un régimen de propiedad y explotación que hagan viable su destino agrícola, compatibilizar la demanda habitacional con el criterio conservacionista, plantear soluciones viables a las demandas económicas de los vecinos en los desembolsos por suelo inicial.

Se pretende el aporte de suelos agrícolas al patrimonio público de suelo, garantizando de esa manera la continuidad de las explotaciones agrícolas, y para ello se propone una reducción limitada del espacio de huerta actualmente existente, con cambio de sus propiedades: "de una huerta totalmente privatizada, gradualmente desasistida, perceptiblemente declinante y amenazada se pasaría a una huerta de propiedad pública y orientación social, adecuadamente explotada y garantizada definitivamente cara al futuro."

La existencia de infraestructuras tales como la V-30 (N-335), la CV400 y la variante de La Torre, así como una línea eléctrica de alta tensión, unido a la proximidad de varias naves industriales, dicen haber contribuido a convertir los terrenos en una zona objeto de una elevada presión urbanística y vocación de unirse con el entorno. Así pues, analizada la situación fáctica de la zona objeto de la propuesta, se ve la necesidad y conveniencia de realizar alguna actuación en aras a 
proteger la zona de huerta de manera efectiva y asegurar su continuidad como tal, objetivos éstos que no se han conseguido a través de la especial protección otorgada en su momento por el Plan General de Valencia. La actuación sobre esta parte de la huerta, se ampara en el concepto de parque público natural perteneciente a la red primaria de la LOTPP (art.13.6), en calidad de norma de aplicación directa, para toda clasificación de suelo no urbanizable en urbanizable que debe ceder gratuítamente a la Administración suelo no urbanizable protegido, no productivo, con una superficie igual a la reclasificada, computado a los efectos previstos en el artículo 8.1.c de la misma ley (no inferior a diez metros cuadrados de zona verde por habitante) .

Por consiguiente, la actuación es considerada compatible con los principios inspiradores de la Ley, con la reclasificación propuesta de la huerta afectada como ZONA VERDE perteneciente a la RED PRIMARIA desde un planteamiento intervencionista caracterizado por la ejecución de actuaciones directas de mejora, recuperación y regeneración del patrimonio rural. La zona de suelo urbanizable objeto del Plan Especial, antes no urbanizable de especial protección agrícola, se incluye en un área de reparto con un aprovechamiento tipo de $0,84 \mathrm{~m}^{2} \mathrm{t} / \mathrm{m}^{2} \mathrm{~s}$, con alturas de torres de hasta 20 plantas.

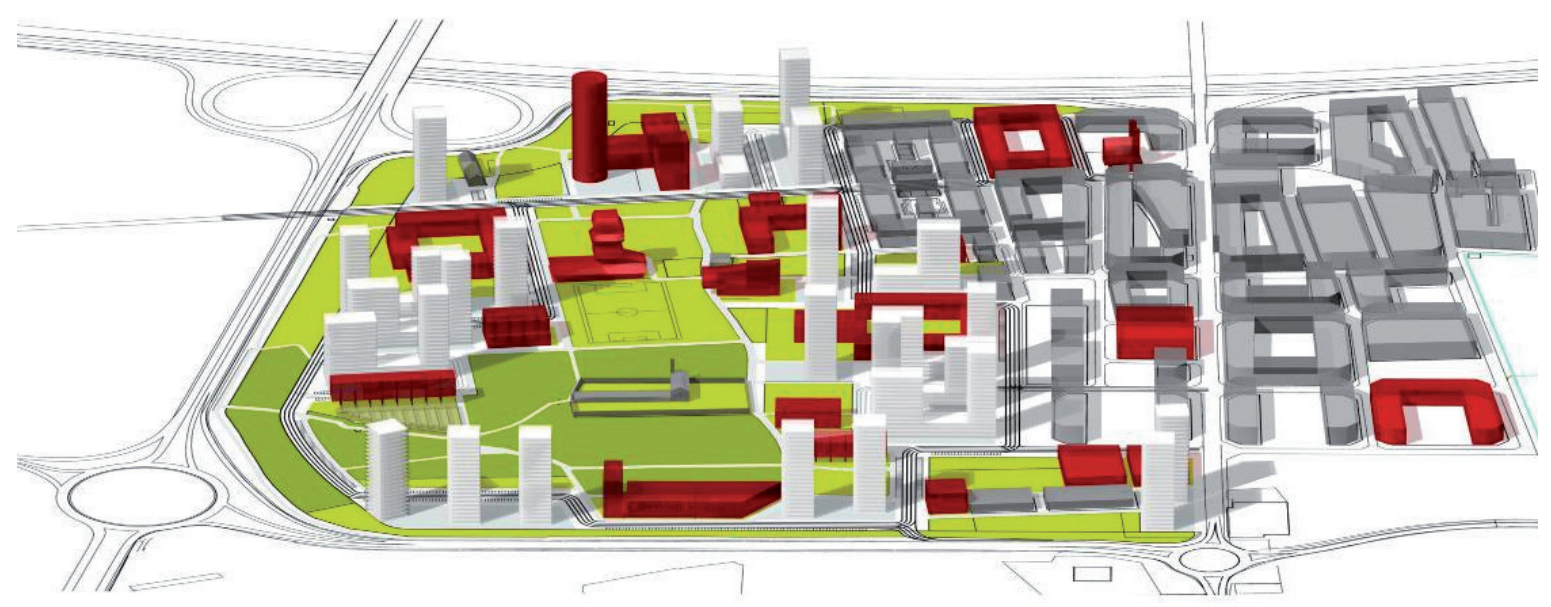

Figura 13. Infografía del Plan Especial de ordenación del Sector La Torre. Enero, 2005

Fuente: Plan Especial de Reserva y Ordenación de Usos para Dotacional Público y Vinculación a Vivienda Protegida, en el ámbito del sector La Torre (Valencia). Enero, 2005. Ayuntamiento de Valencia.

A pesar de las críticas del Colegio de Arquitectos de Valencia, que no veía justificada la reclasificación de 35 hectáreas de huerta protegida por la necesidad de vivienda de protección pública, y los informes desfavorables de tres áreas del Ayuntamiento de Valencia (Ciclo Integral del Agua, Proyectos Urbanos y Circulación y Transporte), que consideraron no aconsejable la ubicación de "Sociópolis" en suelo no urbanizable, la homologación y el Plan Especial fueron aprobados e iniciadas las obras de urbanización y construcción de tres promociones inmobiliarias de las 18 proyectadas, 422 viviendas de las 2.800 proyectadas. En agosto de 2012 se adjudicaron 32 huertos urbanos de los 300 proyectados. Un año más tarde, los 
vecinos residentes en el "barrio ideal" denuncian a través de la prensa las condiciones de ciudad fantasma en la que viven. ${ }^{19}$

El Catálogo de Arquitectura Rural del término municipal de Valencia, expuesto al público pero no aprobado definitivamente, determina los elementos construidos, sujetos a régimen de protección en el sector: la Alquería del Saboner y la Alquería de Pastor, la Barraca de Cotofio o de Tonet, las viviendas rurales de la carretera del Alba n03, 5 y 7 y las Barracas Llácer.

La Homologación Modificativa incluye su propio Catálogo de Arquitectura Rural que modifica las condiciones de protección de los edificios catalogados por el Plan General en este sector y crea tres zonas de ordenación: Zona 1 de las Alquería del Saboner y Alquería Pastor y otras Alquerías; Zona 2 de las casas de Ruiz (urbana) y Zona 3, del nuevo suelo urbanizable.

Otro ejemplo se produce en la pedanía de La Punta (Valencia) con reclasificación de suelo protegido agrícola, en la apliación del ámbito de ocupación de la edificación a $50 \mathrm{~m}$ a ambos lados del eje de la calles Jesús Morante y Borrás y Carretera del Río, con posibilidad de ampliarlo en las zonas de creación de equipamiento; así como la ampliación del ámbito de actuación hasta $150 \mathrm{~m}$ en una zona de mayor consolidación como es la Calle Caminot o Caminos de Noguera.

Con la introducción de parámetros propios del tejido urbano, como la altura máxima de tres plantas y la nueva profundidad edificable, sin la introducción de una ordenanza gráfica, se corre el riesgo de perder el carácter rural de este núcleo de población.

Parece que los redactores de estos planes se olvidaron que en la misma LOTPP en la que se amparan, también se establece que "el paisaje constituye un patrimonio común de todos los ciudadanos y elemento fundamental de su calidad de vida, que la ley aborda desde la más actual concepción del mismo emanada del Convenio Europeo del Paisaje". Que el deber de las actuaciones públicas es "el mantener y mejorar la calidad paisajística y cultural del entorno urbano, regulando los usos del suelo, las densidades, alturas y volúmenes, el uso de tipologías edificatorias."

Es preocupante que actuaciones de este tipo, que suponen la densificación de entornos paisajíticos de calidad, sean promovidas por la propia administración, cuyas acciones en estos ámbitos tan sensibles deberían ser de carácter ejemplarizante.

El Plan de Protección de la Huerta pone freno a más reclasificaciones, pero llega tarde a parar crecimientos urbanísticos ya aprobados en suelo ganado a la huerta como Nou Mileni en Catarroja, con 12.000 viviendas, el Safranar de Torrent, de 10.000 viviendas y Sociópolis con 3.000 viviendas.

\footnotetext{
19 Información obtenida de las noticias de prensa: Ballester, L.: "La ciudad ideal de Sociópolis", Icaro. CTAV, 28/5/2006; Pitarch, S., Parrilla, J.:"El proyecto fallido de sociópolis", Levante, 2/1/2012; Parrilla, J.: "Los huertos urbanos animan sociólpolis", Levante, 28/8/2012; Soriano, L.: "Sociópolis, una ciudad fantasma", Las Provincias, 29/4/2013.
} 


\section{LA CATALOGACIÓN DE LOS PLANES ESPECIALES DE PROTECCIÓN}

\subsection{Los Planes Especiales de Protección de la ciudad de Valencia}

En el caso de la ciudad de Valencia, el expediente de declaración del Conjunto Histórico-Artístico fue incoado el 28 de febrero de 1978, sin concluir hasta el 3 de mayo de $1993^{20}$, así como una serie de expedientes BICs de carácter singular iniciados en 1987, lo que introdujo un factor de incertidumbre en las iniciativas de planeamiento especial en el ámbito del conjunto histórico.

En el plano urbanístico, tras las primeras elecciones democráticas de 1979, el Ayuntamiento de Valencia elabora un Programa de Actuación Municipal (PAM), que propone la remodelación del planeamiento vigente a nivel parcial, a través de un Programa de Intervención de la Periferia Urbana (PIPU) y un Programa de Actuación para la Protección del Patrimonio Arquitectónico (PAPPA), cuya primera fase afecta a Ciutat Vella.

EI PAPPA planificó una estrategia dirigida a la conservación de los tejidos históricos, a través del avance de catálogo que el Ayuntamiento encargó al Colegio de Arquitectos, y de la modificación de la zonificación en la Ciutat Vella. Este cambio de zonificación objeto de protección especial es previa a la redacción de planes especiales de los barrios de Universitat-Sant Francesc, Mercat, la Seu-Xerea, Velluters y El Carme, aprobados definitivamente en 1984

El Plan General de Ordenación Urbana, cuya revisión se inició en 1984 y se aprobó definitivamente en 1989, establecía para Ciutat Vella la calificación de CHP1, Conjunto Histórico Protegido y mantenía transitoriamente la vigencia de los cinco Planes Especiales de 1984, "hasta la aprobación de un nuevo y único Plan Especial de Protección y Reforma Interior"21. La vigencia transitoria de los anteriores planes especiales exime al Plan General de la ordenación pormenorizada de estos espacios, siendo compatibles en todas sus determinaciones los primeros, excepto en lo referencte al establecimiento de usos que era objeto de nueva regulación. El Plan General señalaba los objetivos fundamentales que debían seguirse en la redacción del PEPRI, como eran:

- La inclusión de la regulación propia de los Bienes de Interés Cultural y de sus entornos, como señalaba la LPHE ${ }^{22}$.

- La revisión de los catálogos, sus grados de protección y su alcance, flexibilizando las protecciones.

\footnotetext{
20 Decreto 571993, de 3 de mayo, del Gobierno Valenciano, por el que se declara Bien de Interés Cultural el Cojunto Histórico de Valencia.

21 Plan General de Ordenación Urbana, Normas Urbanísticas Ayuntamiento de Valencia, Oficina Municipal del Plan, Valencia, II-1987, pag.192.

22 La Consellería de Cultura, Educación y Ciencia inició los trámites de declaración de una serie de Bienes de Interés Cultural, edificios y elementos de singular valor e interés arquitectónico, en todo el casco histórico, a través de la redacción de Proyectos de Normativa y Diseño Urbano de Entornos BIC. Estos proyectos en ocasiones alteraban el contenido de los Planes Especiales de 1984, modificando alineaciones e incorporando nuevas regulaciones.
} 
- Redefinición de usos, aprovechamientos, condiciones de parcela, volumen y forma de las edificaciones, desde la perspectiva de la conservación de las tipologías originales y entornos, con las modificaciones de trama compatibles con la protección global de las mismas, pero que permitieran alcanzar un nivel adecuado de habitabilidad y accesibilidad.

- Revisión de la red dotacional, aumentando los espacios libres y reduciendo sobredotaciones.

La causa de revisión de los planes especiales de 1984, fue parar la avalancha de derribos en el casco antiguo con la catalogación en todos los barrios, que lograría la detención de la demolición de un gran número de edificios, pero que causó a su vez la paralización de la iniciativa privada con el deterioro creciente del ámbito.

En cumplimiento del Plan General y previamente a la definitiva declaración de Conjunto Histórico ${ }^{23}$ por el Gobierno Autonómico en el año 93, se produce la revisión de los planes de Ciutat Vella y la aprobación definitiva del planeamiento especial de los cinco barrios en los que se divide la zona:

- Plan Especial de Protección y Reforma Interior (PEPRI) del Barri del Carme ${ }^{24}$ (BOP 18/06/1991)

- PEPRI Barri de Velluters (BOP 22/10/1992)

- PEPRI Barri de la Seu-Xerea25 (BOP 01/02/1993)

- PEPRI Barri del Mercat (BOP 13/04/1993)

- PEPRI Barri de Universitat-San Francesc (BOP 08/01/1993)

Asimismo se desarrollan los Planes Especiales de Campanar (BOP 27/06/1992) y de Patraix (DOGV 11/11/1993) por los servicios técnicos municipales del Ayuntamiento de Valencia, sectores cuya delimitación fue prevista para planeamiento de desarrollo en el PGOU de 1989.

A los Planes especiales de Ciutat Vella le sigue la redacción de otros planes de protección de ámbitos patrimoniales en la Ciudad de Valencia que se aportan en el siguiente listado por orden cronológico (Figura 14).

Como ya se comentó, el régimen del catálogo en los ámbitos de Conjuntos Históricos BIC del Valencia, es transitorio hasta la redacción de los planes especiales de protección, de manera que prevalecen las condiciones de catalogación de los inmuebles en los planes especiales de protección, que vendría a sustituir las del catálogo municipal de 1993.

\footnotetext{
${ }^{23}$ La declaración de Conjunto Histórico del Gobierno Valenciano sólo distinguió parcialmente con la declaración BIC a dos de las seis zonas que desde el Estado se habían incluido en el expediente de incoación de la declaración de conjunto histórico-artítico en 1973: el casco antiguo y su ensanche, la zona comprendida por el Grao, el Cabañal, Cañamelar y Malvarrosa, Benimaclet (casco antiguo), Benicalap, Campanar, Cementerio General. Finalmente la declaración recae únicamente en el casco antiguo sin sus ensanches y en el conjunto del Cabañal y Cañamelar, el resto de zonas incoadas no se pueden localizar en el listado de catálogo municipal de 1993 como conjuntos urbanos por los nombres tradicionales de los barrios.

${ }^{24}$ Los Planes Especiales de los barrios del Carme, Mercat y Universitat-San Francesc fueron redactados por los arquitectos Antonio Ferrer y Fernando Gaja

${ }^{25}$ El Plan Especial del Barrio de la Seu-Xerea fue redactado por Vetges Tu i Mediterrànea, S.L.
} 


\begin{tabular}{|c|c|c|c|}
\hline & PLANEAMIENTO DE PROTECCIÓN CON CATÁLOCO & APROBACIÓN & $\begin{array}{l}\text { NPBIENES } \\
\text { CATALOCO }\end{array}$ \\
\hline PEPRI & PE de Protección y Reforma Interior Barri del Carme & $18 / 06 / 1991$ & 364 \\
\hline PEPRI & PE de Protección y Reforma Interior Campanar (T-5) & $27 / 06 / 1992$ & 62 \\
\hline PEPRI & PE de Protección y Reforma Interior Barri de Velluters & $22 / 10 / 1992$ & 231 \\
\hline PEPRI & PE de Protección y Reforma Interior Barri de la Seu-Xerea & $01 / 02 / 1993$ & 413 \\
\hline PEPRI & PE de Protección y Reforma Interior Barri del Mercat & $13 / 04 / 1993$ & 453 \\
\hline PEPRI & PE de Protección y Reforma Interior Barri de Universitat-Sant Francesc & $08 / 01 / 1993$ & 340 \\
\hline PEPRI & PE de Protección y Reforma Interior Patraix (A-3) & $11 / 11 / 1993$ & 31 \\
\hline PEPRI & PE de Protección y Reforma Interior M-4 Cabanyal-Canyamelar & $24 / 06 / 2001$ & 560 \\
\hline PEP & Plan Especial Protección Entomo Alquería de Bola & $19 / 02 / 2003$ & \\
\hline PEP & Plan Especial PEP-1 Ensanche Pla del Remei-Russafa Nord & $14 / 02 / 2006$ & 297 \\
\hline PEP & Plan Especial de protección Senda de Llora y su entomo (La ZAL) & $24 / 08 / 2006$ & 7 \\
\hline PEP & Plan Especial PEP-2 Ensanche Russafa Sud Gran Vía & $05 / 04 / 2007$ & 402 \\
\hline PEP & $\begin{array}{l}\text { Pla Especial de Conservación y Preservación de la Plaza Redonda Barri del } \\
\text { Mercat }\end{array}$ & $10 / 04 / 2007$ & 33 \\
\hline PEP & $\begin{array}{l}\text { Plan Especial de Protección de entomo del BIC de la Iglesia de Nuestra Señora } \\
\text { de la Misericordia de Campanar }\end{array}$ & En trárnite & 31 \\
\hline PEP & $\begin{array}{l}\text { Proyecto del Plan Especial de Protección de entomo del BIC de la Iglesia y } \\
\text { Monasterio de San Vicente de la Roqueta }\end{array}$ & En trä́rnite & NO INFO \\
\hline \multirow[t]{2}{*}{ PEP } & $\begin{array}{l}\text { Plan Especial de Protección de entomo de los BIC Puerta de Serranos, Santo } \\
\text { Domingo, San Pio V, Temple, Justicia, Carmen y Cervelló }\end{array}$ & En trắrnite & 136 \\
\hline & MODIFICACIONES DE LOS PLANES QUE AFECTAN AL CATÁLOCO & APROBACIÓN & \\
\hline MPEPRI & Modificación PEPRI Seu-Xerea C/Luis Vives, N03 & $31 / 12 / 2003$ & 1 \\
\hline MPEPRI & Modificación PEPRI Carme Guillem de Castro, Lliria y Gutenberg & $24 / 02 / 2006$ & 4 \\
\hline MPEPRI & Modificación PEPRI Carme Muralla Musulmana & $24 / 02 / 2006$ & 2 \\
\hline MPEPRI & Modificación PEPRI Barri de la Seu-Xerea C/Trinitarios,4 & $23 / 03 / 2006$ & 1 \\
\hline MPEPRI & Modificación PEPRI Carme Catálogo C/Beneficencia 3,5,7 y 9 & $14 / 04 / 2005$ & 4 \\
\hline MPEPRI & Modificación PEPRI Barri de la Seu-Xerea BRL Palacio de Cerveró & En tramite & NO INFO \\
\hline MPEPRI & $\begin{array}{l}\text { Modificación PEPRI Barri de la Seu-Xerea C/del Mar, No31 (Palacio de Valeriola) } \\
\text { y C/San Cristóbal }\end{array}$ & $08 / 03 / 2010$ & 2 \\
\hline MPEPRI & $\begin{array}{l}\text { Modificación PEPRI Velluters Manzana delimitada por las Calles Quart, Palomar, } \\
\text { Murillo, Moro Zeit y Rey Den Jaime }\end{array}$ & En tramite & 7 \\
\hline MPEPRI & Modificación PEPRI Carme AUMSA & $04 / 08 / 2001$ & 10 \\
\hline MPEPRI & Modificación PEPRI Seu-Xerea AUMSA & $05 / 02 / 2003$ & 2 \\
\hline MPEPRI & Modificación PEPRI Velluters AUMSA & $16 / 11 / 2004$ & 6 \\
\hline
\end{tabular}

Figura 14. Listado de Planes Especiales de Protección de Valencia y sus modificaciones que introducen nuevos inmuebles catalogados, descatalogan o modifican las condiciones de catalogación de los existentes.

Fuente: Elaboración propia

\subsection{Normativa Urbanística del PGOU de Valencia sobre Planes Especiales de Protección ${ }^{26}$}

Los Planes Especiales de Protección para conjuntos históricos-artísticos se formularán en desarrollo de los Ámbitos de Planeamiento de Desarrollo. Podrán tener doble naturaleza de Planes de Protección y de Reforma Interior y serán el medio primordial para la ordenación urbanística pormenorizada, con asignación de usos y volúmenes, en sus respectivos ámbitos.

26 Artículo 2.7 Planes Especiales de Protección de las Normas Urbanísticas del Plan General de Ordenación Urbana de Valencia. 
Los Planes Especiales de Protección podrán modificar la ordenanza particular de su ámbito de protección que se entenderá dictada a título transitorio y subsidiario para su Zona de Calificación. Su ámbito perimetral podrá diferir del inicialmente establecido incluyendo o excluyendo manzanas, calles o paramentos de borde, según se justifique en el análisis territorial que sirva de base a la redacción de los mismos, sin comportar cambios en la Zona de Calificación Urbanística. Podrán formularse Planes Especiales de Protección para aquellos ámbitos que constituyan el entorno de bienes de interés cultural declarados conforme a la Ley de Patrimonio Histórico Español o incoados como tales. Dichos planes podrán comportar modificaciones del régimen de alturas o de las alineaciones, si ello fuere preciso como medida indirecta de protección del Bien de Interés Cultural.

\subsection{Propuesta de ordenación de los PEPRI del Conjunto Histórico de Valencia}

Como desarrollo de los planes se presentan actuaciones sobre el espacio urbano y sus elementos constituyentes en dos niveles:

- Intervención sobre los espacios parcelados, lucrativos (resienciales y terciarios) o no lucrativos (equipamientos)

- Intervención sobre espacios no parcelados (libres): calles, plazas, jardines, paseos, etc.... de carácter público.

Como hipótesis de ordenación se propone el mantenimiento de la estructura urbana como conservación de los trazados de los espacios no parcelados, hipótesis que se opone a considerar que sólo a través de la conservación generalizada de los inmuebles puede mantenerse la trama histórica. "La sustitución de edificios debe considerarse como parte del proceso normal de la ciudad, si bien puede admitirse la necesidad de establecer condiciones especiales en los centros históricos ${ }^{27 " .}$

Se propone la recuperación de la estructura urbana preexistente, manteniendo las relaciones entre los principales componentes del espacio no parcelado, con transformación acotada de algunos fragmentos de la trama, con sus dificultades de ordenación y gestión.

Puede existir modificación de la trama en una primera intervención, ORDENACIÓN, o bien en posteriores operaciones, REORDENACIÓN, si se intervino antes. Si se mantiene la estructura con sustitución de las redes de servicio, la actuación es de URBANIZACIÓN o REURBANIZACIÓN.

Cuando se introduce la mejora de la escena urbana, sin adecuación funcional de la edificación, a través de proyectos de urbanización, ajardinamiento, peatonalización, regulación del tráfico y aparcamiento, etc. se trata de ADECUACIÓN.

La intervención sobre el espacio no parcelado pasa necesariamente por el análisis y evaluación de las características de la edificación y sus elementos complementarios como patios, jardines, huertos, etc. Los tipos de actuación en el

27 Memoria del Plan Especial de Protección y Reforma Interior del Barri del Mercat. 
espacio parcelado, en función de la intervención en la trama urbana y la tipología edificatoria son los siguientes:

- REMODELACIÓN INTEGRAL, sustitución de la tipología y de la trama urbana, en sectores con alto nivel de degradación social y urbana. La trama urbana se considera degradada por su trazado funcionalmente inadecuado, en caso contrario, se procede a su reconstrucción. Los tipos de actuación incluyen intervenciones de promoción pública y dotación, donde se localizan las principales unidades de actuación y actuaciones aisladas.

- RECONSTRUCCIÓN, sustitución de la tipología y conservación de la trama urbana en las áreas más degradadas, con riesgo de falta de adecuación formal al carácter del barrio. El objetivo es la eliminación de infravivienda mediante la delimitación de áreas de reconstrucción preferente, con simultaneidad de actuaciones públicas y privadas, pudiéndose intervenir de forma puntual y no global.

- REHABILITACIÓN, conservación de la trama urbana y de la tipología, en áreas donde las tipologías hagan viable la operación desde los puntos de vista constructivo, social, económico, funcional y social. El objetivo es adecuar la edificación a los estándares demandados contemporáneamente.

- RESTAURACIÓN, conservación fidedigna de la tipología y de la trama urbana en áreas de gran valor histórico-artístico, con elementos de carácter monumental en buen estado de conservación. Pasan por el señalamiento de Unidades de Actuación para la iniciativa privada preferentemente.

- MANTENIMIENTO, se conserva la trama urbana y la conservación de la tipología es innecesaria, normalmente en espacios reformados $y / o$ reconstruidos recientemente, con viviendas modernas y en buen estado.

La conservación de la tipología y la sustitución de la trama, es una actitud monumentalista que el Plan desaconseja. La combinación de las diferentes opciones planteadas para intervenir sobre los espacios parcelados y no parcelados, origina las Áreas de Intervención:

- Áreas de RENOVACIÓN (ORDENACIÓN + REMODELACIÓN). Áreas donde se actúa preferentemente de forma unitaria, evitando espacios urbanos inacabados, y mediante expropiación, bien por gestión directa o indirecta. Se introducen los mínimos cambios estructurales.

- Áreas de REGENERACIÓN (ADECUACIÓN + RECONSTRUCCIÓN). Operaciones de mejora de la escena urbana, unidas a la reconstrucción de inmuebles, que mantienen la estructura del parcelario. La cesión de espacios no parcelados de nueva creación se gestiona por expropiación.

- Áreas de RECUALIFICACIÓN (ADECUACIÓN + REHABILITACIÓN / RESTAURACIÓN / MANTENIMIENTO). La actuación sobre la trama urbana admite la incorporación de mejoras y pequeñas modificaciones, pero no se admite la sustitución de la edificación. La gestión se desarrollará mediante la 
delimitación de Unidades de Actuación, sin el carácter imperativo de las anteriores.

- Áreas de CONSERVACIÓN (MANTENIMIENTO + RECONSTRUCCIÓN / REHABILITACIÓN / RESTAURACIÓN). Es innecesaria la intervención en espacios no parcelados; en los parcelados, se permite cualquier actuación pero con mantenimiento del parcelario, en el caso de que se sustituya algún edificio.

- Áreas de MANTENIMIENTO (MANTENIMIENTO + MANTENIMIENTO). No se requiere de ningún tipo de actuación.

A la vista de los criterios que establece la normativa actual sobre renovación urbana, las actuaciones en los conjuntos históricos valencianos deben mantener la estructura urbana arquitectónica, las características del ambiente y la silueta paisajística, no permitiéndose la modificación de alineaciones y edificabilidad ni la parcelación o agregación de inmuebles, salvo en el caso excepcional de que mejore la conservación del conjunto.

De ello se desprede que las operaciones de remodelación integral definidas en los PEPRIS, a la luz de la regulación actual, serían operaciones de carácter excepcional, en sectores con alta degradación donde la trama urbana es de trazado funcionalmente inadecuado, en caso contrario, se procedería a su mantenimiento, tal como indica la propuesta de los PEPRIS.

En otro orden de asuntos, los planes establecen la medición de los niveles de equipamientos y de espacios libres del barrio, el cálculo del número de viviendas y el cálculo del número de habitantes, para realizar una propuesta de nuevos equipamientos y de espacios libres. Asimismo, analizan las redes de instalaciones y las características de la urbanización, para elaborar las propuestas concretas.

\subsection{La catalogación. Niveles de Protección propuestos por los planes}

Los "Planes Especiales de Protección incorporarán su propio catálogo de protección, cuyas determinaciones podrán ser coincidentes o no con las correlativas del Catálogo contenido en éste Plan; en caso de que no lo sean vendrán a sustituirlas en el ámbito respectivo sin necesidad de Modificación del Plan General, dado el carácter transitorio del Catálogo para estas zonas." (Art.2.7.4 PGOU Valencia).

\section{a) Catalogación en los PEPRIs de los Barrios del Carmen (1991), Campanar (1992), Velluters (1992), Seu-Xerea (1993), Mercat (1993) y Patraix} (1993). Se abandonan las antiguas categorías de Protección Integral, Protección Individual General y Protección Individual Parcial y se señalan tres nuevos niveles de protección:

- Nivel 1 o Integral: sólo se contempla la restauración fidedigna y el mantenimiento del uso inicial

- Nivel 2 o Estructural: debe respetarse íntegramente los elementos dominantes de su tipología, con modificación de aspectos formales o funcionales. 
- Nivel 3 o Arquitectónico: existe la posibilidad de introducir remodelaciones y rehabilitaciones flexibles sin mantenimiento de la tipología y uso original.

A diferencia de lo que establecen las normas urbanísticas del PGOU de Valencia, los tres niveles de protección señalados son únicos, sin que existan categorías subsidiarias. Los tipos de intervención se resumen en el siguiente esquema:

1. Estricta Conservación o nivel mínima de intervención:
a) mantenimiento
b) consolidación

2. Restauración:

a) arqueológica

b) con recuperación

3. Rehabilitación:

a) modernización

b) reforma

4. Reconstrucción

5. Obras de nueva planta

Intervenciones en edificios con nivel de protección $\mathrm{N}^{0} 1$ :

- Obras de restauración y conservación. Se admite la demolición de aquellos cuerpos de obra que por ser añadidos, desvirtúen la unidad arquitectónica original en su configuración de mayor interés, admitiéndose, en su caso, la reposición o reconstrucción de aquellos cuerpos o huecos primitivos cuando redunden en beneficio del valor histórico-artístico del conjunto.

Intervenciones en edificios con nivel de protección N02:

- Rehabilitación subgrupo b-Reforma en los PEPRIS del Carmen, Velluters, SeuXerea y Mercat.

- Rehabilitación subgrupo a-Modernización en el PEPRI de Campanar y Patraix.

Intervenciones en edificios con nivel de protección N03:

- Rehabilitación subgrupo b-Reforma, con vaciado interior del edificio como caso extremo y justificado. En ningún caso podrá modificarse la envolvente originaria del edificio.

Normas comunes de protección en todo el patrimonio catalogado:

- Queda prohibida la instalación de rótulos de carácter comercial o similar, insertos en la fachada del inmueble, debiendo eliminarse los existentes en el plazo de dos años desde la aprobación definitiva de los planes. Se exceptúan los que se adosen a los huecos de planta baja, cuando su superficie no exceda de $1 \mathrm{~m}^{2}$, ni su altura de $60 \mathrm{~cm}$, no pudiendo en ningún caso rebasar un plano imaginario paralelo a la alineación exterior situado a $15 \mathrm{~cm}$ de esta o los que se integren formalmente en el cerramiento o acristalamiento de dichos huecos. (Seu-Xerea) 
- En los proyectos de renovación de plantas bajas quedan prohibidas todo tipo de marquesinas y salientes no originales. En todo caso deberán respetarse la continuidad y homogeneidad del tratamiento arquitectónico repecto de las plantas superiores.

- La protección se extiende a la totalidad de la parcela, que se grafía como protegida en el Plano de Protecciones, en la que se encuentra el edificio, afectando su régimen a la totalidad del arbolado y jardinería existente en ella.

- En las obras de rehabilitación sobre edificios protegidos, se estará a lo dispuesto en las ordenanzas gráficas, en el caso de haberlas y deberá eliminarse los añadidos impropios

b) Catalogación en el PEPRI del Barrio Universitat-San Francesc (1993). El Plan mantiene los niveles de protección de planes anteriores, pero incluye un nuevo tipo de intervención: las obras de sobreelevación en edificios protegidos, aquellas que se recogen en la Ordenanza Especial de Sobreelevación que afecta a edificios protegidos y señalados en un plano de régimen urbanístico con la denominación "Edificio con Ordenanza Especial"

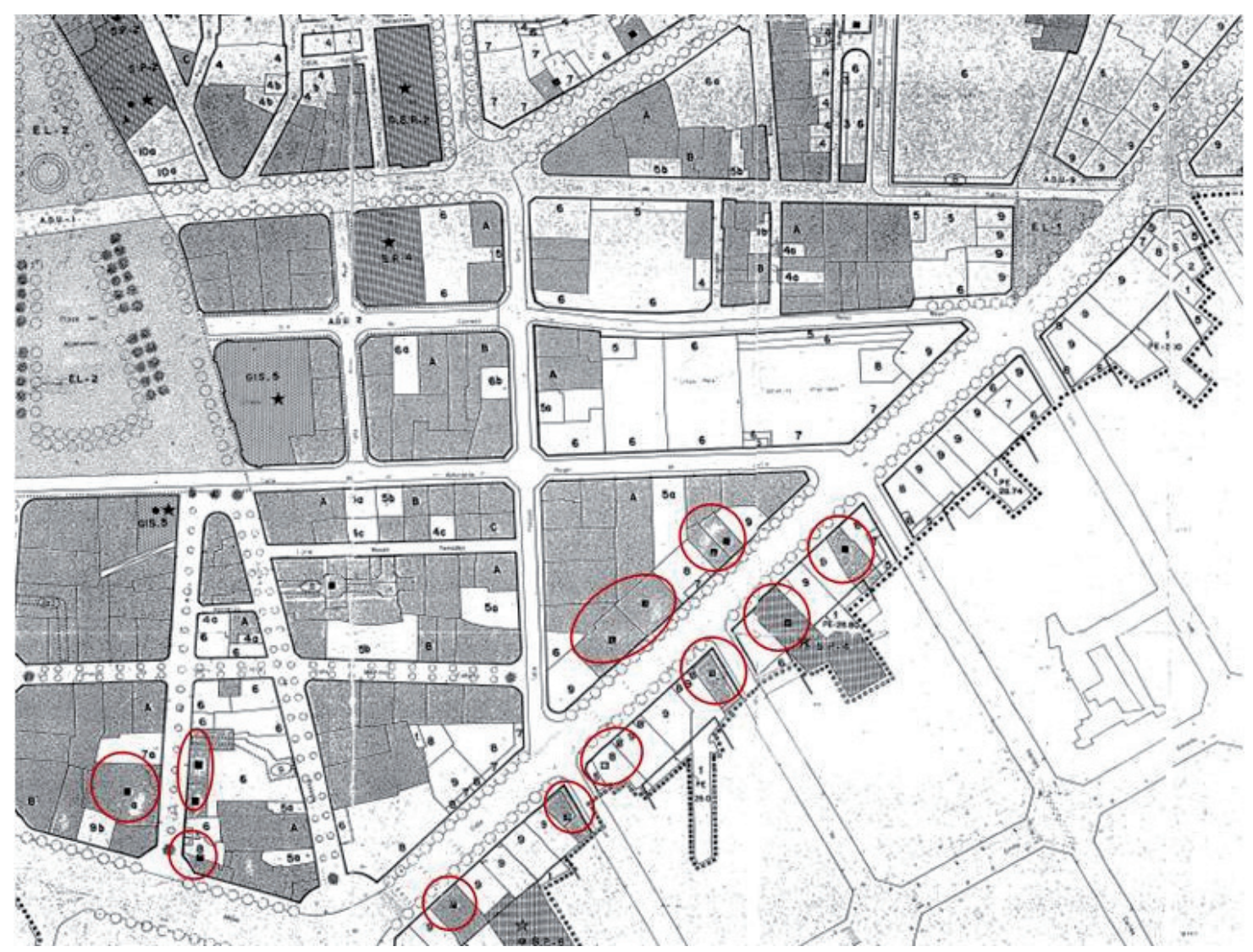

Figura 15. Edificios afectados por sobreelevación en la Calle Colón, Calle Xàtiva, y Calle Rivera, (distinguidos con un cuadrado negro sobre el edificio).

Fuente: Plano de régimen urbanístico del Plan Especial de Protección y Reforma Interior del Barrio de Universitat-San Francesc 
En estos edificios se admite la sobreelevación de la edificación existente y la sustitución edilicia parcial, conservándose los cuerpos, partes o elementos especialmente protegidos por el Catálogo. La altura máxima y mínima de la edificación resultante de la sobreelevación será la que se señala para cada parcela en el plano de régimen urbanístico, complementado por la ficha individualizada. La fachada del cuerpo sobreelevado se retranqueará un mínimo de 0,80 metros y un máximo de 1,60 metros, dependiendo de las especiales circunstancias de cada caso. En los casos en que, a juicio de la Corporación Municipal, y por las peculiaridades de la fachada protegida, por remate 0 composición, no sea posible resolver la sobreelevación retranqueada, podrá resolverse en un plano coincidente. La composición de la fachada del cuerpo sobreelevado no deberá entrar en contradicción con los caracteres propios de la traza de la fachada original protegida, en cuanto a:

- Proporción de huecos y ritmo de vanos y macizos

- Criterio de elementos volados

- Referencia de altura a cornisa y remates de los edificios colindantes

- Tratamiento de los materiales, en cuanto a calidad, colores y acabados.

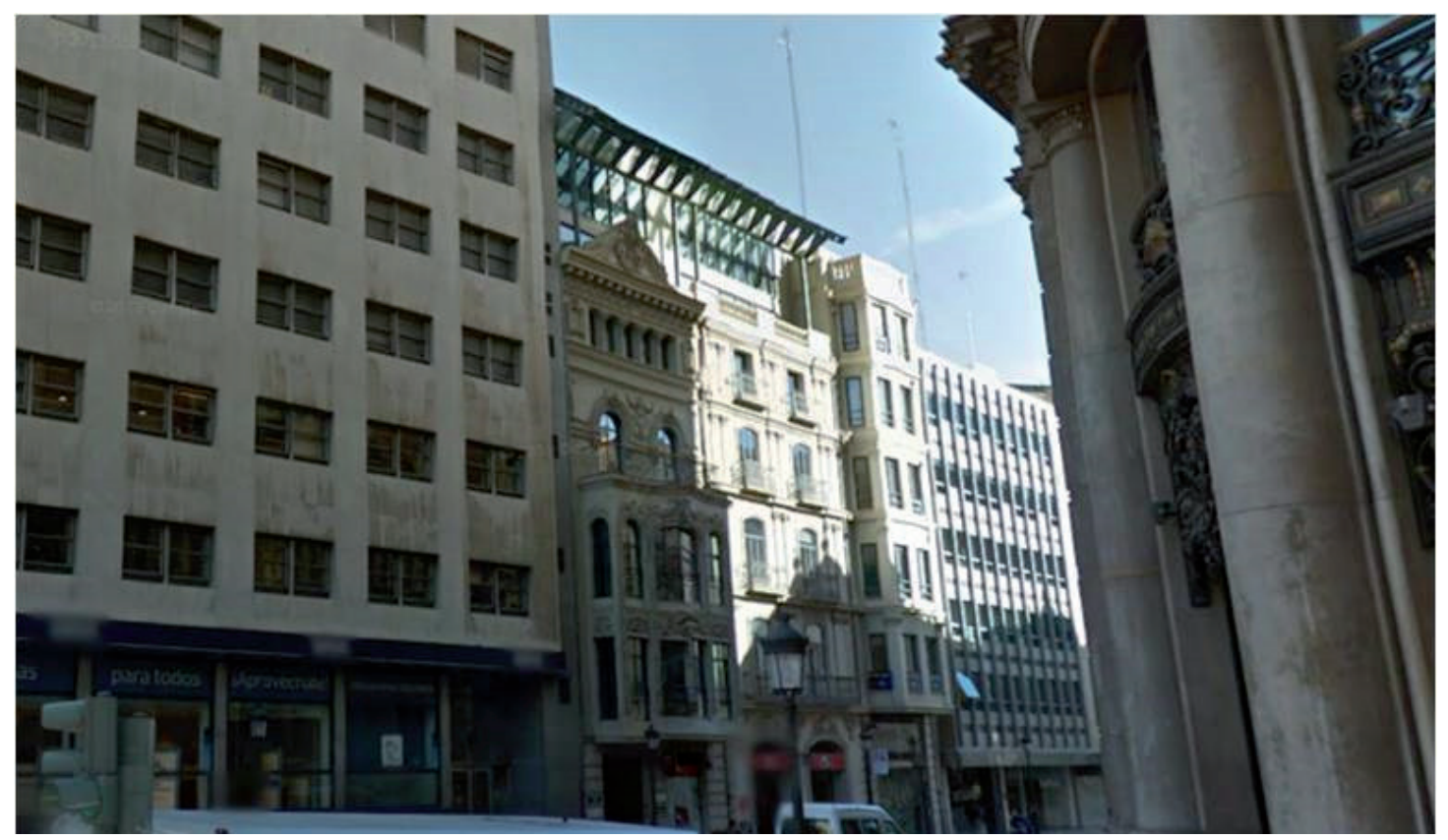

Figura 16. Sobreelevación en edificios protegidos en la Calle Pintor Sorolla, $\mathrm{n}^{\circ} 5$-catalogado con nivel de protección 2- y $n^{0} 7$-catalogado con nivel de protección 3- en el que la composición y los materiales de la sobreelevación no armonizan con el edificio preexistente, ni respetan la parcelación original.

Fuente: Google StrretView (mayo, 2012)

Con respecto a esta variación de edificabilidad no existe en el plan justificación alguna, ni se aporta normativa sobre la necesaria cesión de suelo dotacional público o la compensación económica sustitutoria, en su caso, así como ninguna referencia a la reserva mínima de plazas de aparcamiento por el incremento de superficie residencial. 
c) Catalogación en los Planes Especiales de Protección de los Ensanches: Pla del Remei-Russafa Nord (2006) y Russafa Sud-Gran Vía (2007). Para dos planes que se desarrollan sobre la misma zona de ordenación urbanística, el ensanche valenciano, con el intervalo menor de un año entre sus tramitaciones, cabría esperar que tuvieran los mismos criterios de protección y de intervención, pero como a continuación se muestra cada plan contiene un régimen de propio.

\section{Plan de Ensanche de Pla del Remei - Russafa Nord}

Los niveles de protección son integral, parcial y ambiental, en adaptación a la legislación urbanística, a los que se les asigna los tipos de intervención siguientes:

- Intervenciones en edificios con nivel de protección Integral: Obras de conservación y de restauración

- Intervención en edificios con nivel de protección Parcial: Obras de reforma

- Intervención en edificios con nivel de protección Ambiental: obras de rehabilitación

Se redefinen los tipos de intervención:

- Conservación: su finalidad es mantener y consolidar los elementos constructivos de los edificios, asegurar el funcionamiento y conservación de sus instalaciones $y$, en general, su seguridad, salubridad y ornato, sin pretender alterar su configuración exterior o interior.

- Restauración: Son las obras que persiguen la recuperación de la imagen original del edificio. Supone el repristino de rodos y cada uno de sus componentes originales, incluyendo, tanto la eliminación de elementos impropios como en la recuperación de elementos perdidos o desaparecidos. La protección se extiende, por tanto a todos los elementos definitorios de su estructura arquitectónica; fachada delantera, fachada posterior, zaguán, escalera, formalización de remates y cubierta incluyendo la distribución y acabados interiores de las viviendas o locales, que deban ser respetados en toda intervención.

- Reforma: Quedan permitidas las obras de redistribución interior de las viviendas, conducentes a su mejora, modernización y adecuación de uso y habitabilidad. Se prevé especialmente la inclusión de instalaciones y servicios inexistentes por la edad de la edificación debiéndose compatibilizar las nuevas aportaciones con el carácter del edificio. Respecto al resto de elementos de su estructuctura arquitectónica las obras deberán limitarse al repristino de lo existente.

Dentro de las obras permitidas se contemplan la sistematización de áticos en caso de estar expresamente grafiado en el correspondiente plano de manzana.

Rehabilitación: obras de adecuación del valor de uso del edificio o sus partes, compatibles con la conservación de alguno de los elementos definitorios de su estructura arquitectónica, expresamente indicados en el listado del apartado de la ficha de normativa individual. Se definen tres formas de intervención: 
- La conservación del elemento, lo que supone su repristino, entendido como mantenimiento o devolución a su estado original o primigenio.

- La reproducción, entendida como reconstrucción de un elemento formalizado éste según el modelo original. Admite dos modalidades: La reproducción idéntica y la reproducción tipológica, conceptual, en dimensiones y disposición, interpretando su formalización constructiva.

En cada ficha individual se indican qué elementos se deben conservar y cuál es la forma de intervención permitida: Conservación de la fachada principal y trasera, reproducción de la fachada principal y trasera, conservación del zaguán, reproducción tipológica del zaguán, conservación de la escalera, reproducción tipológica de la escalera, conservación del ascensor o agrupación de zaguán y escalera en una intervención simultánea y conjunta cobre dos edificios contiguos. Aunque el plan parte del principio de consolidación del aprovechamiento, sus normas urbanísticas permiten en algunos edificios con protección ambiental la sobreelevación y el aumento de la profundidad edificable, con el fin de mejorar la regularidad formal y geométrica de algunas manzanas, así como la sistematización ed áticos, recuperando para el uso residencial los volúmenes actualmente existentes destinados a trasteros, porterías, etc. Este incremento de edificabilidad se justifica en proyecto por la mejor contribución a la conservación general del conjunto, conforme a las previsiones de la LPCV.

Plan de Ensanche Russafa-Sur. Se establece la equivalencia de los niveles de protección al ROGTU:

- Al nivel de protección ambiental se asignan obras de conservación, restauración, reforma y reestructuración con conservación de la fachada (no admisible ésta última para todos los edificios protegidos con este nivel).

- La protección singular, equivalente a la protección parcial del ROGTU, como expresa el propio texto, permite las obras de conservación, restauración, reforma; no obstante en ocho edificios se considera que los valores a proteger son compatibles con la total reestructuración de su interior, por lo que se permiten las obras de reestructuración con conservación de fachada.

- La protección monumental (equivalente al nivel integral del ROGTU), corresponde al nivel máximo de protección, no obstante no se asigna el tipo de obras a realizar.

Se redefinen las clases de actuación sobre los edificios, conceptos que estaban claros desde finales del los ochenta:

- Conservación: remite a la definición del artículo 206 de la LUV sobre deber de conservación.

- Restauración: Semejante definición que en el Plan de Ensanche Norte.

- Reforma: máximo nivel permitido en edificios en los que protege los elementos que determinan su estructura: fachada principal y posterior, zaguán y escaleras. Se permiten las obras de adecuación de las viviendas y locales 
interiores, como tabiquería interior, inclusión o modernización de instalaciones, etc. ${ }^{28}$ Con introducción de las siguientes particularidades:

- En fachadas es obligatorio: la eliminación de elementos no originales o impropios, así como aquellos que contradigan la normativa del Plan; la reproducción de elementos originales desaparecidos cuando exista documentación suficiente para este fin; la recomposición de huecos en plantas bajas, en caso de necesidad justificada.

- En zaguanes y escaleras se podrá instalar ascensor en el hueco de la escalera, con cerramientos de mampara de vidrio, o alternativamente fuera del volumen que contiene la escalera. Se permiten obras que mejoren la iluminación y ventilación de la escalera

- En plantas bajas que se produzcan cambios sustanciales en los elementos originales característicos de su fachada, podrá exigirse la restitución a su estado original.

- Obras de reestructuración con conservación de la fachada: se permite cualquier tipo de obras con mantenimiento de su fachada. Se aplica a ocho edificios: Calle Cuba 3, 5 y 45; Calle Sueca 19, 21, 23 y 25; y Calle Doctor Sumsi, 32. En los edificios en los que su ficha normativa permita la reproducción de fachada, o en aquellos donde justificadamente no se pueda mantener la fachada íntegramente debido a su mal estado, o por su extinción física, se prescribirá la reproducción de la misma siempre que los sistemas constructivos necesarios para su ejecución no sean manifiestamente irrealizables.

28 No obstante, existen una serie de 20 edificios en los que, reconociendo su condición de ambientales, se considera necesaria la extensión de su protección a los elementos estructurales de la edificación, por lo que las máximas Obras Admisibles en estos casos son las Obras de Reforma. La lista de los veinte edificios ambientales sometidos a este régimen de obras más restrictivo son los siguientes:

1. Av. Antic Regne de Valencia, 6

2. Av. Antic Regne de Valencia, 8

3. Av. Antic Regne de Valencia, 20

4. Cl. Pintor Salvador Abril, 42

5. Cl. Conde Altea, 30

6. Av. Antic Regne de Valencia, 57

7. Cl. Ciscar, 40

8. Cl. Burriana, 26

9. Cl. Burriana, 28

10. Cl. Ciscar, 27

11. Cl. Burriana, 33

12. Cl. Joaquín Costa, 63

13. Cl. Burriana, 45

14. Cl. Conde Altea, 51

15. Cl. Conde Altea, 49

16. Cl. Ciscar, 63

17. Cl. Salamanca, 50

18. Cl. Mestre Racional, 21

19. Cl. Mestre Racional, 19

20. Cl. Mestre Racional, 17 
- Obras que implican incremento de volumen: Estas obras son independientes y compatibles con las obras de restauración y reforma definidas anteriormente, (por tanto posibles para cualquier nivel de protección), consistentes en la regularización de áticos y el incremento de plantas.

La regulación de áticos, sólo posible en edificios en los que existan volúmenes bajo cubierta, utilizados previamente como viviendas de portero, trasteros y otros. No bstante, es compatible con las sobreelevaciones siempre que ambos tipos de obra estén autorizados en la ficha individual del edificio. La creación de áticos debe ajustarse a las condiciones siguientes:

- Debe regularizarse en volumen y planta.

- El plano vertical de la fachada generada por la intervención deberá contener la traza exterior de la segunda crujía, o en su defecto, se trazará retranqueado $5 \mathrm{~m}$ respecto de la alineación exterior.

- La altura libre máxima resultante será igual a 2,5metros.

- La distancia entre la cara inferior del forjado de la útima planta del edificio y la cara inferior del forjado generado por la intervención será igual o inferior a 3 metros.

- La cubierta generada será plana y horizontal o inclinada con una pendiente máxima del $15 \%$.

- No se admiten elementos emergentes.

- La adecuación a las normas de habitabilidad y la instalación o actualización de los servicios que se requieran, se preverá de modo compatible con el carácter del edificio.

El incremento de plantas se ajustará a las condiciones gráficas establecidas en la ficha normativa de alteraciones volumétricas (Figura 17 y 18) y las siguientes especificaciones estéticas:

- La disposición, composición y proporciones de los huecos en la fachada que se genera deben regirse por las pautas seguidas para las soluciones de fachada de los cuerpos superiores del edificio sin pérdida de su carácter unitario.

- Deberán utilizarse fábricas de albañilería, oficios y tipos de elementos ornamentales acordes con las del resto del edificio.

En los supuestos de incremento de plantas el Ayuntamiento debe requerir previa o simultáneamente a la solicitud de la licencia de obras la adscripción de una plaza de aparcamiento por cada vivienda resultante de la intervención, en el propio aparcamiento del edificio o en un radio de 300 metros, en régimen de propiedad o alquiler durante un plazo mínimo de 50 años. 

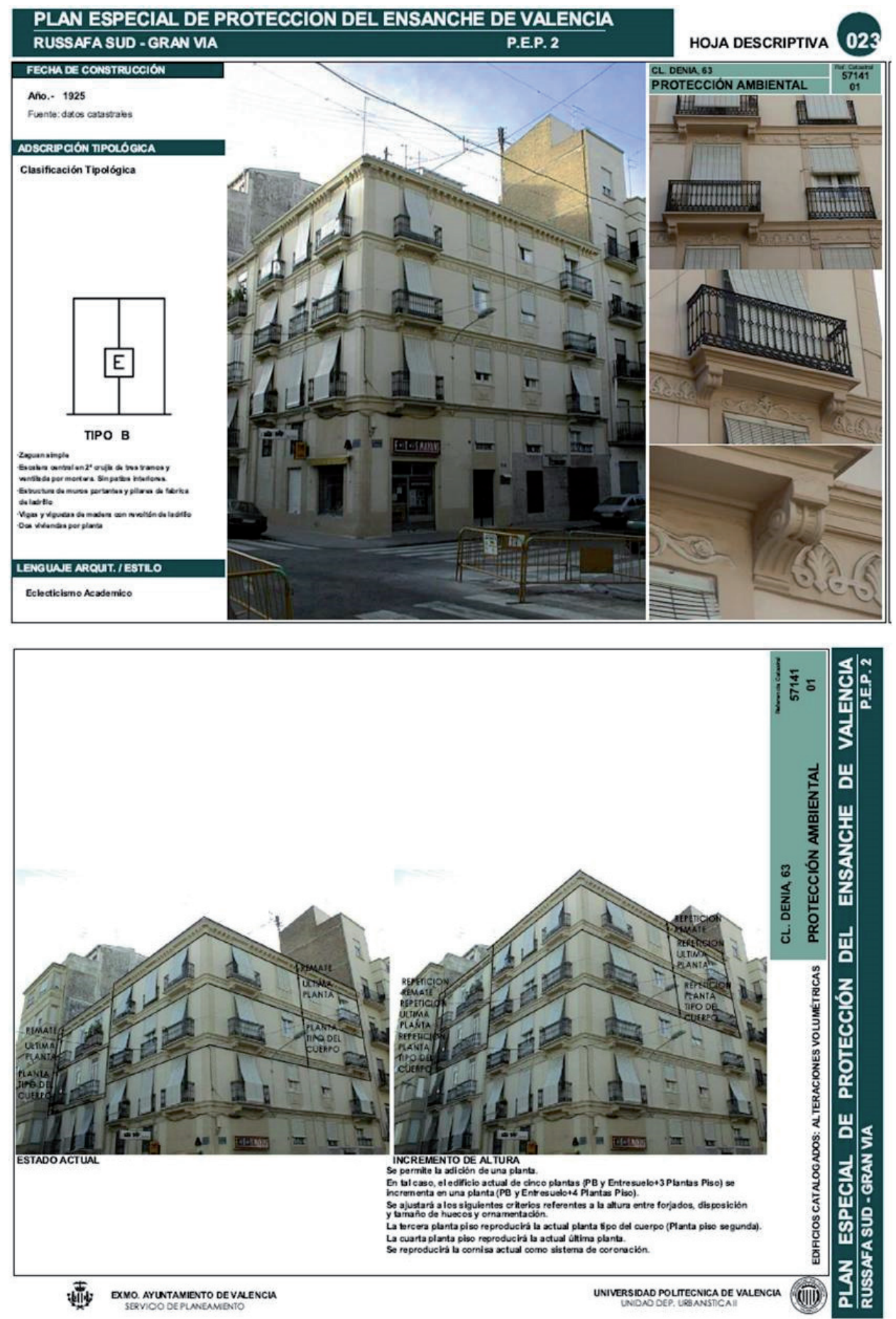

Figura 17. Ficha normativa de alteraciones volumétricas donde se permite en incremento de plantas en el edificio en la C.Denia, $n^{\circ} 63$, del Catálogo de Bienes y Espacios Protegidos del Plan Especial de Protección del Ensanche Russafa Sud-Gran Vía.

Fuente: Catálogo de Bienes y Espacios Protegidos del Plan Especial de Proptección del Ensanche Russafa Sud-Gran Vía 


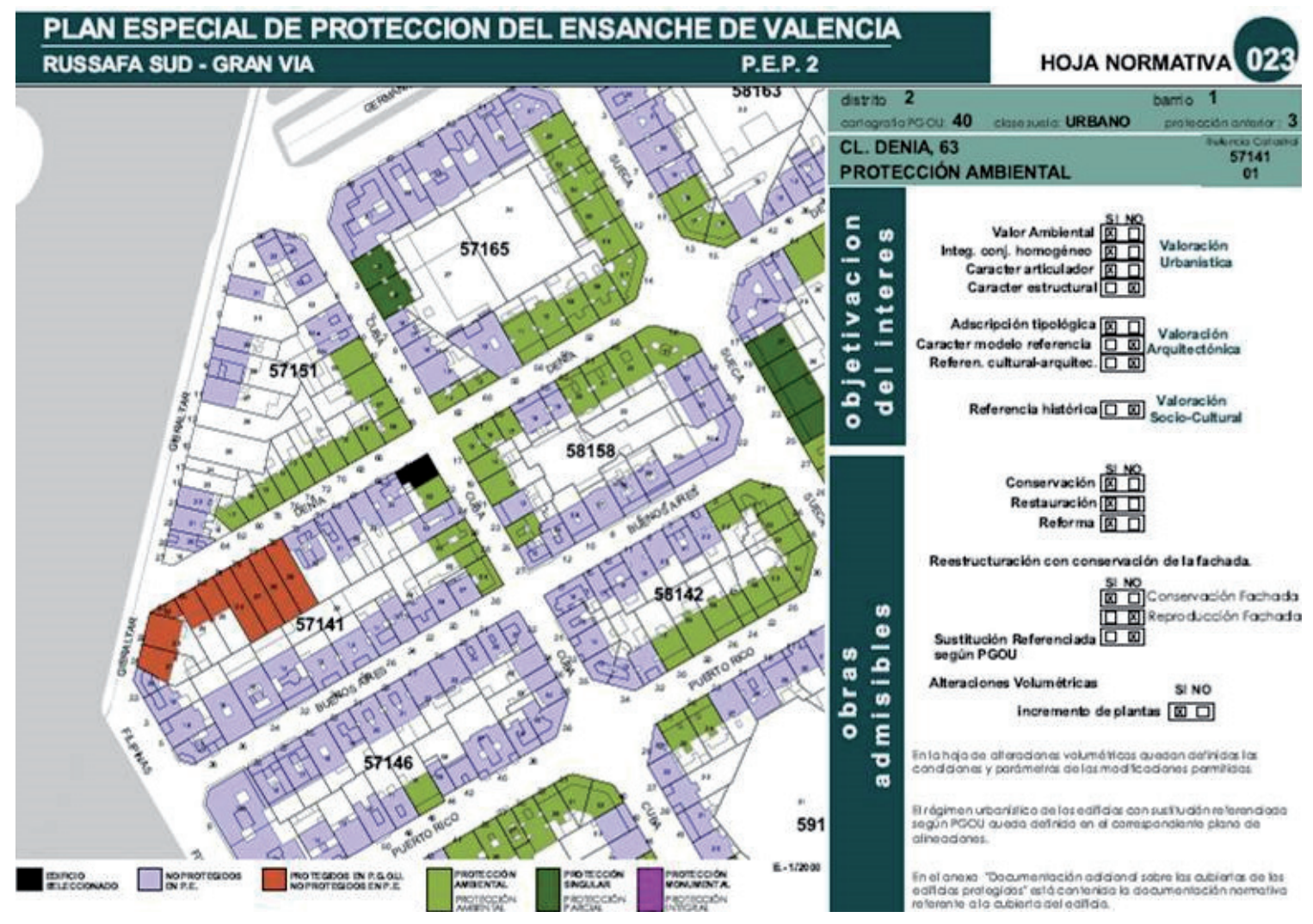

Ficha 18. Ficha individual del edificio C.Denia, n63 del Catálogo de Bienes y Espacios Protegidos del Plan Especial de Proptección del Ensanche Russafa Sud-Gran Vía, inmueble con nivel de protección ambiental del ROGTU y sobre el que es posible las obras de incremento de volumen.

Fuente: Catálogo de Bienes y Espacios Protegidos del Plan Especial de Proptección del Ensanche Russafa Sud-Gran Vía

Asimismo se cederá al Ayuntamiento suelo dotacional público de superficie equivalente al techo edificable resultante de la intervención, que de no ser posible se sustituirá por un pago equivalente en metálico, resultante de aplicar el aprovechamiento objetivo resultante $(\mathrm{AO})$ al valor de repercusión básico del polígono fiscal (VRB), actualizado. Los ingresos obtenidos qedarán afectos a la adquisición de suelo dotacional en el mismo ámbito.

En el Anexo 12 de la tesis se pueden consultar los listados de inmuebles de los Planes de Protección de Ensanche de Valencia y su régimen de intervención, con identificación de los inmuebles descatalogados respecto del catálogo municipal y aquellos que pueden ser objeto de obras de incremento de volumen. 

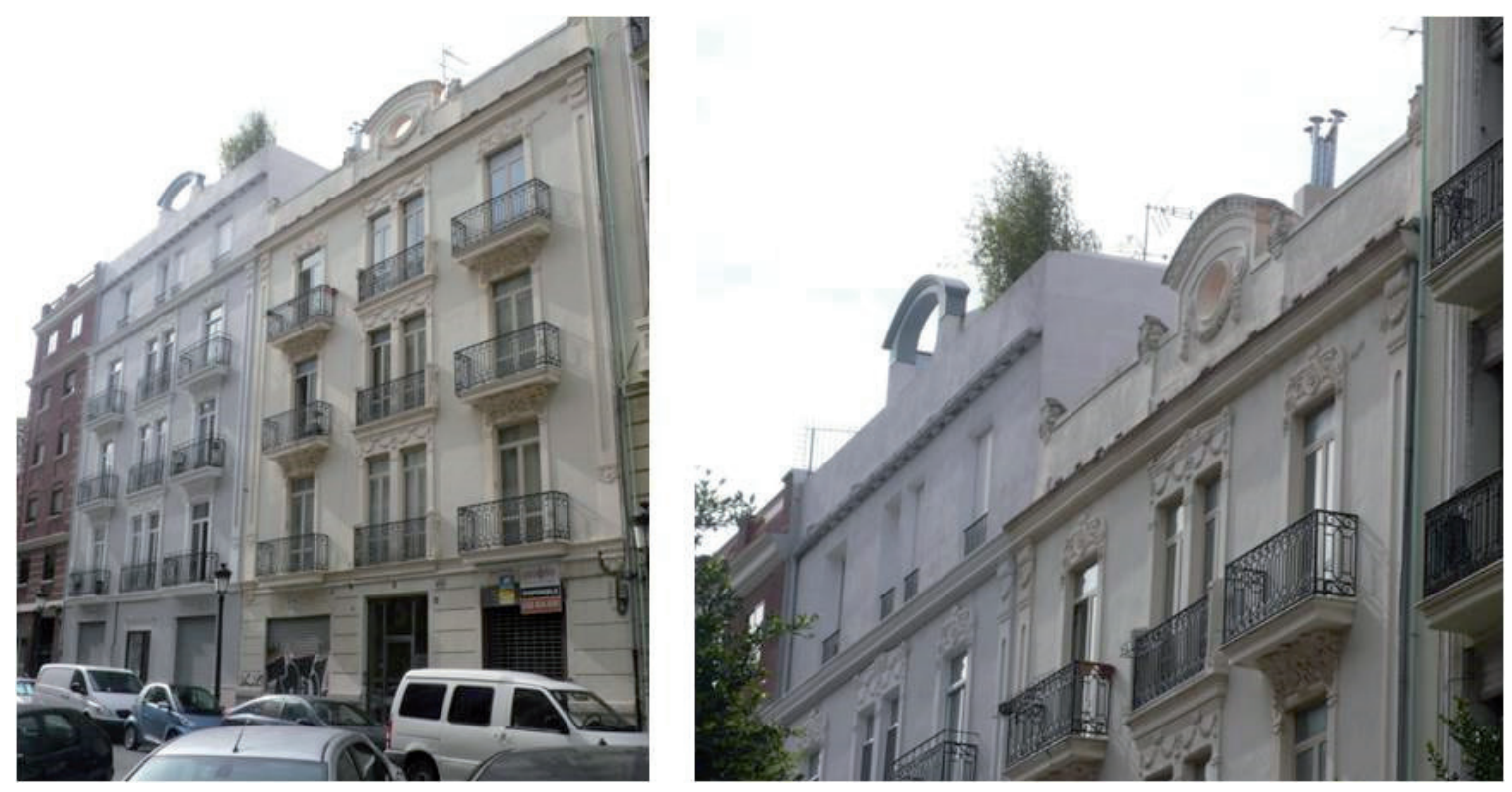

Figura 19. Frente de fachada de los edificios situados en los números 20 y 22 de la Calle Sueca, donde se lleva a cabo la sobreelevación de la última planta sobre la misma línea de fachada, sin acometer el retanqueo que permitiría apreciar la fachada del edificio en su estado original..

Fuente: FTP, 2014.

d) Plan Especial de Protección y Reforma Interior Cabanyal-Canyamelar (2001). El régimen del catálogo en cuanto a intervención sobre los edificios que contiene, asume los niveles de protección del Reglamento de Planeamiento (1998) y los tipos de intervención se redefinen como:

- Obras de conservación: son obras necesarias para adecuar y mantener las condiciones de seguridad, ornato público y decoro según queda definido en el Art.3.86 de LRAU. (Deber de conservación)

- Obras de reforma: Son obras permitidas en edificios en los que se protegen los elementos que determinan su estructura arquitectónica como, fachada principal, fachada posterior y cubiertas debiendo realizarse sin afectar el valor de los elementos protegidos. Se permite la redistribución interior de las viviendas, en orden a su perfeccionamiento y a la adecuación a las Normas de Habitabilidad.

- Obras de restauración: Tienen por objeto la recuperación de la imagen original del edificio entendida como una unidad constructiva inalterable y suponen el repristino de todos y cada uno de sus componentes, la eliminación de elementos impropios y la posible recuperación de elementos perdidos o desaparecidos. No se admiten alteraciones en la distribución ni en los acabados interiores de las viviendas

- Obras de reestructuración con conservación de elementos: son obras coherentes con una valoración pormenorizada condicionadas al mantenimiento de elementos que conciernen a la estructura arquitectónica de los edificios. Se refieren a la fachada principal y a las cubiertas. En los edificios donde no se pueda mantener la fachada y/o la cubierta íntegramente debido a su mal estado 
y su protección lo exija se prescribirá la reproducción de la misma siempre que los sistemas constructivos necesarios para su ejecución no sean manifiestamente irrealizables.

- Obras de alteración de volumen, que el plan prevé en tres supuestos:

- Adecuación del volumen a la edificación auxiliar: se permite que en las superficies no ocupadas por la edificación principal, en las que generalmente se ubican trasteros y edificaciones secundarias situadas en patios traseros del edificio, pueda construirse con objeto de dignificar los frentes del inmueble recayente a la vía pública.

- Adecuación de la profundidad edificable de la edificación principal: En aquellos inmuebles protegidos que están afectados por la expresa definición gráfica de una profundidad edificable en el plano de Régimen Urbanístico, el patio de parcela resultante no podrá ser edificado si se acomete una operación, permitida por el Catálogo, de reestructuración de dichos inmuebles, debiendo, en cualquier caso, eliminar los elementos de la edificación que se consideren impropios en aras de su correcta repristinación. Del mismo modo en otros casos esa nueva profundidad edificable, asignada por el Plan, puede implicar un aumento de la profundidad edificada del edificio protegido, siempre y cuando se permitan en él obras de reestructuración expresamente contempladas en la Ficha individual del Catálogo.

- Sobreelevación referenciada de la edificación principal: casos de sobreelevación y aumento de crujías sobre edificios existentes que cuentan con sistemas portantes compatibles con la alteración de cargas que estas obras comportan y que sin menoscabo de valores urbanos y arquitectónicos, contribuyen a mejorar el entorno inmediato de los edificios.

e) Protección del espacio público en los Planes Especiales de Protección. Desde los PEPRIS de los conjuntos históricos de Valencia se introduce la técnica de catalogación de espacios públicos (puentes, jardines, calles y plazas), y de elementos constructivos y mobiliario urbano (esculturas y fuentes), de esos mismos espacios. La tradición de catalogación en los aún vigentes proyectos de delimitación de suelo urbano y normas subsidiarias, estudiados en el capítulo V, observaba la aplicación del nivel ambiental para las plazas o calles que incluyeran, entendiendo con ello, la conservación del frente de fachadas y cubiertas que recayera a esos espacios. Los planes de protección de los años 90 no establecen normas concretas en la intervención de estos espacios, más allá de las normas de protección arbórea y la prohibición de instalación de publicidad sobre los edificios; como criterios de intervención sobre estos elementos, asignan niveles propios de las edificaciones, que no aclaran nada. En estos casos, la adopción de un nivel de protección para estas áreas, puede dar idea del valor que atribuye el redactor del catálogo a un elemento o una zona concreta, pero no delimita los criteros de intervención sobre el mismo. En planes más próximos en el tiempo, con la catalogación se regulan criterios concretos de intervención sobre el espacio público y no sobre las edificaciones que lo acotan, por ejemplo, la protección parcial aplicada sobre la Gran Vía Marqués del Turia y el Paseo de la Alameda en el PEP Ensanche Pla del Remei-Russafa Nord, supone que toda 
intervención deberá respetar las dimensiones y disposición de su sección viaria general, mientras que la protección integral que ofrece el mismo plan al puente del Mar, supone que toda intervención deberá respetar el puente en su integridad, únicamente se permitirán las obras de mantenimiento, con excepción de las obras en el solado de la bandeja del puente y los soportes del alumbrado público. A título de ejemplo, vemos cómo el plano número dos del catálogo municipal de 1993 (Figura 20) recoge los elementos protegidos en el viejo cauce del río Turia con nivel de protección 1: Puente de san José, Puente de Serranos, Puente de la Trinidad y Puente del Mar, el pretil norte desde el Puente de las Flores hasta el puente de Aragón y el pretil sur desde el Puente de Campanar hasta Puente de Aragón. El nivel de protección $\mathrm{n}^{0} 1$ en el PGOU de Valencia supone protección monumental, con conservación o restauración fidedigna.

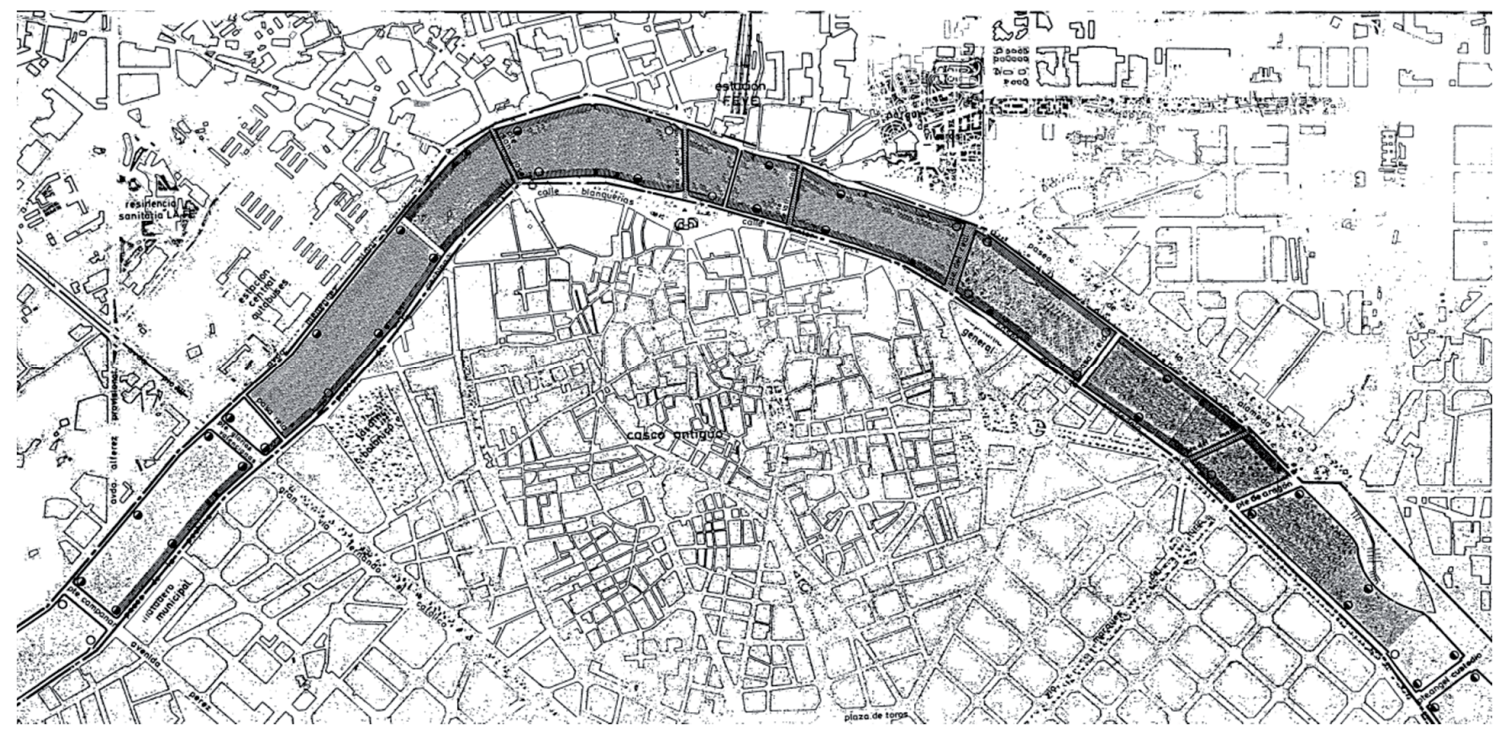

Figura 20. Detalle del plano N02 del Catálogo Municipal de Valencia, de elementos protegidos en el viejo cauce del río Turia (1988): Puente de san José, Puente de Serranos, Puente de la Trinidad, Puente del Mar, pretil norte desde el Puente de las Flores hasta el puente de Aragón y pretil sur desde el Puente de Campanar hasta Puente de Aragón.

Fuente: Catálogo del Plan General de Ordenación Urbana de Valencia. Octubre, 1988. Ayuntamiento de Valencia.

Queda patente la discrecionalida en la técnica de catalogación de estos elementos, cuando el PEPRI del Carmen cataloga los pretiles del cauce del río incluidos en su perímetro, desde Guillem de Castro hasta el paseo de la Pechina con nivel 1, mientras que el PEPRI de Seu-Xerea cataloga los puentes de la Trinidad y del Real, pero no los pretiles entre los dos; para que más tarde los planes de ensanche incorporen los pretiles incluidos en sus ámbitos con diferente niveles de protección: nivel parcial en el Plan de Russafa-Nord y nivel singular en el Plan de Russafa-Sud. Por otro lado, cabría plantear si la catalogación en un catálogo urbanístico del mobiliario urbano y las esculturas, ancladas al espacio urbano para evitar su hurto, ¿supone que el bien mueble tiene valor en sí mismo independientemente del espacio donde se encuentran o por el contrario, podrían permitirse? En todo caso el nivel de protección debería ser único para todos los elementos, y regularía su conservación y/o restauración, y su vinculación al 
espacio urbano donde se encontrara, de otra manera, ¿qué diferencia existe entre una escultura catalogada con nivel 1 y otra con nivel 3? Lo desconocemos. Progresivamente se trivializa el contenido del catálogo, y conjuntamente con la premisividad de la LPCV que en su artículo 38 , que traspasa con creces lo estrictamente entendido como restauración en la LPHE y en la Carta de Venecia, en aquellos monumentos donde se habían fijado intervenciones de estricta conservación y restauración respecto del estado catalogado, sobrevienen actuaciones como la má reciente reconstrucción en el Puente de Serranos de Valencia (Figuras 21 y 22).
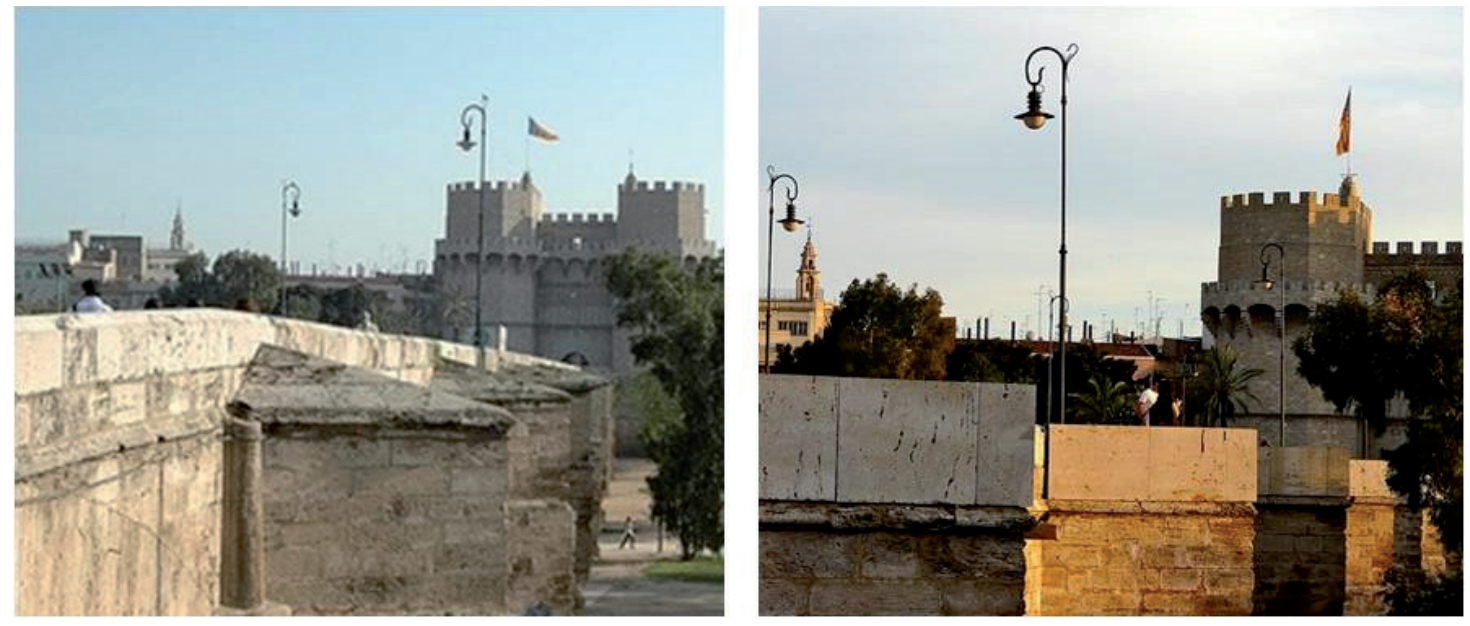

Figura 21. Intervención reciente (2013) sobre los pretiles del Puente de Serranos, que se recortan para recuperar trece arrimaderos, construidos con una piedra de la cantera de la sierra valenciana de Montesa de tamaño y corte diferente a la original del pretil, para diferenciar la reconstrucción Fuente: Marín Segovia, A., www.flickr.com, 17/11/2013
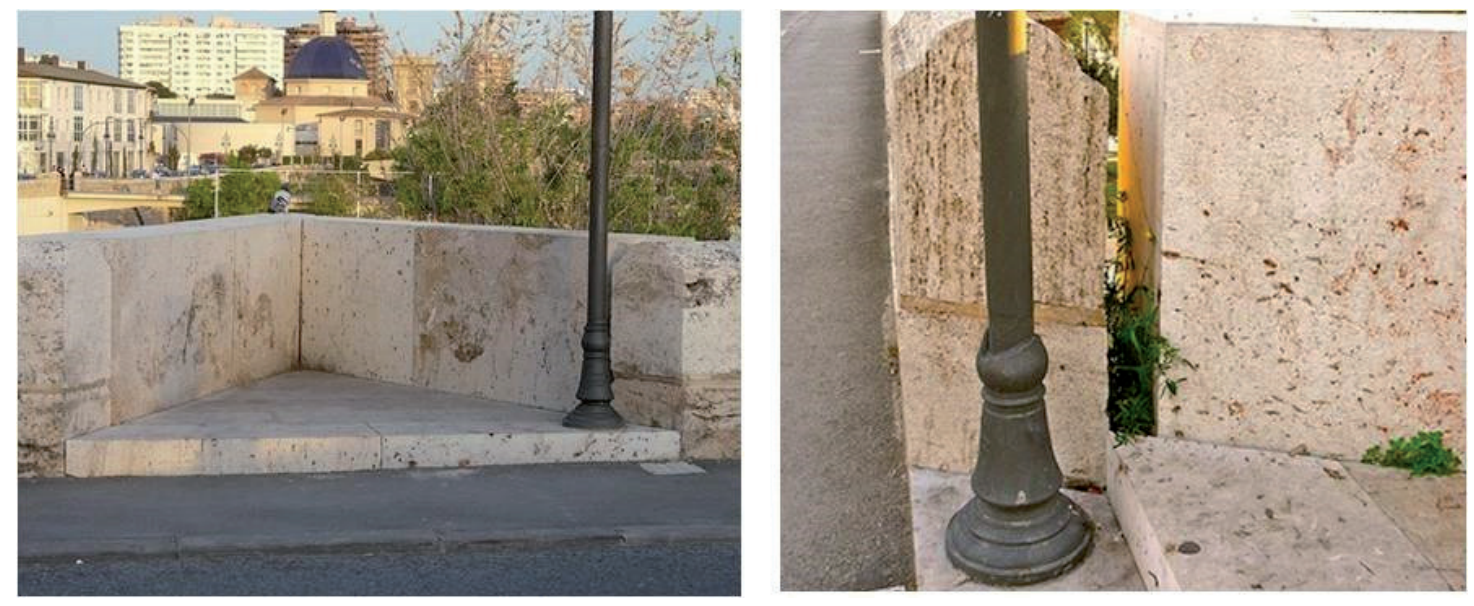

Figura 22. Detalles de construcción de los nuevos arrimaderos del puente de Serranos.

Fuente: Marín Segovia, A., www.flickr.com, 17/11/2013 


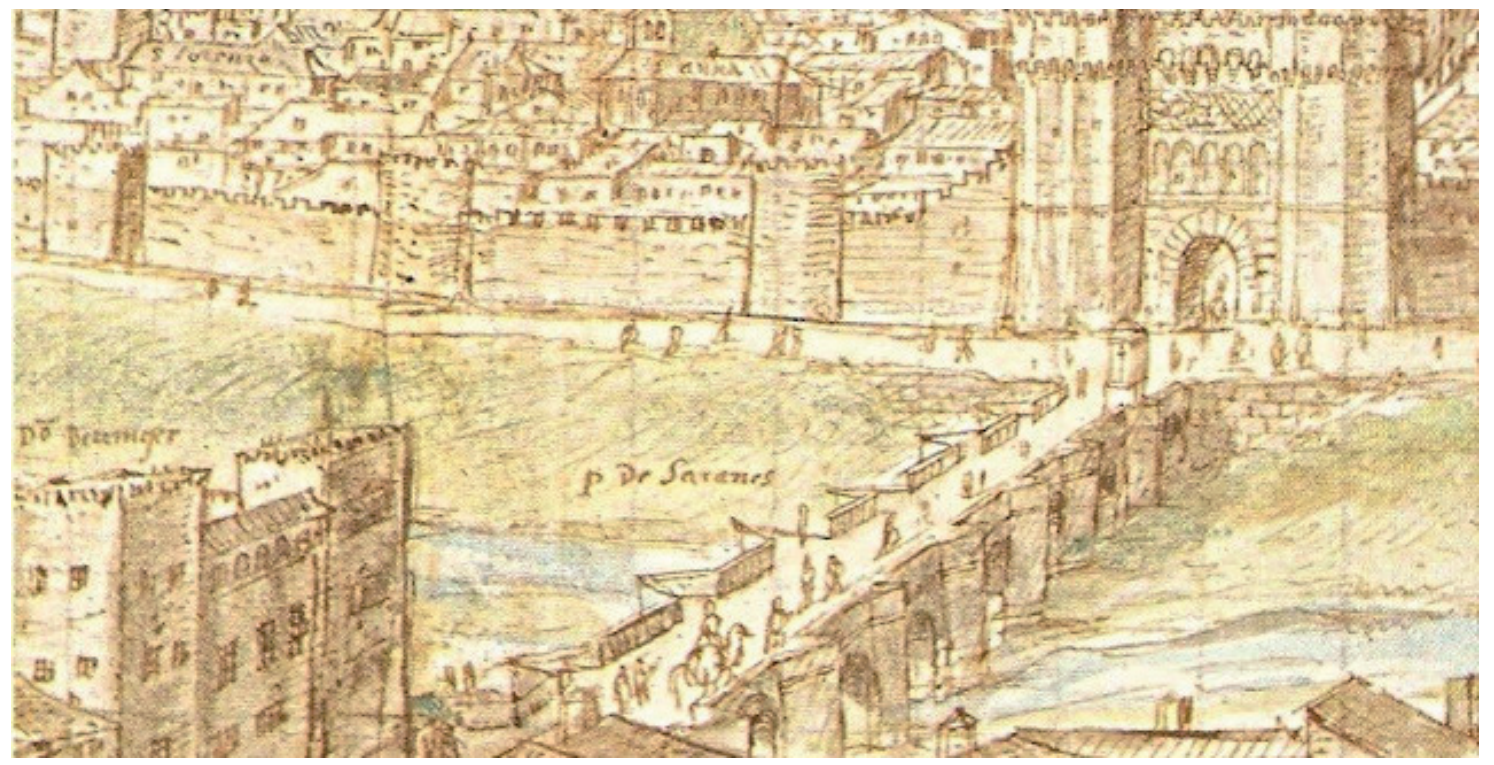

Figura 23. Dibujo del Puente de Serranos de Anthon van der Winjgaerde de 1563. La antigua existencia de estos trece arrimaderos-apartaderos recuperados, la acreditan documentos gráficos como el de Anthon van der Winjgaerde de 1563, el plano de Valencia del Padre Tosca de 1704 (aunque están dibujados erróneamente semicirculares) y en AMV, Libros de Fábrica Nueva del Río, II.II-80,1808-1811, donde se explica el gasto realizado con motivo de "... deshacer trece lunetos o rellanos con sus asientos que había a los lados del puente de Serranos"..

Fuente: Anthon van der Winjgaerde (fragmento, 1563)

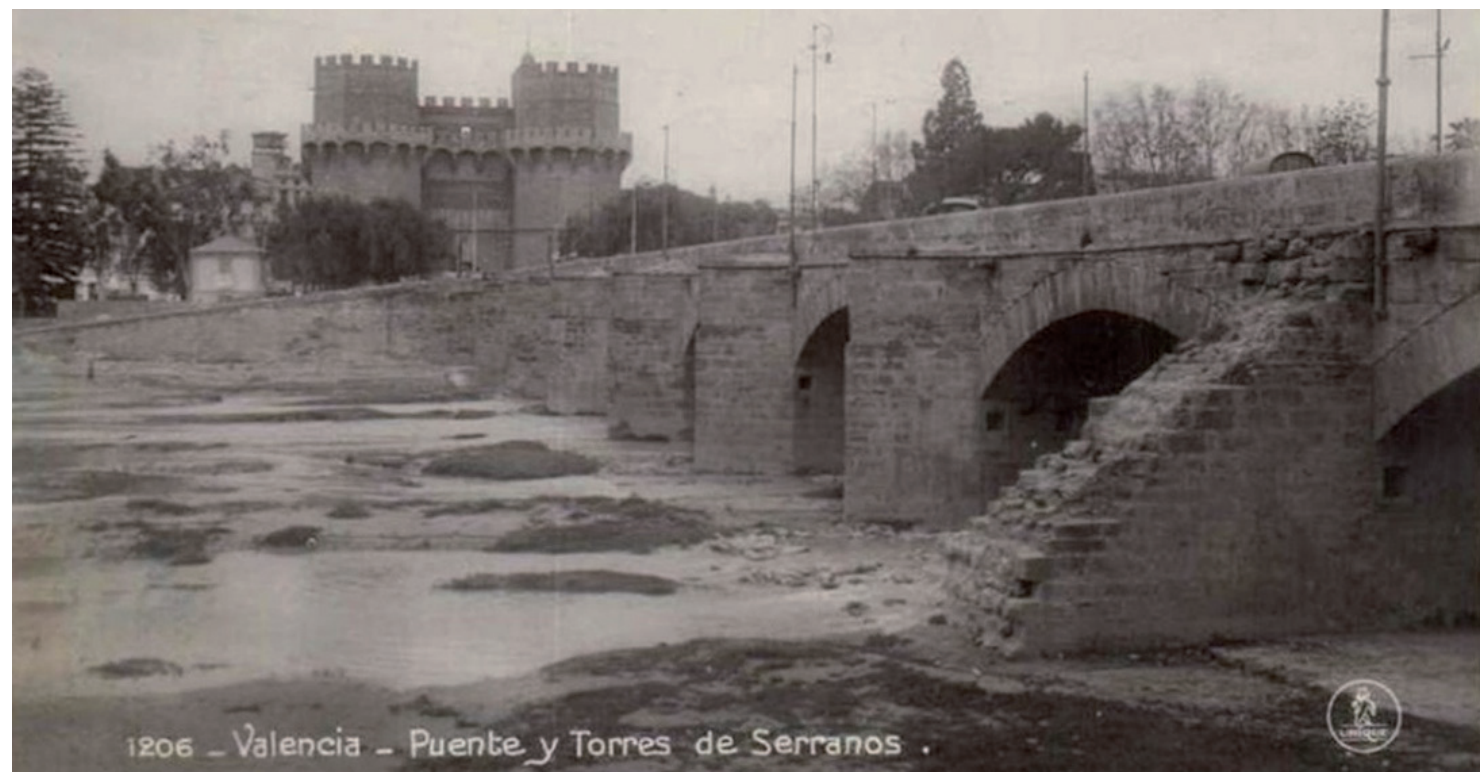

Figura 24. Aspecto que presentaba el puente de Serranos desde inicios del siglo XIX, imagen tomada en 1920 (http://postalesdevalencia.blogspot.com.es, 17/11/2013). La acreditación documental de un estado anterior no justifica una intervención de repristino ni en la Carta de Venecia ni en la Ley de Patrimonio Histórico Español, únicamente en la Ley de Patrimonio Cultural valenciano.

Fuente: http://postalesdevalencia.blogspot.com.es, 17/11/2013. 


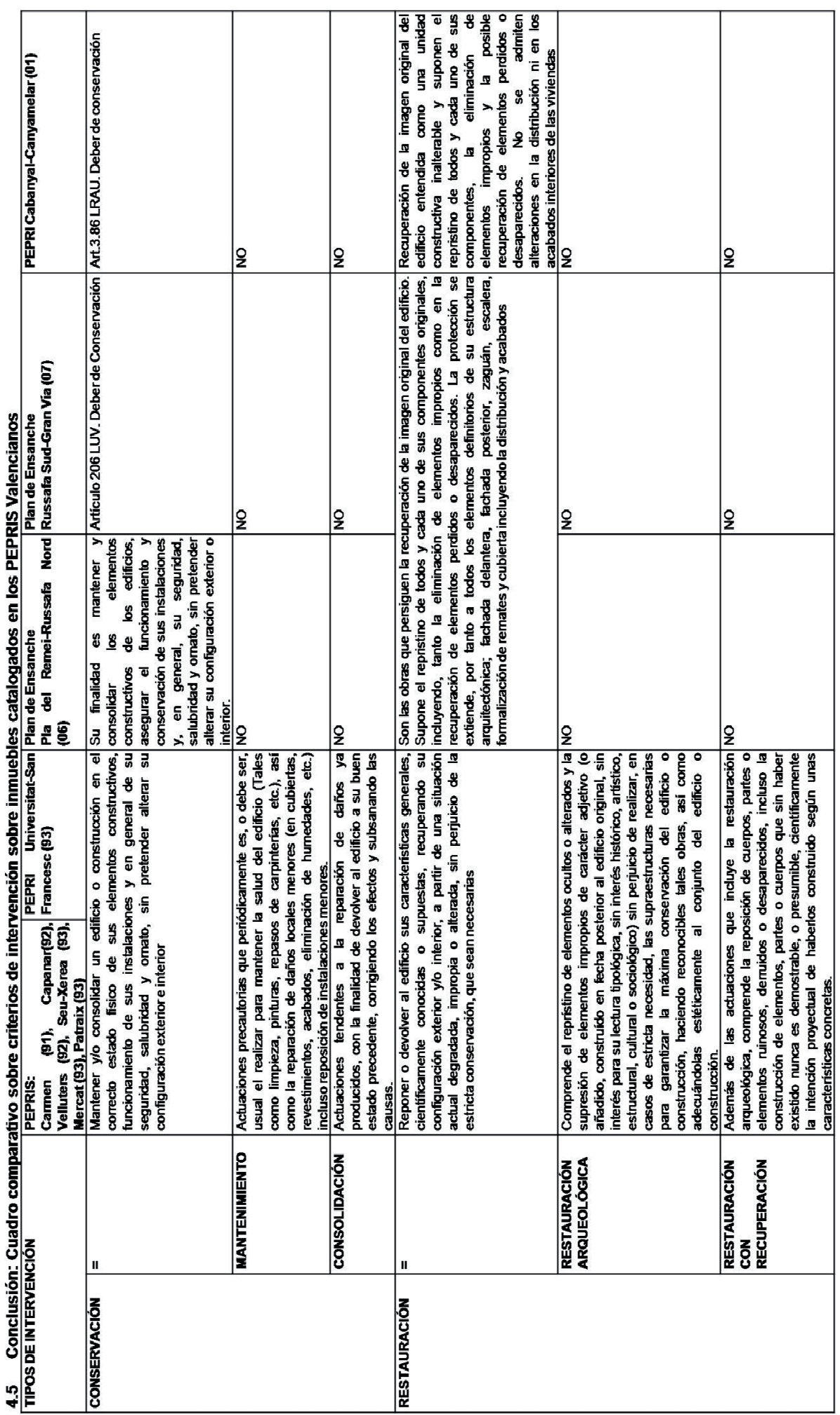




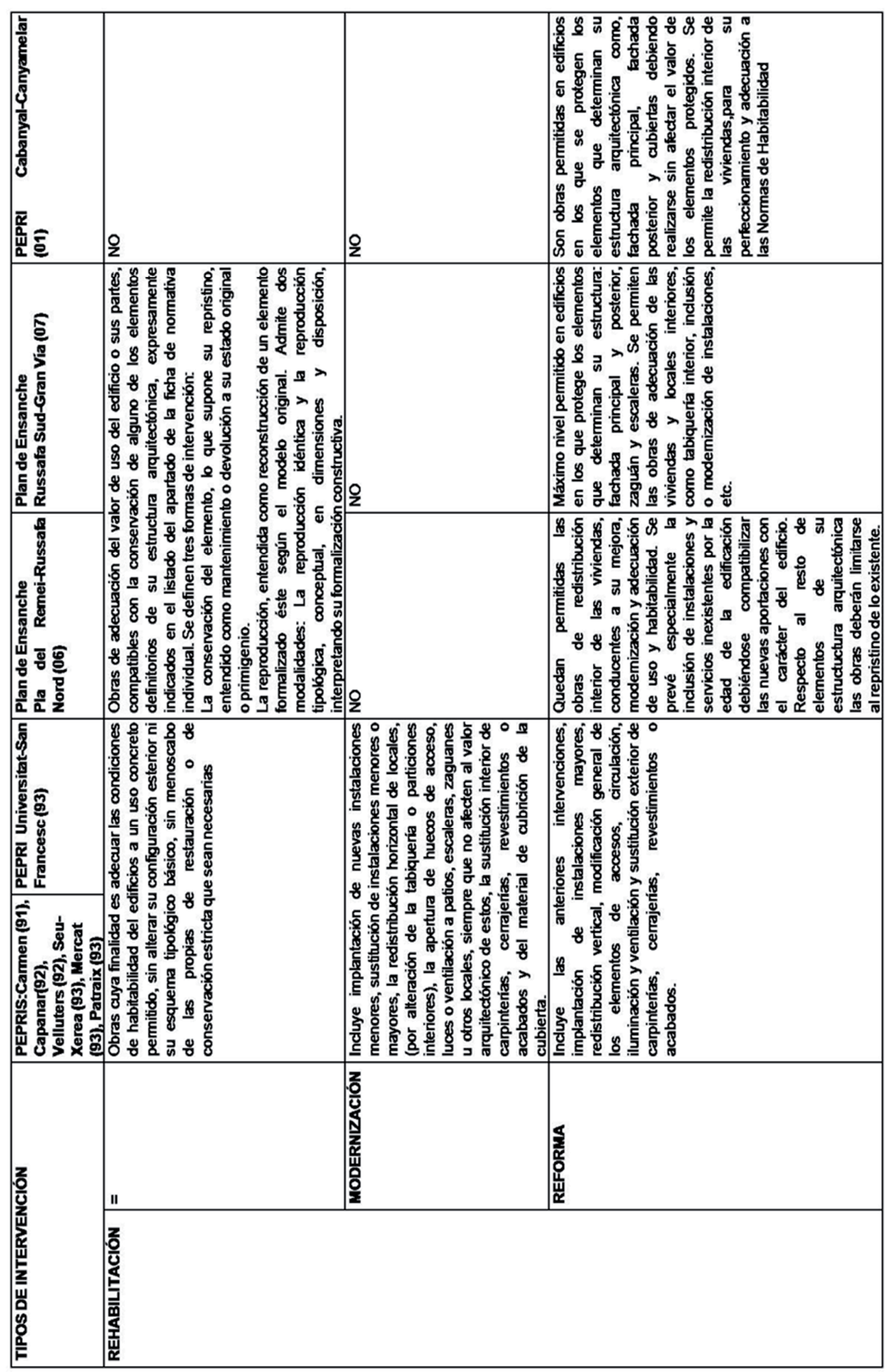









\section{LA CATALOGACIÓN EN ENTORNOS BIC. LA SUPERPOSICIÓN DE CATÁLOGOS}

Considerando lo analizado en capítulos anteriores, queda patente la multitud de ámbitos de la ciudad que abarca la catalogación, y cómo el catálogo crece, de manera ramificada, al yuxtaponerse al original, catálogos de los nuevos ámbitos de crecimiento urbano, o de aquellos en los que el planeamiento especial introduce mayor detalle a la ordenación del patrimonio. Sin embargo, los ámbitos de protección que regula la propia legislación proliferan, y en ocasiones, se superponen los entornos de protección de monumentos sobre ámbitos de conjuntos históricos en los que se cataloga inmuebles a través de un plan especial. En estos casos, en los que la legislación marca la generalidad de las posibles actuaciones, la administración, basada en criterios de coherencia y austeridad, debería procurar ajustar, tanto en economía de medios como en practicidad, sus propuestas de planeamiento e intervención para la protección y restauración del patrimonio.

\subsection{Plan Especial del entorno BIC de la Iglesia de Nuestra Señora de la Misericordia de Campanar}

El nuevo plan de protección sobre Campanar, de reciente aprobación municipal, el 16 de julio de 2013, se redacta con el objeto de cumplir la norma de patrimonio cultural, que obliga a los ayuntamientos a redactar un Plan Especial de Protección en el entorno de un inmueble declarado BIC: El Ayuntamiento tiene la obligación de elaborar el correspondiente Plan Especial de Protección del Entorno u otro instrumento urbanístico, de análogo contenido, conforme al art. 34.2 de la LPCV, donde se establezcan las normas de protección que den mejor respuesta a la finalidad de aquellas provisionalmente establecidas en la declaración, y regule con detalle los requisitos a que han de sujetarse los actos de edificación y uso del suelo y las actividades que afecten a los inmuebles y a su entorno de protección.

Para ello puede asumir esta obligación en el Plan General, donde se dará cumplimiento a los criterios establecidos en el artículo 39 de la LPCV, momento desde el que no requerirá el autorización previa a la concesión de licencias en el entorno de protección del BIC, salvo para aquellas intervenciones que se manifieste expresamente.

Si por el contrario, el Plan General no cumple el artículo 39 LPCV, debe expresarse la transitoriedad del plan en cuanto a la redacción del preceptivo Plan Especial, incorporando como mínimo la propuesta de delimitación del entorno de protección del BIC y su normativa transitoria.

La cuestión es que en el ámbito de Campanar no existía situación transitoria de protección, dado que se aprueba en 1992 el Plan Especial de Protección y Reforma Interior de Campanar, cuya área de protección delimitada en el propio plan (Figura 21), incluye el perímetro del entorno BIC del decreto de declaración de la iglesia de fecha 28/09/2007 (Figura 20). 


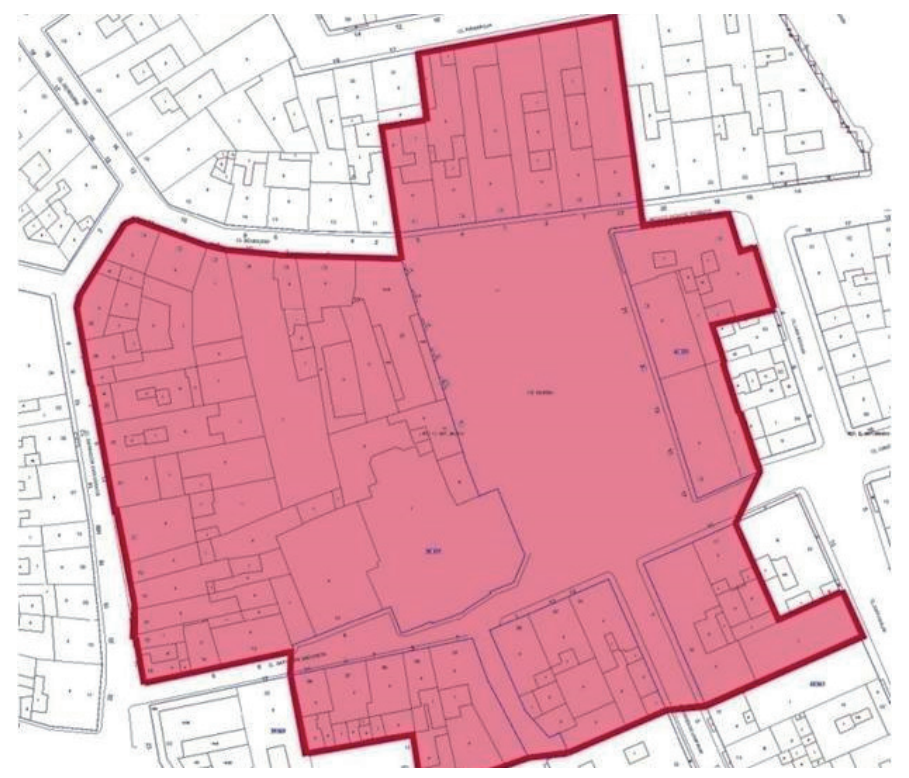

Figura 28. Delimitación de entorno BIC sobre cartografía catastral, conforme a su decreto de declaración de fecha de 28 de septiembre de 2007.

Fuente: Plataforma digital del inventario General del Patrimonio Cultural Valenciano. (http://www.cult.gva.es/dgpa/bics/bics.asp, $15 / 11 / 2013)$
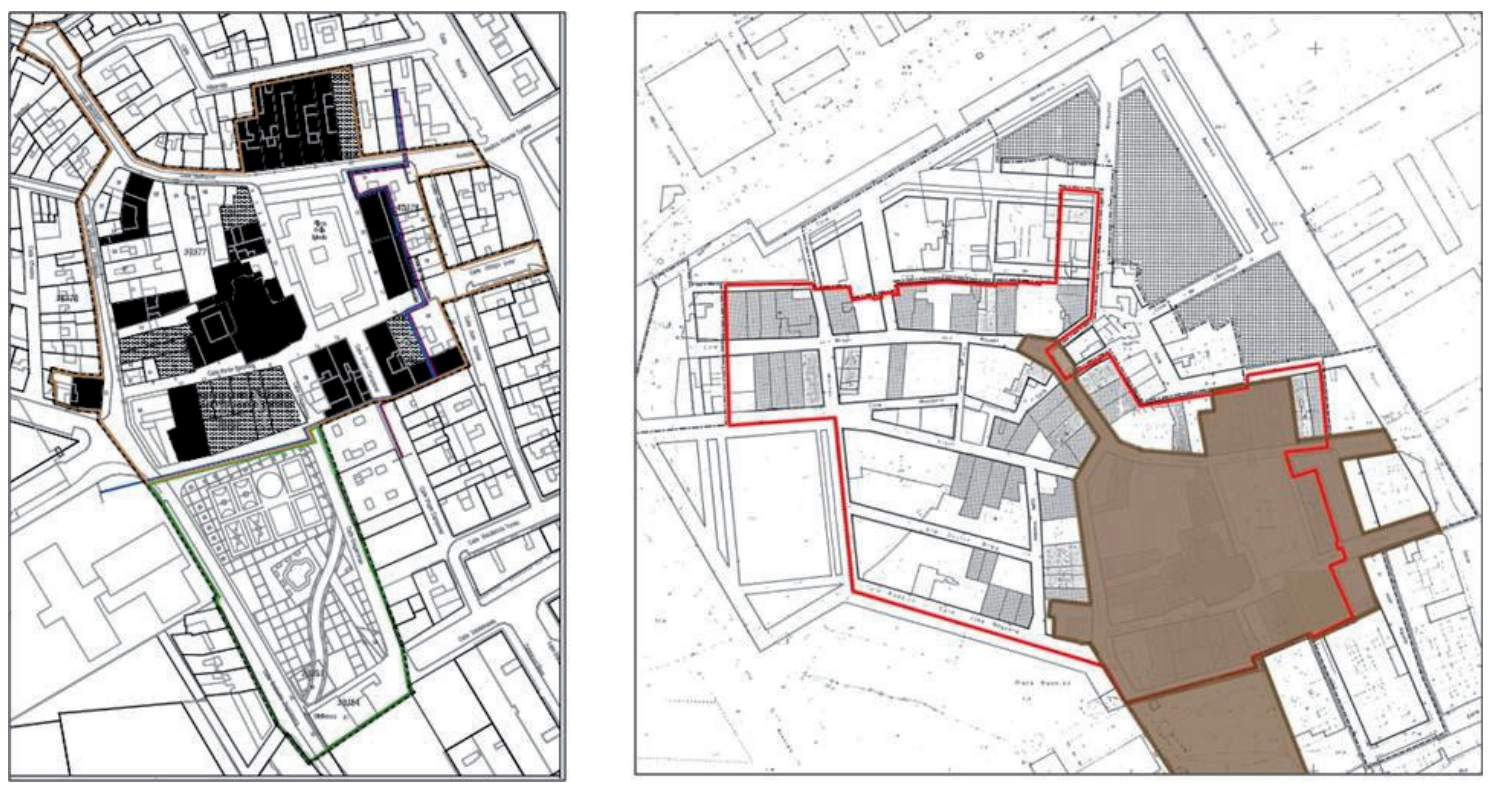

Figura 29. Plano de delimitación del PE de entorno BIC (izquierda), modificado con respecto al entorno de declaración e incluido en el perímetro del anterior PEPRI (a la derecha), excepto por la inclusión del parque en la Calle Grabador Enguídanos, cuyo régimen jurídico quedará establecido por el Plan General y no por el Plan Especial, como el propio documento expresa. Sobre el plano de ordenación del PEPRI del 92, se ha grafiado su área de protección en rojo, y en su interior el área de entrono BIC, en marrón.

Fuente: Plan Especial de Protección del Entorno del BIC Iglesia Parroquial de Nuestra Señora de la Misericordia de Campanar. Marzo, 2010. Ayuntamiento de Valencia. (Izquierda). Plan especial de protección y reforma interior de Campanar, Sector T-5 del PGOU. Diciembre 1991. Ayuntamiento de Valencia. (Derecha) 
El ámbito coincidente hace que el Plan de entorno BIC asigne un nuevo régimen jurídico a los inmuebles del núcleo histórico de Campanar, con los niveles de protección ajustados al ROGTU:

- Nivel de protección Integral, para el que sólo se admitirán obras de conservación y restauración.

- Nivel de protección Parcial, con la rehabilitación como nivel máximo de intervención.

- Nivel de protección Ambiental, en el que no se asigna un tipo concreto de intervención.

Recupera las definiciones de Conservación y Restauración de los PEPRIS aprobados en Ciutat Vella, así como la de Rehabilitación en sus dos acepciones: modernización y reforma. Además de los tipos de actuación propios de cada nivel, podrán autorizarse otras actuaciones que se indican a continuación.

- En Nivel Integral:

- La reposición o reconstrucción de aquellos cuerpos y huecos primitivos cuando redunden en beneficio del valor cultural del conjunto, utilizando siempre técnicas y soluciones constructivas propias de la época de su construcción y recuperando el diseño original utilizando soluciones de acabados que permitan distinguir las partes reconstruidas de las originales.

- Las obras excepcionales de redistribución del espacio interior sin alterar las características estructurales o exteriores del edificio siempre que ello no desmerezca los valores protegidos ni afecte a elementos constructivos a conservar

- En Nivel Parcial:

- La demolición de algunos de los elementos protegidos (espacios libres, alturas y forjados, jerarquización de volúmenes interiores, escaleras principales, el zaguán y la fachada no principal) cuando no gocen de protección específica por el catálogo, en bienes no inscritos en el Inventario General del Patrimonio Cultural Valenciano, y, además, sean de escaso valor definitorio del conjunto o cuando su preservación comporte graves problemas de cualquier índole para la mejor conservación del inmueble.

- En nivel Ambiental:

- La reforma de la fachada y elementos visibles desde la vía pública siempre y cuando no afecte a las características definitorias - valor histórico, ambiental, belleza, tipismo o tradición- del paisaje urbano.

En consecuencia, el Plan Especial de Protección del entorno BIC de la Iglesia de Campanar (PEP-EBIC 02) supone la aplicación de una nueva normativa, que no una revisión de la actual, para un mismo ámbito de actuación, así como una superposición de catálogos de Bienes y Espacios Protegidos en el mismo ámbito. 

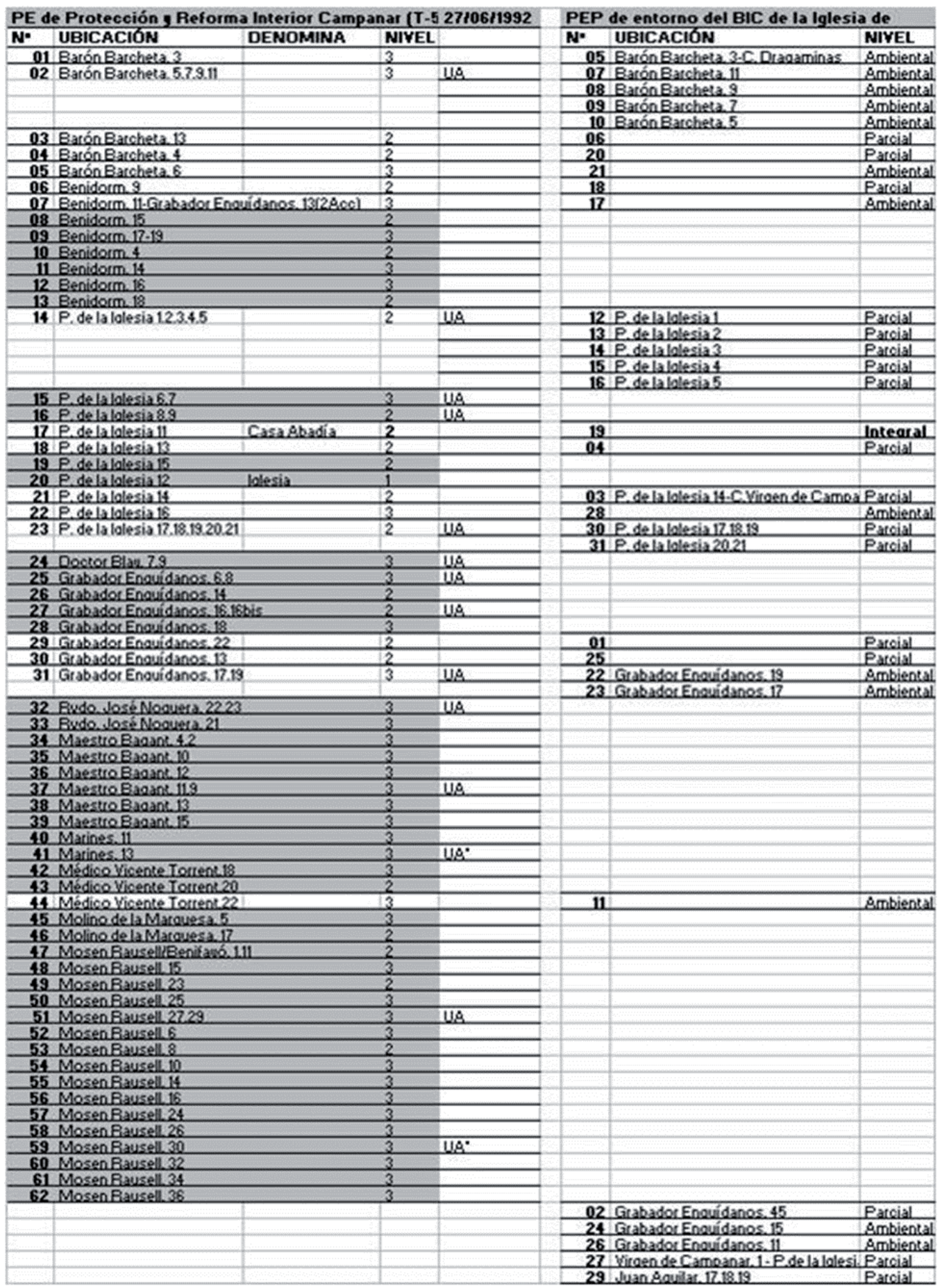

Figura 30. Cuadro comparativo entre los elementos catalogados en el PEPRI Campanar (1992) y en el PEP de entorno BIC de la Iglesia de Ntra. Señora de la Misericordia de Campanar. Los inmuebles en las casillas de color gris quedan sujetos al régimen de protección del PEPRI y los inmuebles en las casillas blancas quedan sujetos al régimen de ambos planes, dado que el segundo no deroga el primero Fuente: Elaboración propia 
En un intento de contrastar los catálogos de ambos planes, lo que no ha sido una tarea sencilla (Figura 30), se podría ver que en el Núcleo Histórico Tradicional de Campanar, (así considerado desde la revisión estructural del Catálogo Valenciano), existen inmuebles para los que se actualiza su régimen de protección a los criterios del ROGTU y nueva normativa vigente en el PEP de entorno, mientras que otros (en gris) mantienen el régimen establecido en el PEPRI del $92^{29}$; sin entrar a comentar la inseguridad jurídica que esto supone y el flaco beneficio para el conjunto, parece obvia la confusión que introduce la profusión de normativa, sin la consideración de una revisión de documentos previos. La redacción del plan parece poco justificada, si no es por la modificación de la delimitación de entorno respecto del perímetro del previo PERPI. La inversión pública en la revisión de instrumentos de protección obsoletos habría sido mucho más productiva.

\subsection{Plan Especial de Protección del Entorno de los BIC Puerta de Serranos, Iglesia y Convento de Santo Domingo, Museo Bellas Artes (Ex-Convento de San Pío V), Monasterio del Temple, Palacio de Justicia, Ex-Convento del Carmen e Iglesia de Santa Cruz y Palacio de los Condes de Cervellón (PEP-EBIC 08)}

Dada la extensión del documento y de las muchas exigencias que debe abarcar un plan de estas características, como ya se ha visto, se resumen los aspectos más relevantes del plan desde la perspectiva del tema que abordamos: la técnica de catalogación y los criterios de intervención.

El Plan Especial de Protección de Entornos BIC, denominado de forma abreviada PEP-EBIC 08, modifica justificadamente la delimitación de entornos de protección establecidos en la declaración, que se justifica a través de un estudio complementario, asumiendo la singularidad que introduce la LPCV en el artículo 39.3.a., donde dice: Excepcionalmente el planeamiento podrá proponer, por motivos justificados en la mejora tutelar, reajustes del ámbito de protección previamente reconocido. La delimitación así tramitada adquirirá vigencia a todos los efectos a partir de la entrada en vigor del correspondiente planeamiento. (Figuras 22 a 24). Los criterios aplicados para la delimitación de los nuevos entornos de protección se contemplan en el apartado b del artículo 39.3 de la LPCV.

Atendiendo a las determinaciones contenidas en el artículo 39.1 de la LPCV, el Plan regula los requisitos a los que han de sujetarse los actos de edificación y uso del suelo y las actividades que afectan a los inmuebles y a su entorno de protección.

\footnotetext{
29 El PEP-EBIC 02, es el documento regulador del planeamiento urbanístico de desarrollo en las zonas por él delimitadas. Modifica y complementa, en su ámbito de aplicación, las determinaciones del Plan General de Ordenación Urbana del municipio de Valencia, así como del PEPRI Casco de Campanar (Art. 0.3 Normas Urbanísticas del PEP). EI PEP-EBIC 02 se plantea como objetivo, entre otros, la revisión de las determinaciones urbanísticas contenidas en el PEPRI de Campanar, con el fin de adecuarlas a las nuevas determinaciones legales. Las Ordenanzas gráficas que contiene este PEP-EBIC 02 (Planos O-05 y 0-06) prevalecen en sus determinaciones sobre cualquier otra disposición contenida en el PEPRI de Campanar o en el PGOU de Valencia. (Art. 4.1.c De las condiciones Generales de la edificación de las Normas Urbanísticas del PEP).
} 
Con este objeto el PEP-EBIC 08 define dos zonas de Ordenación Urbanística: la denominada "Entorno de protección-Trama Histórica" y la denominada "Entorno de protección-Reformas Urbanas s.XIX". La primera comprende parcialmente las áreas de Ciuta Vella calificadas como Barri Històric (CHP-111 del Carme, CHP-121 de SeuXerea, y la CHP-131 de Universitat-San Francesc), para ella la regulación que el plan propone es el mantenimiento casi íntegro de la regulación de los PEPRIS de Ciuta Vella; La segunda comprende las áreas de Ciutat Vella calificadas por el planeamiento previo como CHP-122 Eixample y CHP-121 Barri Históric de SeuXerea, CHP-132 Eixample de Universitat-San Francesc, en las que salvo pequeñas modificaciones, se mantienen las condiciones y parámetros vigentes en los PEPRIS actualmente vigentes; A este respecto el Plan no hace muchas aportaciones a los PEPRIS de Ciutat Vella, de gran calidad en sus normas de edificación y uso.

El Plan fija el régimen jurídico de elementos que afectan negativamente al patrimonio cultural (art.39.2.h) y los califica fuera de ordenación por afección patrimonial, aplicándoles el régimen jurídico previsto en el Plan General de Ordenación Urbana de Valencia en función de la categoría en que se encuentren: sustantivo, adjetivo, diferido o funcional ${ }^{30}$, con la salvedad que el PEP-EBIC-08, modifica el contenido del "fuera de ordenación diferido" respecto del PGOU, considerando en tal situación a las edificaciones que por exceso igual o inferior a una planta superan la altura de cornisa $(\mathrm{Hc})$ permitida $(\mathrm{Hc}=4.80+3.15 \mathrm{~Np}$ ).

Las normas urbanísticas del Plan que afectan a las condiciones de la edificación no catalogada consideran las determinaciones del PEPRI de la Seu Xerea para Barri Historic. Para regular la ordenación y diseño de las áreas peatonales y espacios libres se definen los siguientes recorridos:

- Recorrido 1. Marginal izquierda del antiguo cauce: plaza de Santa Mónica, calles Cronista Ribelles, Trinidad y San Pio V.

- Recorrido 2. Marginal derecha del antiguo cauce: calle de Blanquerías, plaza de los Fueros, calles Conde Trénor y Pintor López, plazas del Poeta Llorente y del Temple, paseo de la Ciudadela.

30 El Plan General de Valencia establece el régimen transitorio para la edificación existente con anterioridad al plan en la Disposición Transitoria Novena de sus Normas urbanísticas:

Fuera de Ordenación adjetivo: Afecta a aquellas partes y elementos de los edificios e instalaciones que resulten contrarios a las condiciones de estética de la edificación y, en particular, a aquellos elementos que no constituyendo superficie útil sean visibles desde vía pública.

Fuera de ordenación sustantivo: Afecta a aquellos edificios o instalaciones que sean contrarios al Plan afectando la disconformidad al edificio completo o partes estructurales del mismo.

Fuera de ordenación diferido: Afecta a aquellos edificios que aún cuando no se encuentren adaptados al Plan en todas las condiciones de edificación por él reguladas, la falta de adaptación no revista tal relevancia que puedan considerarse disconformes con el nuevo planeamiento, en los términos prescritos en los siguientes apartados. Por tanto, la construcción podrá considerarse dentro de ordenación hasta el momento en que concluya su vida útil, se produzca la sustitución voluntaria o se operen en ella obras de reforma de trascendencia equiparable a la reedificación (reestructuración total). No obstante, la nueva construcción sobre la misma parcela o la reestructuración total de la existente deberá adaptarse a todas las condiciones de edificación, régimen de alturas y profundidades edificables y reserva de aparcamientos previstas en este nuevo planeamiento.

Fuera de ordenación circunstancial: Afecta a las instalaciones fabriles ubicadas en lugares prohibidos por incompatibilidad con el uso residencial o terciario circundante a las que le sea aplicable régimen de tolerancia en desarrollo de lo previsto por el artículo 61 de la Ley del Suelo. 
- Recorrido 3. Entorno de la plazas de Tetuán, Alfonso el Magnánimo, Jardín de la Glorieta y calle Palacio de Justicia.

- Recorrido 4. Puentes Históricos: puente de San José, de Serranos, de la Trinidad y del Real.

- Recorrido 5. Antiguo Cauce del Turia entre el puente de San José y el puente de la Exposición.

El Plan contiene normas para regular áreas estanciales y peatonales, trasporte y aparcamientos, características de materiales, mobiliario etc. utilizados para la ordenación y diseño de estos recorridos, condiciones particulares de aplicación a los tramos VI ( $a$ y b), el VII y el VIII, del viejo cauce del Turia incluidos en el PEP-EBIC 08 y condiciones sobre el contenido y tramitación de los proyectos realizados para la ordenación y diseño de estos recorridos.

Respecto del artículo 39.2.e de "incentivar operaciones de rehabilitación urbana, implantación de actividades económicas, dotaciones y usos públicos que contribuyen a la puesta en valor y rehabilitación de edificios", el plan propone:

- La recualificación del espacio urbano que rodea a los monumentos mediante la reducción del tráfico y la ampliación de las zonas peatonales. En el caso de optar por la reducción de tráfico mediante la disposición de pasos subterráneos, [...] que permitan la eliminación del tráfico en superficie que utiliza esta ronda para atravesar la ciudad, se establecen condiciones para evitar afecciones a los valores patrimoniales de la zona.

- La recuperación del vínculo histórico existente entre las edificaciones monumentales y el cauce del Rio Turia con todos sus elementos históricos protegidos como son los distintos puentes históricos que van atravesándolo. En el tramo del río incluido en el ámbito se propone una ordenación del espacio tendente a poner en valor los puentes históricos que casualmente también se concentra en esta zona. La nueva ordenación propone la desconcentración de usos deportivos en una zona concreta y propone el diseño del espacio alternando zonas ajardinadas con pistas de uso deportivo, puesta en valor de los elementos históricos de acceso desde el cauce, especialmente los recayentes a la altura de los distintos monumentos.

- No serán de aplicación las Normas Urbanísticas del Plan General respecto de condiciones generales y especificas sobre condiciones de volumen, ocupación y forma de la edificación de los Sistemas Generales y Locales para el caso del tramo del antiguo cauce del río afectado y la zona afectada de Jardines del Real-Viveros (actualmente artículos 6.70 y 6.71). Las normas del plan definen criterios para futuras actuaciones de ordenación y reurbanización del tramo del jardín del Turia y de los Jardines de Viveros teniendo en cuenta la consideración de elementos que contienen valores patrimoniales a preservar. 


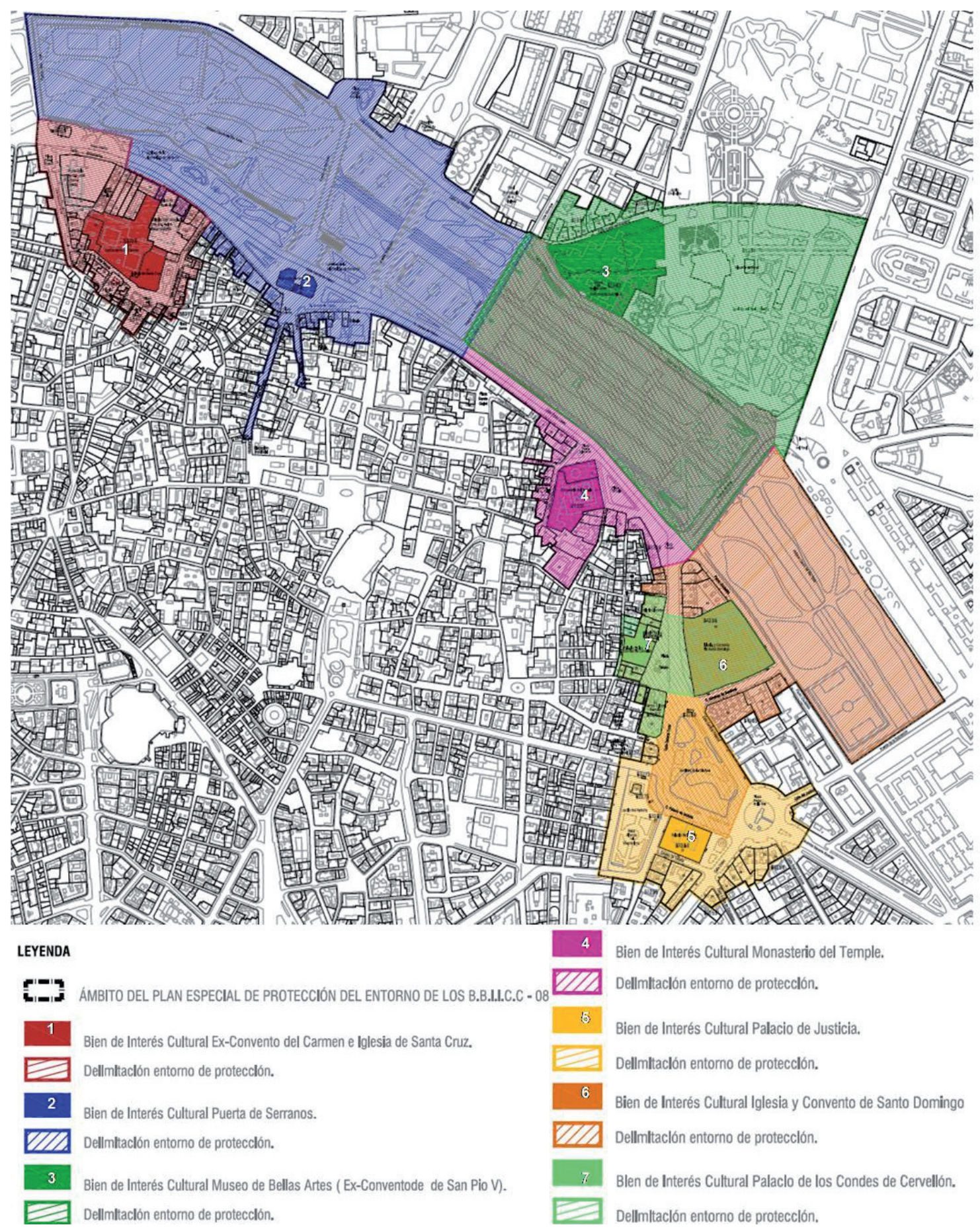

Figura 31. Plano de Ordenación 0.01, Ámbito de protección del entorno de protección de los BIC, PEPEBIC 08.

Fuente: Plan Especial de Protección del Entorno de los Bienes de Interés Cultural -Puerta de Serranos, Iglesia y Convento de Santo Domingo, Museo Bellas Artes (ex-Convento de San Pío V), Monasterio del Temple, Palacio de Justicia, ex-Convento del Carmen e Iglesia de Santa Cruz, Palacio de los Condes de Cervellón y catálogo de bienes y espacios protegidos. Julio 2012. Ayuntamiento de Valencia. 


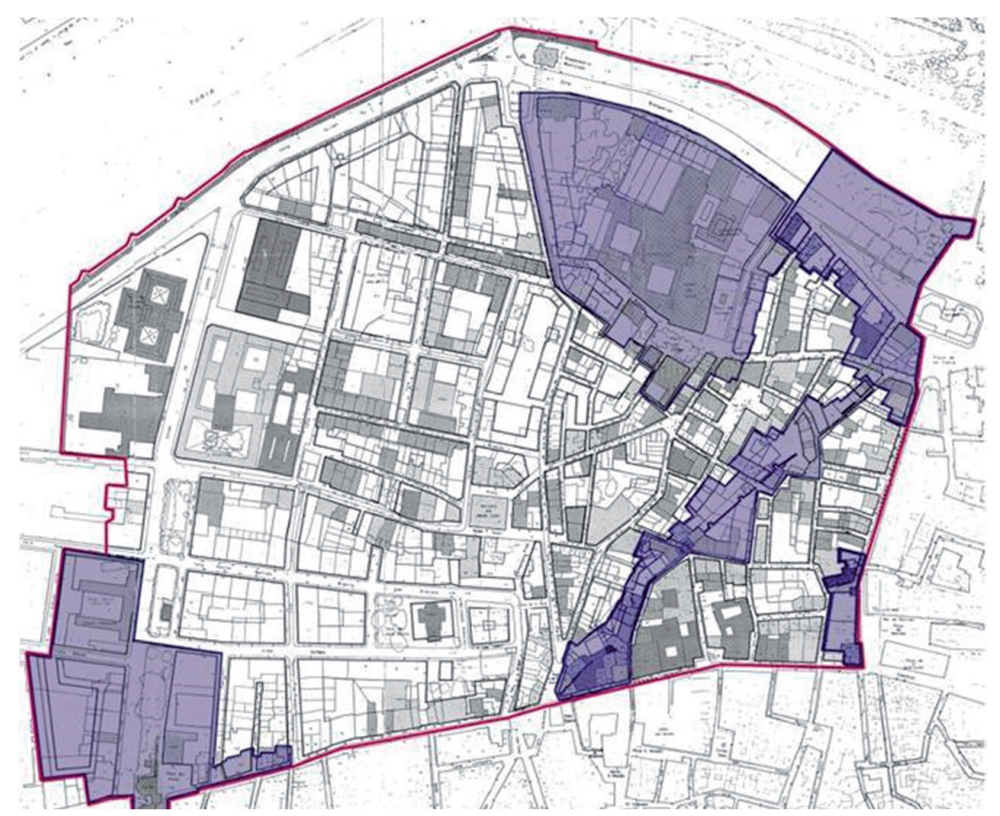

Figura 32. Plano donde se delimita el perímetro del ámbito de actuación del PEPRI del Barrio del Carmen (en rojo) y de los entornos de protección de los BIC incluidos en el ámbito (en morado), de acuerdo con la delimitación en la resolución su declaración: Torres de Quart, Torres de Serranos, Convent del Carme, Murallas Árabes y la Seu-Verge.

Fuente: Pla Especial de Protecció i Reforma Interior del Barri del Carmen. Enero 1991. Ayuntamiento de Valencia.

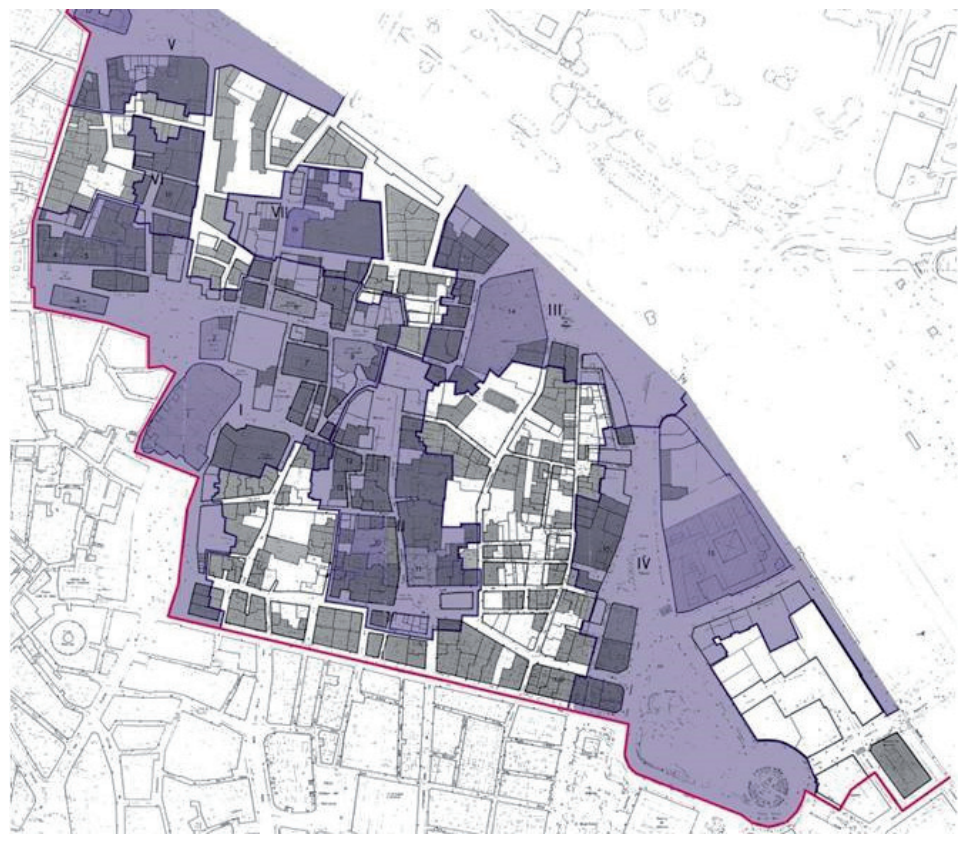

Figura 33. Perímetro del ámbito de actuación del PEPRI del Barrio de la Seu-Xerea (en rojo) y de los entornos de protección de los diecisiete BIC incluidos en el ámbito (en morado), que se concentran en siete áreas: I-La Seu-Basílica; II-Sant Tomás/Sant Joan de I'Hospital III-El Temple; IV-Sant DomènecPalau de Cervelló; V-Torres de Serrans; VI-Palau dels Català de Valeriola; VII-Esglèsia de El Salvador. Fuente: Pla Especial de Protección i Reforma Interior del Barri la Seu-Xerea. Diciembre 1992. Ayuntamiento de Valencia. 


\section{Dimensión horizontal}

El Catálogo del PEP-EBIC 08 refunde y actualiza parcialmente el Catálogo del Plan General de Ordenación Urbana, y el de los Planes Especiales de Protección y de Reforma Interior de Ciutat Vella, el Carmen, la Seu Xerea y Universitat San Francesc, así como los de las distintas modificaciones urbanísticas vigentes que se han ido formulando en estas zonas. Un gran trabajo del Plan es el esfuerzo de volcado de datos proveniente de todos los instrumentos planeamiento y de protección, vigentes en el ámbito del plan sobre un solo plano informativo. (Figura 34)

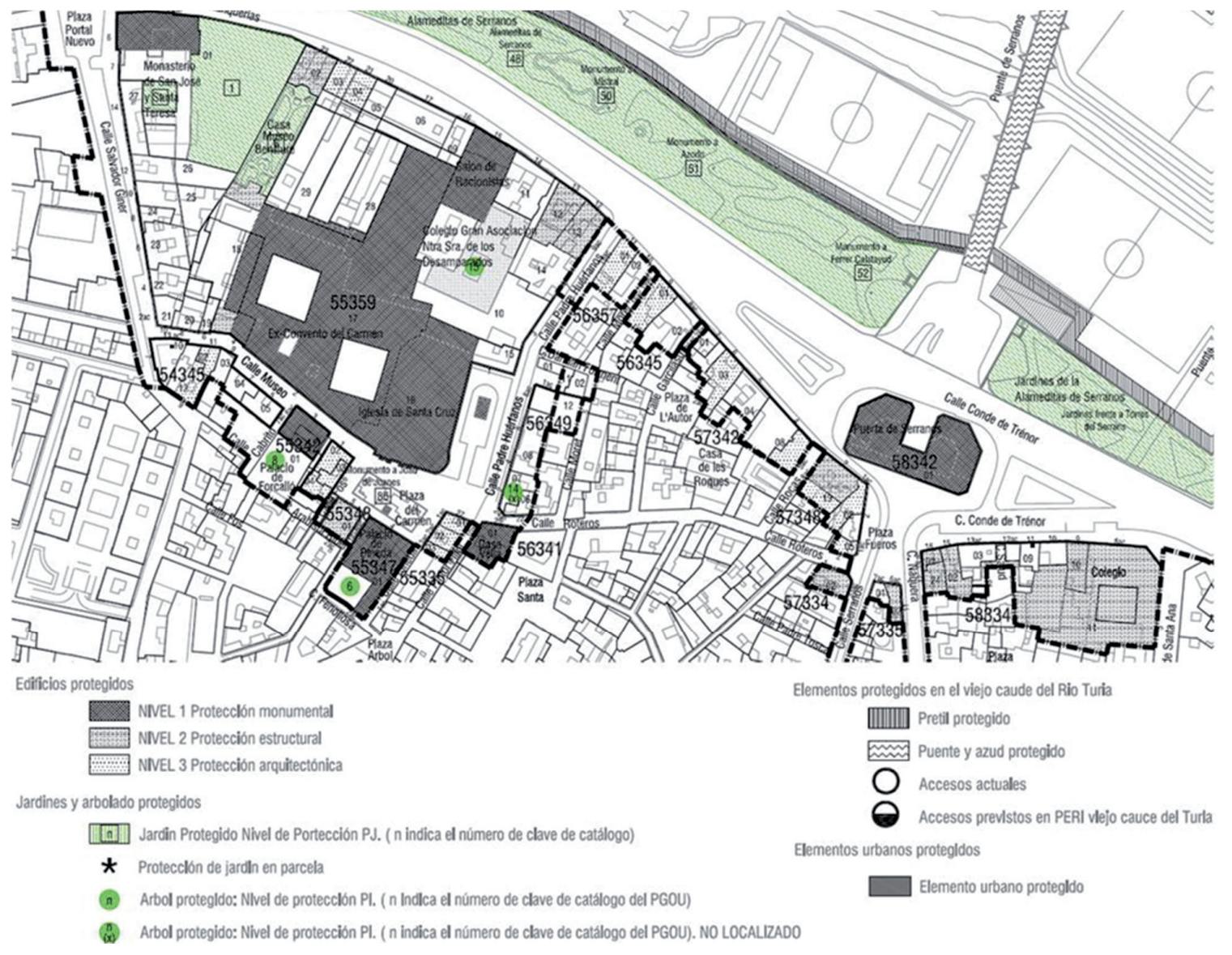

Figura 34. Detalle del Plano de Información I.06: Niveles de protección, edificios, árboles, jardines y elementos protegidos del PEP-EBIC 08 (julio 2012). La representación de la situación de catalogación previa a la redacción del Plan, se obtiene refundiendo en un plano la información proveniente de los catálogos de los siguientes documentos: Plan General de Ordenación Urbana de Valencia, PEPRI del B. del Carmen, PEPRI del B. de la Seu-Xerea, PEPRI del B. Universitat-San Francesc, Modificación PEPRI del B. del Carmen. Cvto. del Carmen y Homologación, Modificación PEPRI del B. del Carmen, Modificación PEPRI del B. Seu-Xerea, Estudio de Detalle de la Unidad de Ejecución UE 12.5 "Plaza de la Salud" del PEPRI del Barrio de la Seu-Xerea, Estudio de Detalle Museo San Pío V.

Fuente: Plan Especial de Protección del Entorno de los Bienes de Interés Cultural -Puerta de Serranos, Iglesia y Convento de Santo Domingo, Museo Bellas Artes (ex-Convento de San Pío V), Monasterio del Temple, Palacio de Justicia, ex-Convento del Carmen e Iglesia de Santa Cruz, Palacio de los Condes de Cervellón y catálogo de bienes y espacios protegidos. Julio 2012. Ayuntamiento de Valencia. 
Se propone la calificación de siete edificaciones como Bienes de Relevancia Local en la categoría de Monumento de Interés Local (MIL) y la incorporación de nuevas edificaciones al catálogo. Los niveles de protección y las obras permitidas en cada uno de los niveles son los establecidos por la legislación urbanística en el ROGTU sin introducir redefiniciones ni especifidades.

De acuerdo con el artículo 48.4.a del Reglamento del Paisaje de la Comunidad Valenciana ${ }^{31}$ el Plan Especial de Protección de los Entornos BIC, se acompaña de un Estudio de Integración Paisajística, un documento de gran extensión (244 páginas y 37 planos) cuyo objeto es valorar la magnitud de los efectos sobre el paisaje y su percepción, de las actuaciones que propone el plan, así como definir estrategias para evitar impactos negativos.

Se llega a la siguiente conclusión en el propio Estudio de Integración Paisajística: "Dado que el objeto del Plan Especial es precisamente la protección, promoción y preservación de los bienes de interés cultural y de sus entornos, se entiende que dichas medidas correctoras se encuentran contenidas en las normas del propio Plan Especial (DOC-3 Documento de Ordenación: Normas Urbanísticas y de Protección) y, por tanto, no se estima necesario establecer medidas de integración suplementarias.

$Y$ es que el PEP EBIC 08, se redacta como documento normativo cuyo objeto es regular los actos de edificación y uso del suelo y las actividades que afectarían a los inmuebles declarados BIC y a sus entornos de protección desde el punto de vista de la mejor preservación y promoción del bien inmueble declarado Bien de Interés Cultural, para cumplimiento de las finalidades establecidas en su decreto de declaración."

Conclusión que deja en evidencia la innecesaria inversión en un documento tan laborioso y costoso, que busca los mismos objetivos que el propio Plan y que se elabora, no por su indispensable aportación científica, sino por mera imposición normativa.

\footnotetext{
31 El Estudio de Integración Paisajística debe acompañar al planeamiento de desarrollo definido en los apartados b, c y d del artículo 38 LUV, entre ellos los Planes Especiales, que, en desarrollo, complemento o incluso modificación del planeamiento general o parcial, cumplen cualquiera de los siguientes cometidos: [...] adoptar medidas para la mejor conservación de inmuebles de interés cultural o arquitectónico; (sin embargo quedan excluidos de ir acompañados del estudio de integración paisajística, los Catálogos de Bienes y Espacios Protegidos). Esta situación persiste en el artículo 42 del Proyecto de Ley de Ordenación Territorial, Urbanística y de Paisaje, LOTUP.
} 


\section{CONCLUSIONES}

Para llegar a una o varias conclusiones concretas a partir de la investigación, debemos preguntarnos qué es lo que estamos analizando y con qué intención, a fin de conseguir mejorarlo. En primer lugar, analizamos la técnica de catalogación a lo largo del tiempo, con especial atención al contenido del catálogo y de las fichas de inmuebles. En segundo lugar el régimen normativo del catálogo, en cuanto al cumplimiento de la relación biunívoca entre niveles de protección y tipos de intervención técnica sobre los inmuebles, desde el convencimiento de que debe existir un principio de igualdad y de justicia subyacente en la catalogación, basado en el establecimiento de un convenio entre niveles de protección y criterios de intervención, fijo por ley, de modo que la relación no esté sujeta a la discrecionalidad de creación de nuevos criterios en cada catálogo.

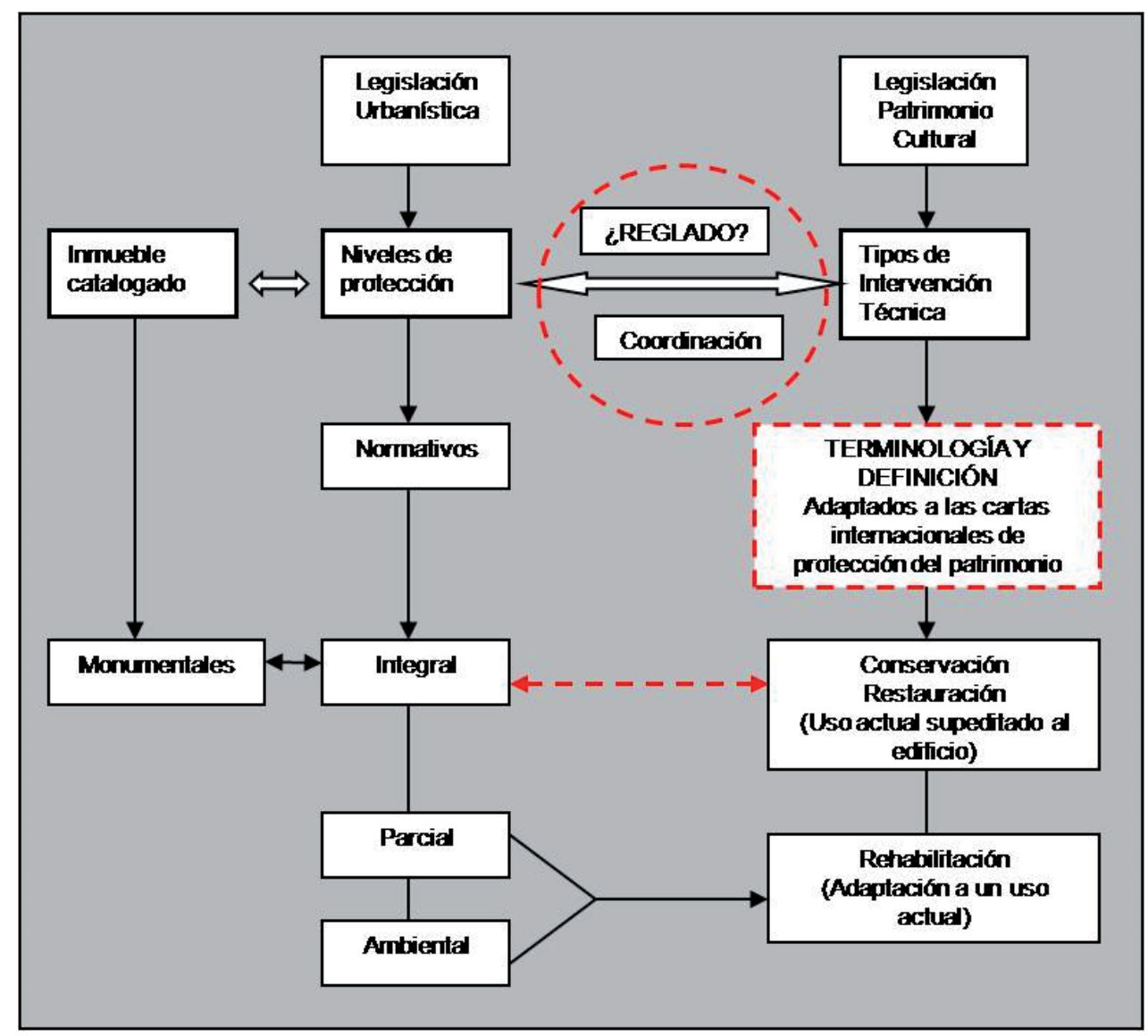

Figura 26. Relación entre niveles de protección y criterios de intervención

Fuente: Elaboración propia 


\section{Sobre el contenido del catálogo}

- La memoria justificativa de los criterios de catalogación: los criterios de catalogación deben ser universales y guiados por los valores culturales de los bienes, el autor de cada catálogo no puede se inspirado por sus propios criterios, y por tanto no debería exigirse una memoria justificativa de los criterios de catalogación como documento integrante del catálogo.

- La documentación del Núcleo Histórico Tradicional - BRL: debe incluir una profusa normativa, con inclusión de la delimitación de su entorno, y la redacción de una ordenanza de edificación que vendrá a superponerse a la ya existente sobre la zona. La exigencia urbanística de delimitación y catalogación parecía suficiente, para cubrir el objetivo de protección, en ocasiones pasarse en la exigencia sin incentivarla, produce el resultado contrario al deseado, la total pasividad de la administración local.

- La normativa de aplicación, diferenciada para cada grado de protección, con expresión escrita y gráfica, del resultado pretendido, ajustada a los niveles de protección del ROGTU. Se alienta la creación exnovo de criterios de intervención técnica para los grados de protección en cada catálogo, en contra de lo que defiende una coherente protección: el establecimiento de una relación biunívoca, única y reglada entre niveles de protección y tipos o técnicas de intervención. Con una terminología apropiada asociada a la definición de la técnica de intervención, regulada desde el órgano con competencia patrimonial. En el caso valenciano es el legislador urbanístico el que propone la vinculación a través de los niveles de protección y técnicas de intervención asociadas, primero en el reglamento de planeamiento y después en el ROGTU. Sin embargo, la legislación de patrimonio cultural propone la introducción de criterios de intervención por cada redactor, en total descoordinación con la legislación urbanística y en flaco favor para la protección de inmuebles.

- Sobre el contenido de una ficha de catalogación:

- Nivel de protección

- Datos identificativos del inmueble

- Descripción de sus características,

- Estado de conservación y prescripciones para mejorarlo,

- Uso actual y propuesto especificando su destino público o privado

- Plano (situación y descriptivos del inmueble)

- Fotografías.

Tras la comparación con las prescripciones de protección exigibles a un catálogo, establecidas en el anterior apartado: situación física, jurídica, intervención administrativa para su protección con regulación de usos y nivel de protección, faltaría incluir la situación jurídica del edificio, las acciones administrativas en su defensa y sobraría el estado de conservación y prescripciones para mejorarlo. 
Para alcanzar el conocimiento del estado de conservación del inmueble y las prescripciones para mejorarlo, se debería realizar una inspección pormenorizada con acceso a cada parte que integra el edificio e inspección del estado de sus instalaciones. La propuesta de mejora es un trabajo concienzudo, fruto del conocimiento del edificio, donde se deben conjugar las restricciones del catálogo con la adaptación a un uso contemporáneo; a nuestro entender debe darse en una fase de intervención sobre el edificio y no en la fase de catalogación. No obstante, puede vincularse el catálogo con la exigencia de presentación de los informes de evaluación de los edificios y con órdenes de ejecución en cumplimiento del deber de conservación, en los casos de mayor degradación y el aviso de riesgo de ruina inminente, que produciría las acciones administrativas en aras a su conservación: la ejecución subsidiaria y la sujeción al régimen de ejecución forzosa, acciones ingratas para propietarios y políticos.

El catálogo puede informar sobre el estado de conservación de los inmuebles en el momento de la redacción del mismo, pero esta información sería inveraz a lo largo del tiempo de vigencia del documento, por el cambio de las condiciones del edificio. Este tipo de información debería recabarse en una base de datos de gestión municipal, en la que se contemplaran las intervenciones de los elementos catalogados. El modelo de ficha para la catalogación de inmuebles con categoría BRL, desde el Decreto 62/2011, de 20 de mayo, del Consell, a pesar de ser un buen intento de homogeneización, entendemos que interpreta erróneamente el régimen de intervenciones, usos y destino propuesto, (que hace referencia a las actividades administrativas en aras a su protección y rehabilitación), cuando introduce en nota al pie los tipos de intervención técnica y no administrativa y habla de: demolición, eliminación, elementos impropios, reposición de elementos desaparecidos, elementos originales, restauración, rehabilitación, refuerzo, redistribución, ampliación, sobreelevación y otros, en referencia al artículo 189.2 del ROGTU, que nada tiene que ver con estos tipos de actuaciones.

La actuación técnica reglada y vinculada al nivel de protección, debería ser definida pormenorizadamente en el proyecto de intervención sobre el edificio. En la ficha, el nivel de protección global es desglosado entre los distintos elementos del inmueble, debiéndose introducir normativa de protección para cada uno de los elementos constructivos, bienes muebles y jardinería aledaña; lo que puede es oportuno en los monumentos más representativos de nuestro patrimonio, no en todos los elementos catalogados, por su falta de flexibilidad a la hora de intervenir, y por ello el modelo sólo es aplicable a los bienes BRL, para el resto de inmuebles catalogados sin ficha modelo, podría ajustarse las exigencias de la misma a la identificación, situación jurídica, tipo de actuación para su mejor conservación y nivel de protección.

\section{Sobre la mejora de la técnica de catalogación}

Más allá del modelo de catalogo y su preceptivo contenido ¿cuál es la técnica de catalogación que se está desarrollando?

En el municipio de Valencia se establece por el régimen de protección transitorio de aquellos inmuebles que están incluidos en ámbitos objeto de desarrollo de Planes 
Especiales de Protección. A medida que se aprueban los Planes Especiales se va vaciando de contenido el catálogo municipal, de forma que desde su aparición, se le imprime un carácter provisional y de poca firmeza, que sumado al contenido artículo 3.61.3 del Plan General, que permite la redefinición de elementos protegidos, de sus grados de protección y de sus usos, hace que la vocación de no permanencia de los valores protegidos del catálogo municipal sea obvia.

Efectos de desprotección son los que provocan algunas técnicas de catalogación, que deberían eliminarse:

- Se prohíbe el aumento de volumen y la alteración de los parámetros propios del edificio catalogado, pero se permite el incremento de la superficie construida sobre rasante con cumplimiento de las ordenanzas generales de la edificación, lo que choca frontalmente con la exigencia de protección extensible a la totalidad de la parcela donde está el edificio y con el concepto de entorno de protección del bien.

- Se permite la reducción de las exigencias de protección del inmueble mediante un nivel de protección subsidiaria, si en aplicación de esta medida, se logra con mayor eficacia la protección de los valores arquitectónicos o urbanísticos del inmueble. Pero la reducción de exigencias de protección no logra mayor protección, sino la mejor adaptación del edificio a un uso para su rehabilitación. Esta adaptación no debería ser admisible en la restauración de monumentos, donde cualquier uso debe supeditarse a la conservación del edificio por sus valores histórico-artísticos, por lo que no sería justificable el relajar sus condiciones de protección a favor de un uso, para el nivel de protección integral, que por el contrario podría admitirse en inmuebles no monumentales.

En el caso de intervenciones sobre edificios monumentales, su valor patrimonial y la intervención para su defensa y realce se anteponen al destino de un uso, que se deberá supeditar a la configuración del edificio y no al revés.

\section{Sobre los criterios de intervención}

Las Cartas del Restauro y Convenciones Internacionales sobre intervención en el patrimonio avalan esta última consideración: en los monumentos se admitirán usos que no alteren su aspecto exterior, su estructura, su distribución y sus espacios. Como síntesis los criterios de actuación sobre monumentos de las cartas de restauración se resumen en:

- Mantenimiento de carácter preventivo para evitar la restauración. EXIGIDO.

- "Repristino", intervención de recuperación de un estilo. PROHIBIDO.

- Restauración, de carácter excepcional que puede conllevar PERMITIDO:

- Modificaciones o añadidos estructurales que no alteren su aspecto exterior.

- Reconstrucción de partes muy limitadas, con significado arquitectónico, basada en una documentación precisa e indiscutible 
- Demolición de alteraciones deformadoras o incongruentes respecto a los valores históricos de la obra o de complementos en estilo que la falsifiquen.

- Adaptación de un uso adecuado al edificio, (sin alteración del aspecto exterior, la tipología constructiva y la secuencia de recorridos interiores), con posibilidad de incorporación de partes espaciales y funcionales más extensas con un lenguaje arquitectónico actual. PERMITIDO

Los criterios de intervención en actuaciones de restauración contemplados en la Ley de Patrimonio Histórico Español, se recogen en su artículo 39:

- Prohibido el "repristino"

- Los añadidos para su estabilidad estructural deberán ser reconocibles y evitar las confusiones miméticas.

- Prohibida la reconstrucción, salvo cuando se utilicen partes originales y pueda probarse su autenticidad.

- Demolición de partes con carácter excepcional y siempre que dichos elementos supongan una evidente degradación del bien y su eliminación fuere necesaria para permitir una mejor interpretación histórica del mismo.

Los criterios de intervención en Monumentos, Jardines Históricos y Espacios Etnológicos en la Comunidad Valenciana se recogen en el artículo 38 LPCV:

- Prohibido el "repristino"

- En caso de que se autorice la demolición de alguna parte deberá quedar debidamente documentada ${ }^{32}$.

- Se permiten reconstrucciones totales o parciales del bien siempre que exista alguna pervivencia de elementos originales o conocimiento documental suficiente de lo perdido, se procurará la utilización de procedimientos y materiales originarios.

- Los bienes muebles vinculados como pertenencias o accesorios a un inmueble declarado de interés cultural sólo podrán ser separados del mismo en beneficio de su propia protección y de su difusión pública o cuando medie un cambio de uso y siempre con autorización de la Conselleria competente en materia de cultura.

Disonancia que aparecen en la LPHE, que al contrario de los criterios internacionales, requiere refuerzos estructurales reconocibles y sin confusiones miméticas, y en la legislación valenciana, cuando elimina el carácter excepcional de las reconstrucciones (incluso totales) y de las demoliciones, y no establece las condiciones en las que éstas últimas podrían darse. Se aporta un cuadro en el que se establece la comparación entre los criterios de intervención en cada norma, donde puede comprobarse como en cada traslación legislativa se ha ido perdiendo el rigor en los criterios.

Desde aquí se denuncia la no adaptación de la LPCV a los criterios de intervención en monumentos defendidos por las cartas internacionales de

\footnotetext{
32 Queda sin definir en qué condiciones puede autorizarse la demolición.
} 
patrimonio de Venecia y Cracovia y se reclama la necesaria revisión legislativa en cuanto a los criterios de actuación técnica para la restauración monumental, que deben ser ajustados a las normas internacionales.

Mientras no se reconduzca el contenido legislativo, mientras en cada catálogo se incorporen nuevos criterios de actuación vinculados al nivel de protección, lo que nos queda es formar a los futuros profesionales en los criterios internacionales de restauración, que deberán vincularse al nivel de protección integral en la catalogación de monumentos. Sin este cambio de dirección en la técnica de catalogación, y sin la revisión de los catálogos existentes a la luz de este aspecto y de la introducción de entornos de protección de los monumentos BIC y BRL, se continuarán dando casos flagrantes de destrucción del patrimonio.

La mala adaptación de la Ley Valenciana y la de los propios catálogos, que en ocasiones divergen incluso de los criterios establecidos por el ROGTU, suponen un gran obstáculo para el objetivo fundamental del catálogo, la conservación de los valores integrantes del patrimonio. Tomando como base la estructura terminológica aportada por los catálogos de los PEPRIS del Conjunto Histórico de Valencia, se sugiere una definición de criterios de actuación técnica homogéneos:

1. Estricta conservación o nivel mínimo de intervención:
a) mantenimiento
b) consolidación

2. Restauración:

3. Rehabilitación:
a) modernización
b) reforma

Conservación: Obras cuya finalidad es mantener un edificio o construcción en el correcto estado físico de sus elementos constructivos, funcionamiento de sus instalaciones $y$ en general de su seguridad, salubridad y ornato, sin pretender alterar su configuración exterior e interior. Pueden distinguirse dos niveles: Mantenimiento y Consolidación.

- Mantenimiento: actuaciones precautorias periódicas exigibles para mantener la salud del edificio (tales como limpieza, pinturas, repasos de carpinterías, etc.), así como la reparación de daños locales menores (en cubiertas, revestimientos, acabados, eliminación de humedades, etc.) incluso reposición de instalaciones menores.

- Consolidación: actuaciones tendentes a la reparación de daños ya producidos, con la finalidad de devolver al edificio a su buen estado precedente, corrigiendo los efectos y subsanando las causas.

Restauración: Obras cuya finalidad es devolver al edificio sus características generales, recuperando su configuración, a partir de una situación actual degradada, sin perjuicio de la estricta conservación, que sea necesaria. Comprende:

- Refuerzos estructurales sin alteración del aspecto exterior. 
- Reconstrucción de partes muy limitadas, con significado arquitectónico, basada en una documentación precisa e indiscutible.

- Demolición de carácter excepcional de partes que supongan la degradación del bien o alteraciones deformadoras o incongruentes respecto a los valores históricos de la obra o de complementos en estilo que la falsifiquen.

- La adaptación del edificio a un uso compatible, incorporando partes espaciales y funcionales, con lenguaje arquitectónico actual, sin alteración del aspecto exterior, la tipología constructiva y la secuencia de recorridos interiores.

Rehabilitación: obras cuya finalidad es adecuar las condiciones de habitabilidad del edificios a un uso concreto permitido, sin alterar su configuración exterior ni su esquema tipológico básico, sin menoscabo de las propias de restauración o de conservación estricta que sean necesarias. Se distinguen dos niveles de rehabilitación: Modernización y Reforma.

- Modernización: incluye implantación de nuevas instalaciones menores, sustitución de instalaciones menores o mayores, la redistribución horizontal de locales, (por alteración de la tabiquería o particiones interiores), la apertura de huecos de acceso, luces o ventilación a patios, escaleras, zaguanes u otros locales, siempre que no afecten al valor arquitectónico de estos, la sustitución interior de carpinterías, cerrajerías, revestimientos o acabados y del material de cubrición de la cubierta.

- Reforma incluye las anteriores intervenciones, implantación de instalaciones mayores, redistribución vertical, modificación general de los elementos de accesos, circulación, iluminación y ventilación y sustitución exterior de carpinterías, cerrajerías, revestimientos o acabados.

El sacrificio de ciertas características y valores del edificio para alcanzar su adaptación a un nuevo uso de prestaciones demandadas en la actualidad, sólo puede darse en los edificios con nivel de protección parcial y ambiental, dentro de los criterios de actuación vinculados a estos niveles. Este sacrificio siempre debe tener un límite: el mantenimiento de la envolvente exterior del edificio en protección de su valor ambiental y por tanto, son técnicas incoherentes e inadmisibles en la catalogación las de obras de sobreelevación y aumento de volumen.

Si esta medida es indispensable para la consecución de suelo dotacional en actuaciones de dotación, o bien se debe sacrificar el valor de algunos edificios por la mejor calidad urbanística del barrio, en cuyo caso no cabría la catalogación, o bien se debe recurrir a la clásica técnica de expropiación en suelo urbano, sin transferencias de aprovechamiento.

Si no existe necesidad de adquirir suelo dotacional en un barrio con déficit histórico de dotaciones, entonces a día de hoy, no existe causa justificada para el aumento de edificabilidad en áreas ya de gran densidad, sino la mera financiación de la administración actuante. 


\section{Sobre la multiplicidad de catálogos}

Como ya se ha comentado, la multiplicidad de catálogos la propicia la interpretación de incorporación de un nuevo catálogo en cada Plan de Desarrollo, en sustitución de la revisión y/o modificación del catálogo municipal.

Los catálogos incorporados a Planes Parciales, Especiales y de Reforma Interior son de ámbito municipal y deberían contemplar la modificación excepcional del catálogo urbanístico, dado que éste no prevé la protección transitoria en estos ámbitos; esta modificación debe trasladarse de manera rápida y eficaz al catálogo municipal. La superposición de contenidos no homogéneos de los distintos catálogos, en los que nunca se ha procurado la refundición de información, acaba en un galimatías de datos y regímenes de protección complejo de descifrar para la administración, los propietarios y los profesionales.

Faltan herramientas adecuadas para el tratamiento de datos al servicio de la catalogación de inmuebles, que cada vez crea documentos con mayor profusión informativa y normativa, imposible de abarcar por los usuarios, con medios tradicionales de adquisición de conocimiento. La adopción de las nuevas tecnologías no ha alcanzado el campo de la protección del patrimonio en el primero de sus niveles: la catalogación de inmuebles. A su vez, el contenido aumenta con la aportación de los planes y catálogos de ámbito supramunicipal, y los catálogos del paisaje, de reciente aparición en el panorama valenciano.

Si ya de por sí el Reglamento del Paisaje es un documento de confusa comprensión y aplicación, lo es más la figura que el propio texto define como catálogo de paisaje; que puede ser regional o local, parte de un Plan Territorial o de uno General, de competencia autonómica o municipal, e integrarán los estudios de paisaje y de integración paisajística en cada actuación o proyecto con independencia de su escala; en resumidas cuentas, un auténtico cambalache, de finalidad incierta y utilidad por el momento ignorada, pero preceptivo desde el año 2006.

Como ejemplo, el Catálogo de Paisajes de Relevancia Regional, con objetivos de calidad que deberán considerarse en la planificación del municipio y en la redacción de futuros catálogos municipales, que deben preservar los espacios de interés o por razones paisajísticas, conforme a la LUV.

Una nueva incorporación al planeamiento supramunicipal es el Catálogo de Bienes y Espacios Protegidos Rurales del Plan de Acción Territorial de Protección de la Huerta de Valencia, que incide en los catálogos municipales de aquellos términos incluidos en el Plan.

El régimen de protección del PAT de la Huerta, aunque dice regirse por los niveles de protección del ROGTU, los incumple en el momento que introduce un nuevo criterio de intervención vinculado a los niveles, como es la ampliación y el aumento de volumen en edificaciones inventariadas y propuestas como BRL, donde se pierde el rigor en la técnica de la catalogación, desde el momento en que la intervención en monumentos BIC y BRL se supeditan a la introducción de un uso, cuando su alto valor cultural, sólo nos permitirá la conservación o la restauración conservativa. 
Una de dos, o estamos asignando la categoría de monumento a inmuebles que no lo merecen, o una vez reconocido su valor cultural, no lo sabemos respetar y preservar. A mi entender, pecamos de la primera actitud, dada la sencillez para entender la segunda.

\section{Sobre la revisión del Catálogo Municipal}

Los trabajos de revisión de los catálogos municipales son fundamentales para la conservación del patrimonio urbano, si en la época expansiva y de gran desarrollo urbanístico de principios del 2000, cuando las arcas municipales estaban llenas, no se pensó en este tema, más difícil es ahora que están vacías; sin embargo el Ayuntamiento de Valencia presenta recientemente la revisión estructural de su catálogo y contrata un ambicioso proyecto de redacción de Planes Especiales de los entornos de los monumento BIC en Ciutat Vella.

El esfuerzo de revisión del catálogo es notable, aunque sólo abarca una pequeña proporción respecto de los más de 3.800 inmuebles del catálogo municipal, sólo los bienes incluidos en el Inventario General del Patrimonio Valenciano, en su consideración de determinación estructural de la ordenación urbanística. Por tanto, se dota a los inmuebles de carácter monumental de mayor claridad en su identificación, ubicación, delimitación de entornos y régimen de protección.

El papel de los Planes de Protección de Entornos BIC, se estudia a través del recientemente aprobado (julio 2013) en el entorno de la Iglesia de la Virgen de la Misericordia de Campanar, que con un ámbito prácticamente coincidente con el PEPRI de Campanar de 1992, podría haber sido una excelente excusa para realizar la revisión normativa del ámbito, y sin embargo, supone una superposición de catálogos en un mismo espacio difícil de conjugar, que produce la acumulación normativa, sin considerar la revisión de documentos previos.

El Catálogo del PEP-EBIC 08 refunde y actualiza parcialmente el Catálogo del Plan General de Ordenación Urbana, y el de los Planes Especiales de Protección y de Reforma Interior de Ciutat Vella, el Carmen, la Seu Xerea y Universitat San Francesc, así como los de las distintas modificaciones urbanísticas vigentes que se han ido formulando en estas zonas.

Un gran trabajo del Plan es el esfuerzo de volcado de datos proveniente de todos los instrumentos planeamiento y de protección, vigentes en el ámbito, sobre un solo plano, como trabajo de fusión informativa. También se hace un esfuerzo de objetividad y de concisión en la ficha de catalogación, que podría servir de futuro modelo para los catálogos municipales.

Sin embargo, no aporta novedades en la ordenación de la edificación respecto del PEPRI de Seu-Xerea y sus aspiraciones de recualificación del espacio público mediante la reducción de tráfico, sin vinculación a un programa económico, parece una conclusión de pocas repercusiones para un plan tan extenso y costoso, que nos hace cuestionarnos: la utilidad real de este tipo de planes, cuando tanta falta hace la revisión del catálogo municipal. 


\section{La aportación práctica: el sistema de gestión del catálogo municipal}

Teniendo como objetivo principal la conservación y activación del patrimonio cultural de la ciudad de Valencia como fuente de recursos y la información del patrimonio arquitectónico valenciano como primer instrumento hacia su revalorización, se plantea en el Proyecto SIPAV: "Sistema de información del Patrimonio de Valencia", que consiste en:

- La creación de un Sistema de Información del Patrimonio Arquitectónico de la Ciudad de Valencia (SIPAV)

- La incorporación de un Sistema de Información Geográfica (SIG) con localizador cartográfico de los inmuebles.

- La incorporación de un Sistema de Información técnica y jurídica de los inmuebles enfocado a la gestión de su rehabilitación.

El desarrollo de la tesis supone el trabajo de investigación de todos los documentos de catalogación del término de Valencia, así como aquéllos supramunicipales que afecten al catálogo municipal, que sirve de base científica y documental para la elaboración del sistema, que contará con la ayuda de un equipo técnico especializado en el tratamiento de las bases de datos de distribución gratuita, con especial atención a la conexión universal de las bases de datos ya establecidas por las distintas administraciones.

El sistema de ordenación del patrimonio que se diseña debe ser 'exportable' al ámbito de la Comunidad Valenciana, y por tanto a entidades locales de menor rango. Obligado por este aspecto, la sistematización y homologación son requisitos necesarios que garantizan la utilidad de la herramienta informática.

La puesta en marcha del sistema de información del patrimonio genera beneficios en cada uno agentes participantes en la activación del patrimonio, y tiene comofinalidad alcanzar los siguientes objetivos:

- Acceso a la cultura: la tutela y protección de bienes culturales es una demanda reclamada socialmente por parte de un consumidor harto de productos materiales, que busca experimentación y vivencias basadas en valores intangibles. Creación de recursos culturales vinculados a los bienes: monografías, guías, publicaciones temáticas, etc.

- Aprovechamiento productivo de los bienes culturales basado en el uso turístico: la cultura, y en especial el patrimonio arquitectónico, como motor de desarrollo económico y social de la ciudad en un futuro Plan Estratégico de Cultura.

- Reinvención del patrimonio cultural: creación de itinerarios o distritos culturales relacionados con personajes, épocas o temas que fomentan la diversidad cultural, el respeto de los derechos humanos y el fomento de la cultura de la paz.

- Promoción y valoración de la ciudad consolidada a través de su conocimiento como bien cultural y producto inmobiliario. 
- Habilitación de instrumentos que agilicen la gestión cultural y urbanística de la ciudad consolidada. La rehabilitación como técnica de activación del patrimonio cultural y ambiental.

- Incorporación de las tecnologías de información geográfica y cartográfica (TICS) en la administración local en cumplimiento de la Directiva Comunitaria 2007/2/CE, de 14 marzo 2007, para el establecimiento de una infraestructura de información espacial de la Unión Europea (Inspire)

- Habilitar el acceso a la información y a la participación pública en materia de medio ambiente y patrimonio cultural (Ley 27/2006 de 18 julio)

- El proyecto Banco de Imágenes del Patrimonio Arquitectónico Valenciano. 


\section{BIBLIOGRAFÍA}

ABAD LICERAS, J. M. (1999). "La distribución de competencias entre el Estado y las Comunidades Autónomas en materia de patrimonio cultural histórico-artístico: soluciones doctrinales". Revista española de derecho constitucional, vol 19, núm.55, p.133 -184.

ABAD LICERAS, J. M. (2000). Urbanismo y patrimonio histórico. Madrid: Montecorvo.

ALDANA FERNÁNDEZ, S. (1999). Monumentos desaparecidos de la Comunidad Valenciana. Valencia: Consell Valencià de Cultura.

ALDANA FERNÁNDEZ, S. (2004). Monumentos desaparecidos de la Comunidad Valenciana, Alicante. Valencia: Consell Valencià de Cultura.

ALONSO IBÁÑEZ, M. (2004). Los catálogos urbanísticos: aspectos jurídicos, metodológicos y de gestión. Oviedo: Universidad de Oviedo.

ALONSO IBÁÑEZ,M. (2005). Los catálogos urbanísticos y otros catálogos protectores del patrimonio cultural inmueble. Navarra: Revista Aranzadi de urbanismo y edificación.

BAÑo LEÓN, J. (2009). Derecho Urbanístico Común. Madrid: Iustel.

BARTOLOMEI, C. (2010). "La documentazione dei Beni Culturali", Disegnarecon, vol 3 núm.6.

BARRERO RODRÍGUEZ, C. (1990). La ordenación jurídica del Patrimonio Histórico. Madrid: Civitas.

BARRERO RODRÍGUEZ, C. (1998). "Los Conjuntos históricos y el planeamiento de protección. Especial referencia a la Comunidad Autónoma de Andalucía", Revista electrónica de derecho ambiental, núm.0.

BARRERO RODRÍGUEZ, C. (2006). La ordenación urbanística de los conjuntos históricos. Madrid: Iustel.

BASOLS COMA, M. (1990). "Instrumentos legales de intervención urbanística en los centros y conjuntos históricos", Revista de Derecho Urbanístico, núm.118, p.41.

CAMACHO MARTÍNEZ, R. (1993). Inventarios y catálogos monumentales, bases teóricas para la conservación del Patrimonio histórico artístico, Arquitectura y Ciudad II y III. Madrid: Ministerio de Cultura ICRBC.

CAMPESINO FERNÁNDEZ, A. (1989). "La rehabilitación integrada de los centros históricos: el reto urbanístico de finales de los ochenta", Investigaciones Geográficas, n07, pag.7-17.

CARDACI, A. \& VERSACI, A. (2012). "Documentare per conservare: I'uso delle nuove tecnologie per la conoscenza, la salvaguardia e la comunicazione del patrimonio culturales armeno", Disegnarecon, vol: 5 núm.10, p.265-272.

CARPICECI, M. \& COLONNESE, F. (2012). "Le comunità locali e la documentazione come sistema aperto di conoscenze", Disegnarecon, vol: 5 no 10, p.187-192. 
CASAR FURIÓ, E. (2008). "Interconexión normativa de la legislación urbanística y sectorial valencianas en materia de patrimonio cultural y de los bienes inmuebles de interés cultural en particular", Revista Aranzadi de Urbanismo y Edificación, nº18, p.43-52.

CASAR FURIÓ, E. \& BROSETA PALANCA, T. (2011). "Nuevas consideraciones del bien inmuebles de relevancia local valenciano", Práctica Urbanística, n¹10, p.44-51.

CASAR FURIÓ, E. \& BROSETA PALANCA, T. (2013). "Regulación Valenciana de los catálogos municipales", Actualidad Administrativa, no1, p.33-44.

CASAR PINAZO, J. (2009). Planes especiales de protección de los conjuntos historicos y de los entornos de proteccion de monumentos: nuevos planteamientos propuestos por la legislación valenciana, Curso sobre afecciones sectoriales en el planeamiento urbanístico: el patrimonio histórico y cultural. Valencia: Colegio Territorial de Valencia, 2009.

CENTOFANTI, M. (2008). "Il progetto del SIARCH-UNIVAQ, Sistema Informativo Architettonico", Disegnarecon, vol: 1 no 2.

CLUSA ORIACH, J. (1983). Planes Especiales de Protección del Patrimonio Histórico-Artístico. Problemática del reparto de cargas y beneficios. Madrid: MOPU.

FARIÑA TOJO, J. (2000). La protección del patrimonio urbano: instrumentos normativos. Madrid: Akal.

FERNÁNDEZ RODRÍGUEZ, T. (2000). "La ordenación urbanística de los conjuntos históricos: breve denuncia de los excesos al uso", Revista Aranzadi de urbanismo y edificación, nº1.

FRONER GONÇALVES, Y. (2012). "Patrimônio Arquitetônico: conceitos contemporâneos, políticas públicas e TICs", Disegnarecon, vol: 5, núm.10, p.87-94.

GAIANI, M. (2012). "Creari Sistema informativi per studiare, conservare, gestire e comunicare sistema architettonici e archeologici complessi", Disegnarecon, vol: 5 núm.10, p.9-20.

GAJA I DÍAZ, F. (2001). Intervenciones en centros históricos de la Comunidad Valenciana. Valencia: Consellería d'Obres Públiques, Urbanisme i Transports.

GALVÃO, A. (2008). "Contributos para um modelo sustentável de gestão e conservação do património arquitectónico", Disegnarecon, vol: 1 núm. 2.

GONZÁLEZ SIMANCAS, M. (1916). Catálogo monumental y artístico de la provincia de Valencia, Volumen I y II (Manuscrito). Reproducción digital por el Instituto del Patrimonio Cultural de España, en depósito, en la biblioteca Tomás Navarro Tomás del CSIC

GONZÁLEZ-VARAS IBÁÑEZ, S. (1998). La rehabilitación urbanística. Pamplona: Aranzadi.

GONZÁLEZ-VARAS IBÁÑEZ, S. (2005). "Catálogos urbanísticos de edificios singulares e indemnizaciones a favor de los particulares", Patrimonio Cultural y Derecho, no9, p.217-230.

GUISASOLA LERMA, C. (2000). "La ley de patrimonio cultural valenciano". Valencia: I Congreso de centros históricos de la Comunidad Valenciana: Historia, Patrimonio y Arte. Archival. 
LÓPEZ BRAVO, Carlos. "Interrelación de las categorías legales de protección del Patrimonio Cultural en España". Revista ph. 1999, n²7, p.83-90.

LÓPEZ-YARTO ELIZALDE, A. (2012). El catálogo monumental de España (1900-1961): investigación, restauración y difusión. Madrid: Ministerio de Educación, Secretaría General Técnica.

LORENTE TALLADA, J. \& ROMERO SAURA, F. (1996). El Régimen urbanístico de la Comunidad Valenciana. Valencia: Universidad Politécnica de Valencia.

NAVASCUES PALACIO, P. (1987). La restauración monumental como proceso histórico: el caso español, Curso de mecánica y tecnología de los edificios históricos. Madrid: COAM

PELLICIO, A. et Al. (2008). "Sistemi Informativi per il patrimonio urbano. Riflessioni ed aplicazioni", Disegnarecon, vol: 1 n० 2.

RIVERA BLANCO, J. (1999). Patrimonio, restauración y nuevas tecnologías-PPU. Valladolid: Universidad de Valladolid.

RIVERA BLANCO, J. (2001). De varia restauratione: teoría e historia de la restauración arquitectónica. Valladolid: R\&R.

RIVERA BLANCO, J. (2003). Nuevas tendencias en la identificación y conservación del patrimonio. Valladolid: Universidad de Valadolid.

SEMES, S. (2009). "Differentiated and Compatible: conservation in the Context of a Recovered Tradicional Architecture and Urbanism", Disegnarecon, vol: 2 no 4.

TABERNER PASTOR, F. (2004). La evolución de los criterios de protección en el patrimonio arquitectónico: del monumento histórico artístico al valor cultural. Valencia: Universidad Politécnica de Valencia.

TABERNER PASTOR, F. (2012). "Patrimonio arquitectónico y legislación". En: TORMO ESTEVE, S., PALAIA PÉREZ, L. 24 Lecciones sobre conservación del patrimonio. Su razón de ser. Valencia: Universidad Politécnica de Valencia. 
LOS CUADERNOS DE INVESTIGACIÓN URBANÍSTICA publicados por el Departamento de Urbanística y Ordenación del Territorio desde el año 1993, difunden bimensualmente aquellos trabajos de investigación realizados en el área del Urbanismo, la Ordenación Territorial, el Medio Ambiente, la Planificación Sostenible y el Paisaje, que por sus características, muchas veces de investigación básica, tienen difícil salida en las revistas profesionales. Su objetivo es la difusión de estos trabajos, en el convencimiento de que es necesario potenciar el uso de este idioma entre el mundo científico para conseguir alcanzar ámbitos de difusión a los que, de otra forma, no se podría acceder.

Su formato no es el convencional de una revista de este tipo, con artículos de diferentes autores que, en realidad, abordan aspectos parciales de cada trabajo, muy adecuados para la difusión y el conocimiento rápido de los mismos, pero que no pueden profundizar demasiado debido a su limitada extensión, sino que se trata de amplios informes de la investigación realizada que ocupan la totalidad de cada número. Esto permite, sobre todo a aquellos investigadores que se inician, el tener accesibles los aspectos más relevantes del trabajo y conocer con bastante precisión el proceso de elaboración de los mismos.

La realización material de los Cuadernos de Investigación Urbanística está a cargo del Departamento de Urbanística y Ordenación del Territorio de la Escuela Técnica Superior de Arquitectura de Madrid, garantizándose el respeto de la propiedad intelectual, pues el registro es siempre en su totalidad propiedad del autor. Está permitida su reproducción parcial en las condiciones establecidas por la legislación sobre propiedad intelectual citando autor, previa petición de permiso al mismo.

\section{NORMAS DE PUBLICACIÓN}

Las condiciones para el envío de originales se pueden consultar en la página web:

http://www.aq.upm.es/Departamentos/Urbanismo/publicaciones/ciurpublicar.html

\section{FORMATO DE LAS REFERENCIAS}

Monografías: APELLIDOS (S), Nombre (Año de edición). Título del libro (No de edición). Ciudad de edición: Editorial [Traducción castellano, (Año de edición), Título de la traducción, No de la edición. Ciudad de edición: editorial].

Partes de monografías: APELLIDOS (S), Nombre (Año de edición). "Título de capítulo". En: Responsabilidad de la obra completa, Título de la obra (No de edición). Ciudad de edición: Editorial.

Artículos de publicaciones en serie: APELLIDOS(S), Nombre (Año de publicación). "Título del artículo", Título de la publicación, Localización en el documento fuente: volumen, número, páginas.

Asimismo, se recuerda que el autor tendrá derecho a tres ejemplares gratuitos.

\section{CONSULTA DE NÚMEROS ANTERIORES/ACCESS TO PREVIOUS WORKS}

La colección completa se puede consultar en color y en formato pdf en siguiente página web:

The entire publication is available in pdf format and full colour in the following web page:

http://www.aq.upm.es/Departamentos/Urbanismo/publicaciones/ciurnumeros.html

\section{ÚLTIMOS NÚMEROS PUBLICADOS:}

97 Juan Ramón Selva Royo: "Antecedentes y formación del Plan General de Valencia de 1966 ", 68 páginas, Noviembre 2014.

96 Irina Tumini: "The urban microclimate in open space. Case studies in Madrid", 78 páginas, Septiembre 2014.

95 Luz Elena Cornejo Ganga: "Categorías de análisis de un modelo de planificación turística sustentable", 96 páginas, Julio 2014.

94 Mattia Bertin: "Cittá al limite. Per una trattazione urbanística del disastro", 78 páginas, Mayo 2014.

93 Luis Alberto Salinas Arreortúa: "Transformaciones urbanas en el contexto neoliberal", 74 páginas, Marzo 2014. 
PROGRAMA OFICIAL DE POSGRADO EN ARQUITECTURA

MASTER PLANEAMIENTO URBANO Y TERRITORIAL

URB

Escuela Técnica Superior de Arquitectura de Madrid (UPM)

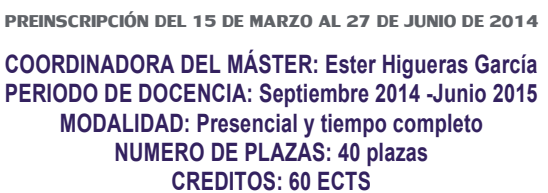

El Máster se centra en la comprensión, análisis, diagnóstico y solución de los problemas y la identificación de las dinámicas urbanas y territoriales en curso, atendiendo a las dos dimensiones fundamentales del fenómeno urbano actual: por un lado, el proceso de globalización y, por otro lado, las exigencias que impone la sostenibilidad territorial, económica y social. Estos objetivos obligan a insistir en aspectos relacionados con las nuevas actividades económicas, el medio físico y natural, el compromiso con la producción de un espacio social caracterizado por la vida cívica y la relación entre ecología y ciudad, sin olvidar los problemas recurrentes del suelo, la vivienda, el transporte y la calidad de vida. Estos fines se resumen en la construcción de un espacio social y económico eficiente, equilibrado y sostenible. En ese sentido la viabilidad económica de los grandes despliegues urbanos y su metabolismo se confrontan con modelos más maduros, de forma que al estudio de las técnicas habituales de planificación y gestión se añaden otras nuevas orientaciones que tratan de responder a las demandas de complejidad y sostenibilidad en el ámbito urbano.

El programa propuesto consta de un Máster con dos especialidades:

- Especialidad de Planeamiento Urbanístico (Profesional)

- Especialidad de Estudios Urbanos (Investigación Académica)

Se trata de 31 asignaturas agrupadas en tres módulos:

MÓDULO A. Formación en Urbanismo.

MÓDULO B. Formación en Estudios Urbanos e Investigación.

MÓDULO C. Formación en Planeamiento.

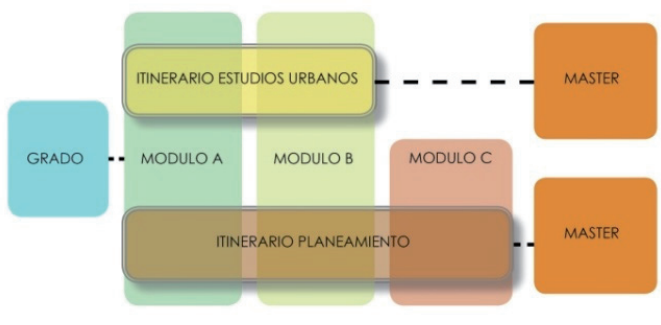

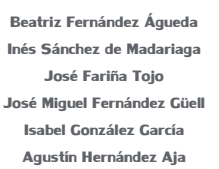

Agustín Hernández Aja
PROFESORADO:

Ester Higueras García

Francisco José Lamiquiz

Julio Pozueta

Fernando Roch Peña

Felipe Colavidas

Luis Moya

José María Ezquiaga
Llanos Masiá

Javier Ruiz Sánchez

Carlos Verdaguer

Enrique Villa Polo

Carmen Andrés Mateo

Álvaro Sevilla

ENTIDADES COLABORADORAS:

(0) C Ci[ur] =urban

CONTACTO: masterplaneamiento.arquitectura@upm.es www.aq.upm.es/Departamentos/Urbanismo/masters/index.html 


\section{ALGUNAS DE LAS ACTIVIDADES REALIZADAS DURANTE EL CURSO 2014/15...}
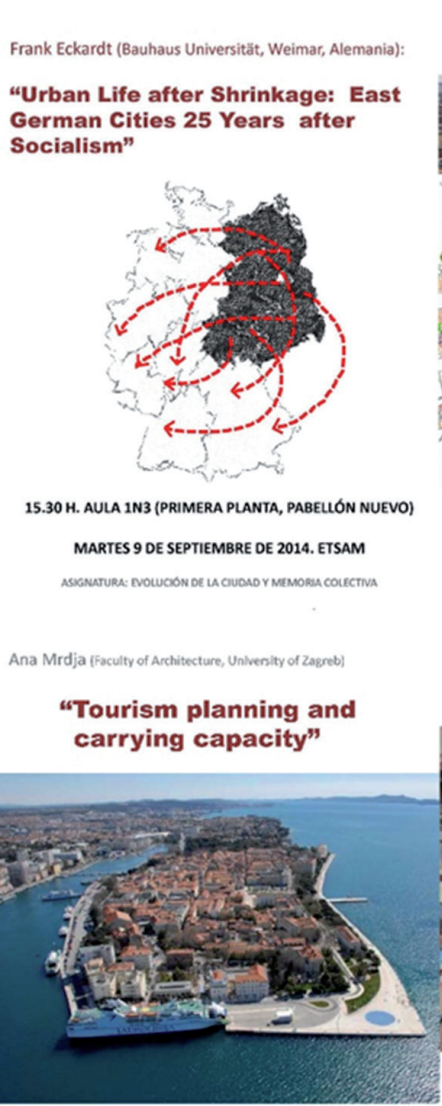

11.30 H. SALA DE GRADOS B (PABELLÓN ANTIGUO) JUEVES 18 DE SEPTIEMBRE DE 2014. ETSAM ASORATURA: SEM MARO EN UINEAS DE IWESSIGAOON
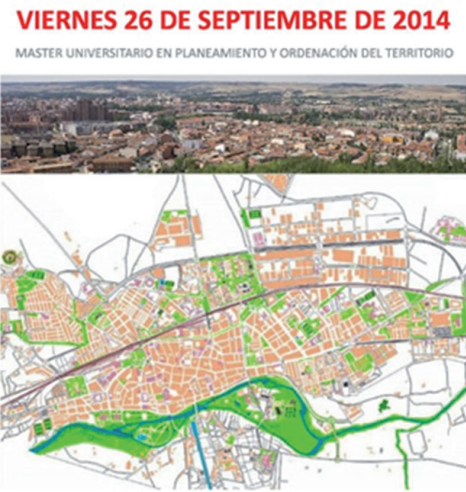

"Visita a la ciudad de Palencia"

RECEPCION EN EL ATUNTAMIENTO Y PASEO POR L CIUDAO Y SUS BARRIOS

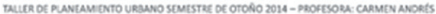

MIÉRCOLES 11 DE FEBRERO DE 2015. ETSAM MASTER UNIVERSTARIO EN PLANEAM ENIO Y ORDERACÓN OEL TERRIORIO

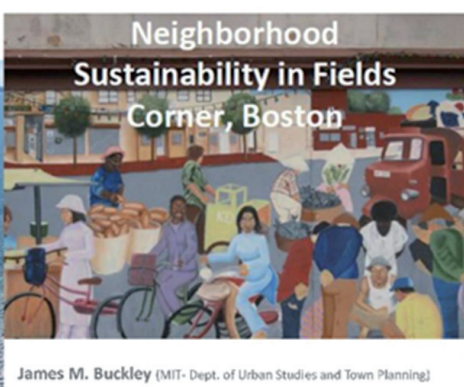

"Urban regeneration in USA"

11.30 H. AULA 1N3 (AULA MÁSTER)

MQUGURACON ACCOEMICA DEL SSGUNDO SEMESTRE OEL MASTrR

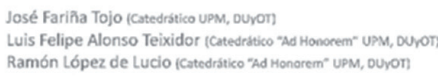

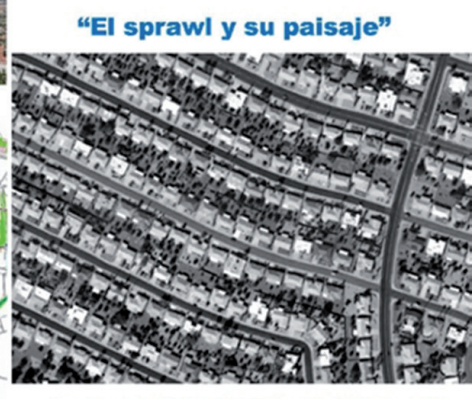

11.30 H. SALA DE GRADOS B (PABELOÓN ANTIGUO) JUEVES 9 DE OCTUBRE DE 2014. ETSAM ASGGMTURA: SEMINARO EN LINEAS DE INUESTGGCION

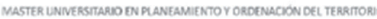

MIÉRCOLES 5 DE NOVIEMBRE DE 2014. ETSAM MUSTER UNVERSTINRO EN PLANEAMIENTO Y ORDERMCON DEL TERR TORIO

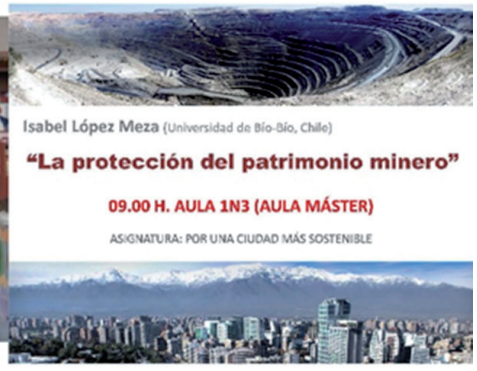

Mario Torres Jofré \{Univensidad de Chile)

"La ciudad contemporánea. Una perspectiva crítica"

16.00 H. AULA 1N3 (AULA MASTER)

VIERNES 27 DE FEBRERO DE 2015 JUEVES 19 DE MARZO DE 2015 MIÉRCOLES 25 DE MARZO DE 2015

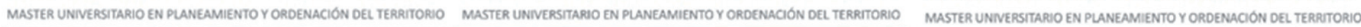

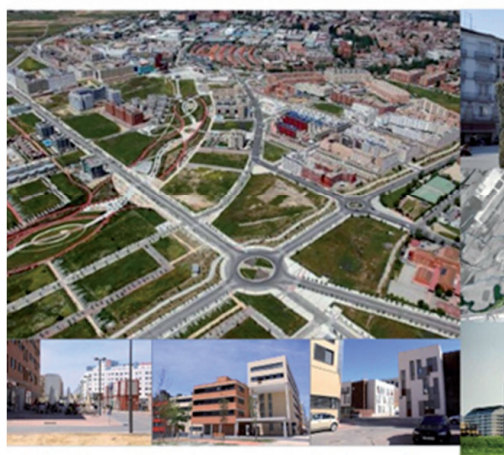

"Visita a Móstoles Sur (Madrid)"

15.30 H. MEtro MANUELA MALASAÑa (MEtrosur)

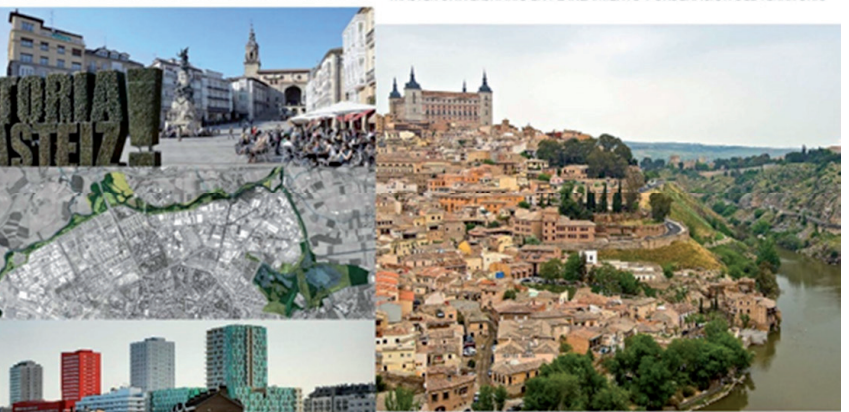

"Visita a Toledo"

"Visita a Vitoria-Gasteiz"

12.00 H. PLAZA DE LA VIRGEN BLANCA (CENTRO)
16.00 H. PLAZA DE ZOCODOVER (CENTRO)

JOINT WORKSHOP - SPRING 2015 - EVOLVING CMTIS

(1) (1) DUyOT 
Otros medios divulgativos del Departamento de Urbanística y Ordenación del Territorio:

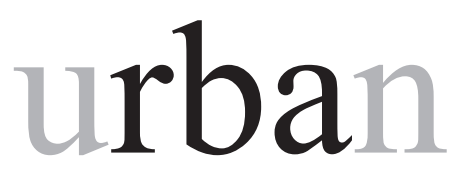

ReVISTA del Departamento de URBANÍStiCA y Ordenación del TerRITORIO ESCUELA TÉCNICA SUPERIOR DE ARQUITECTURA

\section{PRESENTACIÓN SEGUNDA ÉPOCA}

DESDE el año 1997, URBAN ha sido vehículo de expresión de la reflexión urbanística más innovadora en España y lugar de encuentro entre profesionales y académicos de todo el mundo. Durante su primera época la revista ha combinado el interés por los resultados de la investigación con la atención a la práctica profesional, especialmente en el ámbito español y la región madrileña. Sin abandonar dicha vocación de saber aplicado y localizado, la segunda época se centra en el progreso de las políticas urbanas y territoriales y la investigación científica a nivel internacional.

\section{CONVOCATORIA PARA LA RECEPCIÓN DE ARTÍCULOS:}

Urban mantiene abierta una convocatoria permanente para la remisión de artículos de temática relacionada con los objetivos de la revista: Para más información:

http://www2.aq.upm.es/Departamentos/Urbanismo/institucional/publicaciones/urban/ns/instrucciones-para-autores/

Por último, se recuerda que, aunque La revista URBAN organiza sus números de manera monográfica mediante convocatorias temáticas, simultáneamente, mantiene siempre abierta de forma contínua una convocatoria para artículos de temática libre.

\section{DATOS DE CONTACTO}

Envío de manuscritos y originales a la atención de Javier Ruiz Sánchez: urban.arquitectura@upm.es

Página web: http://www.aq.upm.es/Departamentos/Urbanismo/public/urban/info.html

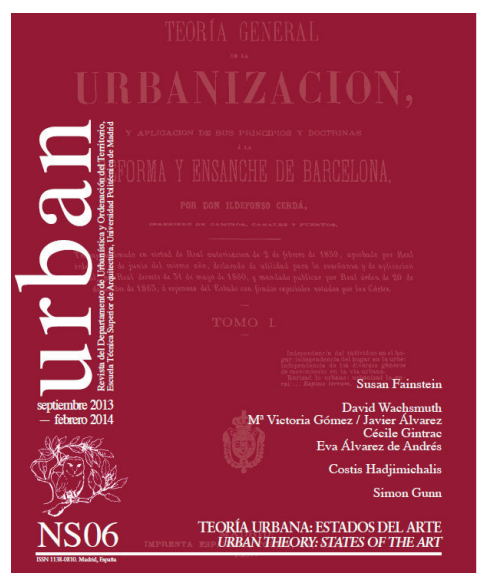

Consulta y pedido de ejemplares: ciur.urbanismo.arquitectura@upm.es

Web del Departamento de Urbanística y ordenación del Territorio:

http://www.aq.upm.es/Departamentos/Urbanismo

Donde figuran todas las actividades docentes, divulgativas y de investigación que se realizan en el Departamento con una actualización permanente de sus contenidos. 